\title{
A AMOSTRAGEM SEQUENCIAL BÁSEADA NO TESTE SEQÜENCIAL DA RAZĀO DE PROBALIDADES E SEU USO NO CONTROLE DAS LAGARTAS DA SOJA NO ESTADO DO RIO GRANDE DO SUL
}

\section{VALDUINO ESTEFANEL}

Prot. Assist. do Depto. de Fitotecnia

Universidade Federal de Santa Maria

Orientador: Prof. Dr. Décio Barbin Dissertação apresentada à Escola Superior de
Agricultura "Luiz de Queiroz", da Universi-
dade de São Paulo, para obtenção do título
de Mestre em Experimentação e Estatística.

$P \mid R A C I C A B A$

Estado de São Paulo - Brasil

Novembro, 1977 
ii.

Ao meu pai (memória)

$$
\begin{aligned}
& \text { A minha mãe } \\
& \text { A minha esposa } \\
& \text { Ao meu filho }
\end{aligned}
$$

$D E D I C O$ 


\section{AGRADECIMENTOS}

\section{Expressamos nossos sinceros agradecimentos:}

Ao Dr. Dëcio Barbin. Professor Assistente Doutor do Departamento de Matemática e Estatística da Escola Superior de Agricultura "Luiz de Queiroz", pela orientação segura, o qual, mais do que orienta dor, foi amigo.

A Universidade Federal de Santa Maria, pela oportunidade oferecida para a realização do curso.

Ao colega Dr. Dionísio Link. Professor Adjunto do Departamento de Fitotecnia da Universidade Federal de Santa Maria, pela sugestão do tema.

Ao Prof. Dr. Frederico Pimentel Gomes, Coordenador do Curso de PósGraduação em Experimentação e Estatística, pelas valiosas sugestões apresentadas.

Aos demais professores e funcionários do Departamento de Matemática e Estatística da Escola Superior de Agricultura "Luiz de Queiroz" pela dedicação, sabedoria e espírito de colaboração.

A Eng: ${ }^{a}$-Agra Ione A. Bernardes Pignataro, Professora Adjunto do Departamento de Fitotecnia da Universidade Federal de Santa Maria, que galhardamente acumulou minhas funções docentes, possibilitan do a realização do curso.

A CAPES e CNPq, que, atravës do Plano Institucional de Capacitação de Docentes da Universidade Federal de Santa Maria (PICD-UFSM), 
administrado pelo Prof. Adjunto Dr. Zósymo Lopes dos Santos, con cedeu bolsa de estudos.

Ao Centro de Processamento de Dados do Departamento de Matemática e Estatística da Escola Superior de Agricultura "Luiz de Queiroz" e ao Centro de Processamento de Dados da Universidade Federal de Santa Maria, onde foi feito o processamento dos dados deste trabalho. 


\section{INDICE}

Pag.

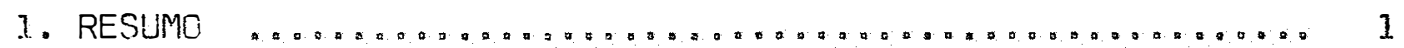

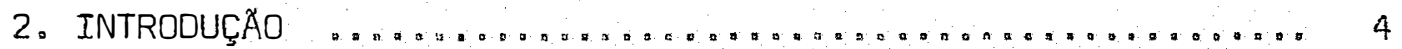

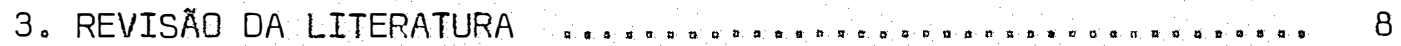

3.1 - Teste Sequiencial da Razão de Probabilidades ...... 8

3.2 - Distribuição Espacial dos Insetos m........... 12

3.3 - Escolha da Unidade Amostral e Nümero de Unidades Necessárias para Estabelecer a Distribuição Espacial dos

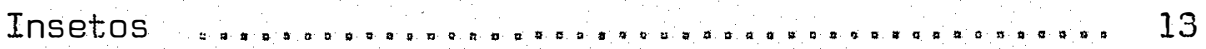

3.4 - Danos Causados pelas Lagartas da Soja ............ 15

3.5 - Estimativa do Parâmetro $k$ da Distribuição Binomial Ne

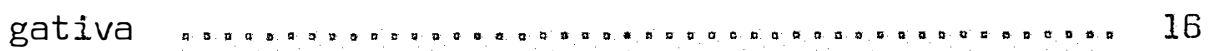

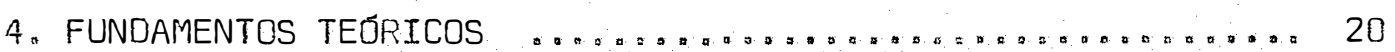

4.1 - Teste Sequiencial da Razão de Probailujlidades . ...... 20

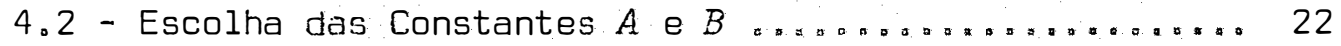

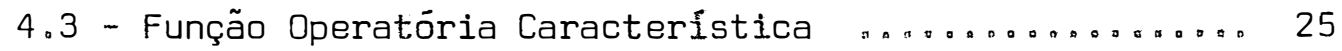

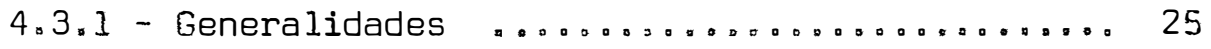

4.3 .2 - Dedução da fórmula geral a............ 28

4.4 - Função do Tamanho Médio das Amostras ............ 31

4.4 .1 - Generalidades ....................... 31

4.4 .2 - Dedução da fórmula geral ................... 32

4.5 - Elaboração de um Plano de Amostragem Seqüencial . . . 35 *

4.6 - Riscos Tolerados de Tomar Decisões Erradas ....... 36 \%

4.7 - Plano de Amostragem Sequiencial para Testar a Média de Uma Distribuição Binomial ........................ 39

4.7.1 - Apresentação do problema ............. 39

4.7 .2 - Desenvolvimento das fórmulas ..........4 40

4.7.3 - Obtenção da curva característica de operação 46

4.7.4 - Obtenção da curva do tamanho médio das amostras o... 
4.8 - Plano de Amostragem Seqüencial para Testar a Média de

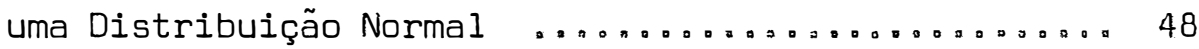

4.8 .1 - Apresentação do problema ..............448

4.9 .2 - Desenvolvimento das fórmulas ............ 49

4.8 .3 - Obtenção da curva característica de operação 53

4.8 .4 - Obtenção da curva do tamanho médio das amos-

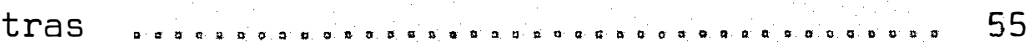

4.9 - Plano de Amostragem Sequiencial para Testar a Média de uma Distribuição de Poisson .................. 56

4.9.1 - Apresentação do problema .............. 56

4.9 .2 - Desenvolvimento das fórmulas ............ 57

4.9 .3 - Obtenção da curva característica de operação 62

4.9.4 - Obtenção da curva do tamanho médio das amos-

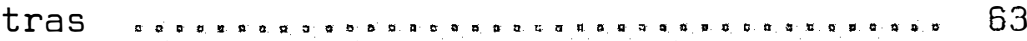

4.10 - Plano de Amostragem Sequoencial para Testar a Média de uma Distribuição Binomial Negativa . . . ....... 65

4.10 .1 - Apresentação do problema .............. 65

4.10 .2 - Desenvolvimento das fórmulas ............. 66

4.10 .3 - Obtenção da curva característica de operação 71

4.10 .4 - Obtenção da curva do tamanho médio das a-

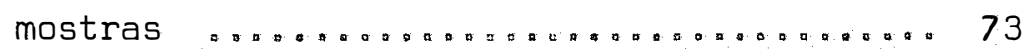

4.11 - Arredondamento de $a_{m}$ e $x_{m}$ e truncamento do teste $\ldots 75$

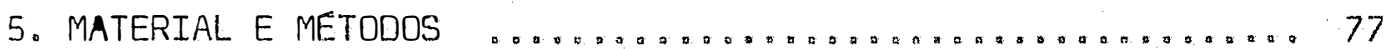

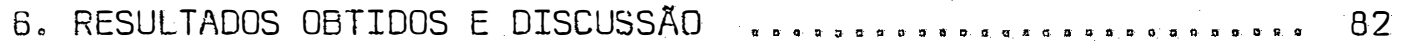

6.1 - Distribuição Espacial das Lagartas da Soja ...... 82

6.2 - Plano de Amostragem Seqüencial para Classificar a Infestação de Lagartas em Lavouras de Soja em Baixa, Mo.

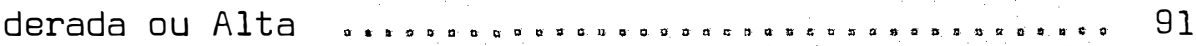

6.3 - Curva Caracterĩstica de Operação e Curva do Tamanho Médio das Amostras ............................. 97 
vii.

Pag.

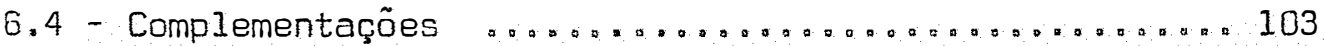

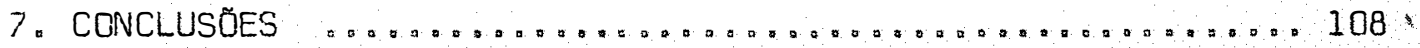

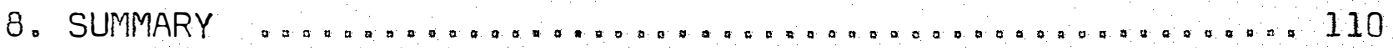

9. LITERATURA CITADA $\ldots \ldots \ldots \ldots \ldots \ldots \ldots \ldots \ldots \ldots \ldots \ldots \ldots$ 
1. RESUMO

E feita uma revisão bibliográfica sobre o uso da amostragem seqiencial em problemas de controle de pragas e descrita a metodologia para a execução de planos de amostragem seqüencial. As fórmulas, baseadas no processo aproximado de WALD, para calcular os parâmetros das linhas de decisão e os pontos para traçar as curvas da função operatória característica e do tamanho médio das amostras para as distribuições binomial, normal, Poisson e binomial negativa são apresentadas. E discutido tambēm um método prático de truncamen to do teste.

Foi desenvolvido um plano de amostragem seqüencial para classificar a infestação de lavouras de seja pelas lagartas Anticarsia gemmatalis e Plusia spp em baixa, moderada ou alta.

Para conhecer a distribuição espacial da praga obtiveram-se dados de contagem de lagartas em 3 municípios do Estado do Rio Grande do Sul. Em cada local foram examinadas 50 unidades a- 
mostrais escolhidas ao acaso, caminhando-se em "zig-zag" numa area de aproximadamente um hectare. Cada unidade amostral constou de 3 seções contíguas de 0,50 m de Iinha, obtendo-se então unidades de $0,50 \mathrm{~m}, 1,00 \mathrm{~m}$ e 1,50 m de linha, sendo as linhas espaçadas de 0,60 $\mathrm{m}$.

Verificou-se que os dados obtidos se ajustavam à dis tribuição binomial negativa e que o método da máxima verossimilhança para estimar o parâmetro $k$ apresenta algumas vantagens sobre o método dos momentos. Constatou-se também que 50 unidades amostrais em cada lavoura é um número insuficiente e que em próximos levantamentos deverão ser usadas no mínimo 100 unidades.

Concluiu-se que a unidade amostral de 1,00 m apresen ta maiores vantagens e foi usada para desenvolver o plano de amostragem seqüencial.

Para classificar a infestação de uma lavoura em baixa ou moderada, o plano foi delineado para testar as hipóteses $M=$ $=15$ versus $M=25$ lagartas por metro de linha. Para classificar a infestação de uma lavoura em moderada ou alta, o plano foi delineado para testar as hipóteses $M=45$ versus $M=60$ lagartas por metro de linha.

E apresentada uma tabela que permite classificar a infestação das lavouras nas 3 categorias acima, com base no número acumulado de lagartas colhidas. A curva característica de operação e a curva do tamanho médio das amostras também constam do trabalho. 
Se a infestação da lavoura for considerada baixa não é preconizado o uso de inseticidas. Se a infestação for alta sao aconselhadas medidas de controle químico. Se a infestação da lavoura for moderada o uso de inseticidas dependerá do estágio da cultura e do grau de desfolhamento. 


\section{INTRODUÇÃO}

A amostragem seqüencial caracteriza-se por envolver amostras de tamanho variável, em contraposição com a amostragem con vencional que tem um nümero fixo de itens. Dutra diferença è que enquanto a amostragem convencional procura estimar os parâmetros populacionais para depois, eventualmente, testar uma hipótese a respeito dos mesmos, na amostragem seqüencial é testada uma hipótese a respeito desses parâmetros sem a preocupação em estimá-los.

Assim. por exemplo, pode-se verificar a hipótese de que o parâmetro $\theta$ de uma população ë maior que o valor $\epsilon^{\prime}$ sem procu rar estimar $\theta$. Por isso a amostragem seqüencial é também conhecida como teste seqüencial ou análise seqüencial.

Na amostragem seqüencial as unidades amostrais são examinadas em seqüência até que os resultados acumulados tornem uma ou mais classes distintas de limites previamente determinados. Assim, com base na primeira observação pode-se chegar a uma das três 
seguintes decisões: (1) aceitar a hipótese $H$ formulada, (2) rejeitar a hipótese $H$ e (3) continuar a amostragem. Se for tomada a deci são (3) outra unidade amostral é examinada, e, com base nos resultados acumulados dos dois ítens da amostra, as três possíveis deci sões são examinadas novamente. O processo é continuado até que a de cisão (1) ou a decisão (2) seja tomada.

A grande vantagem da amostragem seqüencial consiste na considerável poupança de tempo que ela proporciona por evitar a excessiva amostragem quando o parâmetro populacional $\Theta$ é bastante maior ou bastante menor que o valor $\theta^{\prime}$ determinado para comparação. WALD (1947) afirma que em certos casos a amostragem seqüencial requer, em média, amostras com $1 / 3$ do tamanho que seria usado com a amostragem de tamanho fixo.

Quando o parâmetro populacional $\Theta$ não é muito diferente do valor $\theta^{\prime}$ o procedimento seqüencial conduz a amostras maiores que a amostragem convencional, constituindo uma desvantagem da amostragem seqüencial.

Outrossim a amostragem seqüencial não pode ser aplicada em todos os casos. Se houver interesse em estimar os parâmetros populacionais este método não pode ser usado. Além disso, a amostra gem seqüencial exige para que possa ser vantajosamente aplicada,que a população não esteja dispersa e que as unidades amostrais colhi das possam ser prontamente avaliadas (OAKLAND, 1950).

No campo agronômico a amostragem seqüencial tem sido 
muito aplicada para avaliar a infestação de insetos nas culturas e decidir sobre a aplicação ou não de inseticidas. Nesse caso a população está reunida na área delimitada pela cultura e a avaliação das unidades amostrais, ou seja, a contagem do número de insetos ou a verificação da existência ou não de danos, ê feita imediatamente, sem necessitar de análises de laboratório ou outro processo moroso. Por outro lado, não se está interessado em conhecer o parâmetro da infestação, mas, somente se a infestação atinge determinado nível a partir do qual a aplicação do inseticida deve ser executada. As condições permitem, portanto, o uso da amostragem seqüencial.

o uso desnecessário de inseticidas onera o custo da produção, constituindo-se num desperdício de mão-de-obra e de material. Acrescente-se ainda que o princípio ativo ë produto de importação e se constitui num fator de evasão de divisas. Os danos ecoló gicos não devem ser esquecidos: intoxicação de operários e animais, desequilíbrio biológico e polvição ambiental são efeitos que poderiam ser minimizados se hou esse mais racionalidade ne aplicação de defensivos agrícolas, sendo os mesmos usados somente quando realmen te necessários.

A cultura da soja (Glycine Max (L) Merril) vem tendo a cada ano maior importância econômica, principalmente nos Estados sulinos. Hoje a soja se constitui num dos produtos de maior destaque na pauta de exportações, propiciando divisas e com isso ajudando a equilibrar a balança de pagamentos do país. 
As lagartas da soja, Anticarsia genmatalis (Hübner) e Plusia spp são pragas que todos os anos causam danos em maior ou menor intensidade à cultura. Por outro lado, o uso de inseticidas para seu controle é feito quase sempre de maneira desordenada e muí tas vezes sem necessidade. Mesmo para o técnico não é fácil decidir quando é necessário e quando não é necessário adotar medidas de con trole químico na lavoura.

Um plano de amostragem seqüencial é um instrumento de fácil uso para técnicos e mesmo para agricultores mais esclarecidos, que facilita a tomada de decisóes quanto a executar a aplica ção de defensivos ou não fazê-1o.

Neste trabalho será elaborado um plano de amostragem sequencial para classificar a infestação de lagartas da soja em alta, média ou baixa, visando auxiliar na tomada de decisão quanto à necessidade ou não do uso de inseticidas. 


\section{REVISÃO DE LITERATURA}

\section{1 - Teste Seqüencial da Razăo de Probabilidades}

A primeira idéia da amostragem seqüencial foi lançada por DODGE e ROMIG (1929) ao sugerirem a amostragem em duas etapas sucessivas. Depois deles outros autores aperfeiçoaram a idéia, mas o procedimento ainda carecia de bases teóricas.

WALD (1945 e 1947) trabalhando para a Marinha dos Es tados Unidos, iniciou a pesquisar o problema em 1940, visando o con trole de qualidade do material bélico. Em 1943 WALD apresentou seu primeiro relatório que foi taxado de "secreto" pelas Forças Armadas Americanas, temerosas de que o inimigo se utilizasse dessa técnica. Em 1945, terminada a guerra, o relatörio foi liberado. A partir de então, muitas indüstrias passaram a usar o procedimento desenvolvido por Wald, baseado no teste sequiencial da razão de probabilidades, para controlar a qualidade de seus produtos. 
Wald apresenta fórmulas aprcximadas, mas que para Fins práticos são perfeitamente satisfatórias, que permitem calcular as linhas de decisão, a função operatória característica, a fun ção do tamanho médio das amostras e dá regras práticas para efetuar o truncamento do teste.

0 mesmo autor deduziu as förmulas para calcular exatamente a função operatória característica e o tamanho médio das amostras para o caso em que

$$
z_{i}=L \frac{f\left(y_{0} \theta_{1}\right)}{f\left(y_{0} \theta_{0}\right)}
$$

essume somente um nümero finito de inteiros, mültiplos de uma constante $d$. E um resultado bastante geral porque qualquer $z$ contínuo pode ser aproximado a uma distribuição discreta tão próximo quanto se deseje.

PAGE (1954) sugeriu uma modificação para as fórmulas de Wald com o fim de melhorar a aproximação da função operatória ca racterística e da função do tamanho médic des amostras. KEMP (1958) usando a mesma metodologia de Page apresentou modificações ainda mais vantajosas.

TALLIS e VAGHOLKAR (1965) obtiveram aproximações paIa a função operatória característica e para o tamanho médio das amastras por outro método e chegando à mesma precisão de Page e Kemp. ANDERSON (1960) apresentou método para calcular a fun gẫo característica e a função do tamanho médio da amostra para o tes 
te seqüencial truncado. Anderson se fundamente num processo de wiener para aproximar a soma de variávels normal e independentemente distribuídas e substitui as linhas de decisão paralelas de Wald por linhas não paralelas que são funções do tamanho da amostra. o método é facilmente aplicável para distribuições exponenciais.

MADSEN (1974), estudando o mesmo problema, apresentou método mais aproximado que o de Anderson, extensivo a outras distri buições, tratando o teste seqüencial da razão de probabilidades como uma cadeia de Markov.

BARTENSCHLAGER(1970) mostrou um método de calcular as constantes $A$ e $B$ do teste seqüencial da razão de probabilidades, baseado em tentativas e válido para certos tipos de variáveis discretas.

MANLY (1969) deduz aproximações para o cálculo da fun ção operatória característica e para o tamanho médio das amostras. Estas aproximações são exatas quando o tamanho médio das amostras tende para 1, mas resultados numéricos indicam razoável precisãomes mo quando o tamanho médio das amostras não é pequeno.

As fórmulas de Wald são simples, e aplicáveis a todas as distribuiçóes teóricas mais utilizadas em trabalhos de controle de insetos. Talvez por isso, e por não ser a amostragem de in setos muito dispendiosa em relação a outros tipos de amostragem onde há destruição da unidade amostral, continuam sendo as mais usadas. 
FOI OAKLAND (1950) quem pela primeira vez utilizou a amostragem seqüencial em problema biológico ao desenvolver um plano de amostragem para estimar o número de cistos existentes no peixe branco (Coregonus clupeaformis) a ser exportado para o Canadá.

o primeiro plano de amostragem seqüencial para controle de insetos foi desenvolvido por STARK (1952) para a broca do broto do pinheiro (Evagoria starki), baseado na distribuição normal. MORRIS (1954) desenvolveu plano de amostragem para a lagarta do bro to do pinheiro (Choristoneutra fumiferana (Clem.), baseado na distribuição binomial negativa. Utilizando a distribuição binomial, IVES \& PRENTICE ( 1958 ) desenvolveram plano de controle do serrador do leriso (Pxistiphora erichsonii). WATERS (1555) forneceu algumas referêncìas básicas para a amostragem seqüencial e apresentou fórmu las para o desenvolvimento de planos sequenciais para as distribuições normal, binomial, Poisson e binomial negativa.

MORRIS (1960) comentou que planos de amostragem sequiencial tinham sido desenvolvidos para a maioria dos insetos desfolhadores de plantas florestais da Amërìca do Norte e se declarava surpreso que a tëcnica não tỉvesse sido rapidamente adotada em outras áreas da Entomologia e em outros países. De 1960 para cá o uso da amostragem sequéencial foi introduzido em diversos países e para muitas culturas anuais.

WADDILL et alii \{1974\} elaboraram planos seqüenciais para controle dos percevejos Nabis spp e Geocomis spp na cultura da 
soja.

\section{2 - Distribuição Espacial dos Insetos}

Para delinear um plano de amostragem seqüencial pelo método do teste da razão de probabilidades deve-se inicialmente conhecer a distribuição espacial da população.

EVANS (1953) estudou a aderência de contagens de plan tas em diversas pradarias da Europa e Estados Unidos e de diversas espécies de insetos às distribuições Polya-Aeppli, Neyman tipo A e binomial negativa. Concluiu que contagens de insetos existentes numa determinada parcela se ajustam melhor à distribuição binomial n气 gativa, enquanto contagens de plantas seguem mais a distribuição Neỵ man tipo $A$.

HARTENSTEIN (1961) estudou a determinação de 31 amos tras de micro-artrópodos de solos florestais incluindo diversas espécies. Das 31 amostras somente 1 se ajustou à distribuição de Pois son e 28 amostras se ajustaram à distribuição binomial negativa. En tre 25 amostras, 13 se ajustaram à distribuição de Neyman, mas somente numa amostra a distribuição de Neyman foi melhor que a binomial negativa.

SHEPARD e CARNER (1976) estudaram durante 3 anos a distribuição espacial de diversos insetos que atacam a soja, entre eles a Anticarsia gematalis (Hübner) e diversas espëcies de Plusia, usando 1,20 m de linha como unidade amostral. Fizeram testes de ade 
rência com as seguintes distribuições: Poisson, dupla Poisson de Tho mas, Poisson com zeros, Poisson binomial, Neyman tipo A e binomial negativa. Concluiram que a distribuição dos insetos estudados concorda mais com a distribuição de poisson do que com as outras.

A distribuição espacial dos insetos depende da unida de amostral, do comportamento da espécie e do tipo de avaliação que é feita. Planos de amostragem seqüencial para controle de insetos foram desenvolvidos para as distribuiçōes binomial, normal, Poisson e binomial negativa. Das quatro distribuições teóricas acima, a nor mal foi a menos utilizada.

\section{3 - Escolha da Unidade Amostral e Nümero de Unidades Necessä- rias para Estabelecer a Distribuição Espacial dos Insetos}

$E$ fato conhecido que num experimento obtem-se maior precisão tanto aumentando o número de repetições como aumentando o tamanho da parcela. Entretanto, conservando constante a ärea do experimento, é mais vantajoso usar maior número de repetições com par celas menores do que usar poucas repetições com parcelas maiores ICALZADA BENZA, 1954). PIMENTEL GOMES et alii (1963) ao estudarem o melhor tipo de unidade amostral para proceder a determinações tecno lógicas em cana-de-açúcar concluiram que è mais vantajoso retirar uma cana por touceira, usando maior número de touceiras do que usar menor nümero de touceiras e retirar maior número de canas de cada uma. Isso parece indicar que é mais vantajoso examinar maior número 
de unidades amostrais menores do que poucas unidades de tamanho mais avantajado.

SHEPARD et alii (1974) concluiram que o melhor método para estimar a população de larvas de lepidópteros em soja é colocar uma lona no chão e, curvando as plantas de 1,20 m de linha so bre a lona, golpeá-las com violência, TURNIPSEED (1976) chegou à mesma conclusão quanto ao método, porém concluiu ser vantajoso usar as plantas de duas linhas adjacentes, colhendo insetos de $1,20 \mathrm{~m}$ de cada linha. HILLHOUSE e PITRE (1974)usaram unidades amostrais constituídas de $6,00 \mathrm{~m}$ de linha, concordando os resultados com os anteriores quanto ao método.

TURNIPSEED (1975) aconselha, para as condições do sul do Brasil, colher unidades amostrais constituídas por 1,00 m de Iinha.

Quanto ao tamanho da amostra, ANSCOMBE (1949) sugere que deve ter pelo menos 10 unidades para verificar o ajustamento à distribuição binomial negativa. Mas, no mesmo artigo, o autor chegou à conclusão que esse tamanho era insuficiente.

$$
\text { HARTENSTEIN (1961) usou amostras de } 200 \text { unidades a- }
$$
mostrais ao estudar a distribuição espacial de micro-artrópodos em solos florestais.

SHEPARD e CARNER (1976) não especificaram claramente o tamanho da amostra utilizada ao estudarem a distribuição de insetos na cultura da soja, mas deduz-se que foram 60 unidades amos- 
trais em 1972 e 30 unidades em 1973 e 1974.

\section{4 - Danos Causados pelas Lagartas da Soja}

BOLDT et alii (1975) constataram que a Anticarsiagem-

matalis (Hübner) devora $86 \mathrm{~cm}^{2}$ de folhas para completar o ciclo, en quanto a Pseudop Zusia includens (Walker) necessita de $114 \mathrm{~cm}^{2}$ e a Trichoplusia ni (Hübner) $119 \mathrm{~cm}^{2}$.

Diversos artigos foram publicados visando medir o efeito de diversos graus de desfolhamento manual no rendimento. TURNIPSEED (1972) observou que um desfolhamento de 17\% não causou dano significativo em nenhum estágio de desenvolvimento e 33\% não cau sou dano no estágio da floração.

TODD e MORGAN (1972) estudaram o efeito de $33 \%$, $66 \%$ e $100 \%$ de desfolhamento em diversos estágios da cultura desde a 6 a folha até 8 semanas após as primeiras flores. Constataram que em to dos os graus de desfolhamento os prejuízos foram maiores à medida que o desfolhamento era executado mais tardiamente.

THOMAS et alii (1974) concluiram que no fim da flora ção, quando recém uma vagem dos últimos 4 nós é visível, é necessário um desfolhamento de $30 \%$ para que haja uma queda significativa no rendimento. Constataram também que o período mais crítico é quando os grãos dos 4 últimos nós apicais começam a se desenvolver. Nessa ocasião basta um desfolhamento de 6\% para causar queda significativa no rendimento. Os mesmos autores concluem que para haver dano que 
justifique a aplicação de inseticidas a lavoura deve ter 53 lagartas por pé $(0,30 \mathrm{~m})$ de linha no primeiro caso e 7 lagartas no segun do.

Na República Argentina, ROSAS (1967) não verificou queda do rendimento com desfolhamento de 0 a $50 \%$ praticado aos 15 , 30, 45 e 70 dias após a germinação.

Para as condições do Sul do Brasil, TURNIPSEED (1975) aconselha o uso de inseticida se houver mais de 20 lagartas por metro de linha, associadas a um desfolhamento de $30 \%$ no estágio da flo ração ou de $15 \%$ no estágio de desenvolvimento das vagens. Para estimar o nümero de lagartas, sugere colher 4 amostras de $1 \mathrm{~m}$ de linha, operação a ser realizada em mais de um local se a lavoura for grande.

\section{5 - Estimativa do Parâmetro $k$ da Distribuição Binomial Negativa}

$$
\text { ANSCOMBE (1949) apresenta } 3 \text { métodos para estimar o }
$$

parämetro $k$ da distribuição binomial negativa e discute as situações onde cada um pode ser aplicado.

0 primeiro método, chamado dos momentos porque se ba seia no $1^{8}$ e no $2^{8}$ momento, respectivamente, a média e a variãncia, é dado por

$$
\hat{k}=\frac{\vec{y}^{2}}{s^{2}-\bar{y}}
$$


onde $\bar{y}$ é a estimativa da média e $s^{2}$ é estimativa da variância do nú mero de insetos por unidade amostral. Este método é eficiente quando $k$ é maior que 1 e a média é relativamente elevada.

PIEDRABUENA (1975), ao tratar da distribuição binomial negativa como integrante da "estrutura binomial", apresenta uma fórmula para estimar $k$ que corresponde ao primeiro processo descrito por Anscombe.

Os métodos apresentados por Anscombe são fáceis de calcular, mas não são gerais. Existem casos onde nenhum deles é efi ciente.

BLISS e FISHER (1953) apresentam a estimativa de $k$ pelo método da máxima verossimilhança. o $\hbar$ estimado por este proces so deve tornar nula a equaçäo

$$
z=\sum_{i=1}^{y}\left(\frac{A_{i}}{k+y_{i}}\right)-n L\left(1+\frac{\bar{y}}{k}\right)
$$

Antes de aplicar esta fórmula as $n$ unidades amostrais coletadas devem ser arranjadas em $Y$ classes, contendo $y=0,1,2, \ldots$ $\ldots . y_{-1}$ insetos. $A_{y_{i}}$ indica a frequência acumulada de todas as clas ses contendo mais que $y_{i}$ insetos e $L$ indica o logaritmo neperiano.A estimativa $\hat{k}$ é obtida por tentativas, procurando um valor que torne $z=0$.

Este processo, embora se aplique em todas as situações, é bastante trabalhoso para quem não dispõe de computador ele- 
trónico. DAVIS (1971) apresenta um programa para estimar $k$ por esse processo com computador.

Quando são feitas observaçōes em diversos locais não é aconselhável tomar a média das estimativas $\hat{k}$ de cada local para obter a estimativa $\hat{k}$ comum a todos os locais.

ANSCOMBE ( 1949 ) descreve 3 mëtodos de estimar o $k$ co mum, correspondentes a cada método por ele apresentado para estimar o $k$ simples, e que tem as mesmas limitações.

BLISS e FISHER (1953) apresentam a estimativa do $k$ co mum pelo mëtodo da máxima verossimilhança com as vantagens e desvan tagens citadas acima com respeito à estimativa do $k$ simples. $0 \hat{k}$ co mum deve tornar nula a soma dos z de todos os locais calculados pela expressão (3.5.b). E obtido por tentativas.

BLISS e OWEN (1958) deduzem uma estimativa do $k$ comum a vários grupos de dados baseada na média e na variáncia, mas em termos de regressão. E uma extensão do $1^{8}$ método apresentado por Anscombe. Por este método inicialmente calcula-se

$$
\hat{k}_{p}=\sum_{i=1}^{l}\left(\bar{y}_{i}^{2}-s_{i}^{2} / n_{i}\right) / \sum_{i=1}^{l}\left(s_{i}^{2}-\bar{y}_{i}\right)
$$

onde $\ell$ é o nümero de locais, $n_{i}$ o nümero de unidades amostrais colhidas, $\bar{y}_{i}$ é a estimativa da média de infestação e $s_{i}^{2}$ é a estimativa da variância, todas do local $i$.

Embora esta estimativa do $k$ comum tenha sido usada in distintamente, ela só é válida quando os $\hat{k}$ dos diversos locais fo- 
rem homogêneos. Quando isso não acontece deve-se calcular a estimativa do $k$ comum pela expressão:

$$
\hat{k}_{c}=\sum_{i=1}^{l}\left(\bar{y}_{i}^{2}-s_{i}^{2} / n_{i}\right)^{2} c_{i} / \sum_{i=1}^{l}\left(\bar{y}_{i}^{2}-s_{i}^{2} / n_{i}\right)\left(s_{i}^{2}-\bar{y}_{i}\right) c_{i},
$$

onde

$$
c_{i}=\frac{0,5\left(n_{i}-1\right) \hat{k}_{p}^{4}}{\left[\hat{k}_{p}\left(\hat{k}_{p}+1\right)-\left(2 \hat{k}_{p}-1\right) / n_{i}-3 / n_{i}^{2}\right]\left[\bar{y}_{i}^{2}\left(\bar{y}_{i}+\hat{k}_{p}\right)^{2}\right]}
$$


20.

\section{FUNDAMENTOS TEORICOS}

A teoria apresentada neste trabalho para o teste seqüencial da razão de probabilidades, função característica e função do tamanho médio da amostra é baseada em WALD (1947).

\section{1 - Teste Seqüencial da Razão de Probabilidades}

Seja y uma variável aleatória e seja $f(y ; \theta)$ a distrị buição dessa variável. Se $y$ for variável discreta $f\left(y_{9} \theta\right)$ indicará a probabilidade dessa variável tomar o valor $\theta$. Se y for variável con tínua então $f\left(y_{\Sigma} \Theta\right)$ indicará a função densidade de probabilidades.

Seja $H_{0}$ a hipótese que $\theta=\Theta_{0}$ e seja $H_{1}$ a hipótese

que $\Theta=\Theta_{1}$. Então a distribuição de $y$ é dada por $f\left(y_{j} \Theta_{0}\right)$ quando $H_{0}$ for verdadeira e por $f\left(y_{9} \Theta_{1}\right)$ quando $H_{1}$ for verdadeira.

A probabilidade de obter uma amostra $y_{1}, y_{2}, \ldots, y_{m^{3}}$ sendo $m$ um valor inteiro positivo é dada por 


$$
p_{1 m}=f\left(y_{1} ; \theta_{1}\right) \cdot f\left(y_{2} ; \theta_{1}\right) \ldots f\left(y_{m} ; \theta_{1}\right)
$$

quando $H_{1}$ for verdadeira, ou por

$$
p_{0 m}=f\left(y_{1} ; \theta_{0}\right) \cdot f\left(y_{2} ; \theta_{0}\right) \ldots f\left(y_{m} ; \theta_{0}\right)
$$

quando $H_{0}$ for verdadeira.

$$
\text { A "Razão de Probabilidades", também chamada "Razão }
$$

de Verossimłlhanças" é definida como

$$
\frac{p_{1 m}}{p_{0 m}}=\frac{f\left(y_{1} ; \theta_{1}\right)}{f\left(y_{1} ; \theta_{0}\right)} \cdot \frac{f\left(y_{2} ; \theta_{1}\right)}{f\left(y_{2} ; \theta_{0}\right)} \cdots \frac{f\left(y_{m}: \theta_{1}\right)}{f\left(y_{m} ; \theta_{0}\right)}
$$

que pode ser escrita de forma abreviada da seguinte maneira

$$
\frac{p_{1 m}}{p_{0 m}}=\prod_{i=1}^{m} \frac{f\left(y_{i} ; \theta_{1}\right)}{f\left(y_{i j} \theta_{0}\right)}
$$

Para facilitar os cálculos é vantajoso usar o logaritmo da razão de probabilidades em lugar da razão propriamente dita. Assim pode-se escrever

$$
L \frac{p_{1 m}}{p_{0 m}}=L \frac{f\left(y_{1} s \theta_{1}\right)}{f\left(y_{1} s \theta_{0}\right)}+L \frac{f\left(y_{2} ; \theta_{1}\right)}{f\left(y_{2} ; \theta_{0}\right)}+\ldots+L \frac{f\left(y_{m} \cdot \theta_{1}\right)}{f\left(y_{m} \cdot \theta_{0}\right)}(4.1 . b)
$$

onde $I$ indica o logaritmo neperiano.

Pode ser usado o logaritmo em qualquer base, entretanto para a distribuição normal e distribuição de Poisson há vantagens em usar o logaritmo neperiano.

Duas constantes $A$ e $B$ são escolnidas, sendo $A>B .0$ "Teste Seqüencial da Razão de Probabilidades" consiste em comparar 
a razão de probabilidades com os valores $A$ e $B$, ou, o que é feito mais comumente, comparar o logaritmo da razão de probabilidades com - logaritmo dos valores $A$ e $B$.

Esta comparação é feita em cada estágio da amostra-

gem. Se

$$
L B<L \frac{p_{1 m}}{P_{0 m}}<L A
$$

a amostragem é continuada colhendo outra observação adicional e sen do novamente calculada a razão de probabilidades. Se

$$
L \frac{p_{1 m}}{p_{0 m}} \geq L A
$$

a amostragem é terminada com a rejeição da hipótese $H_{0}$ ao nível $\alpha$ de significância. Se

$$
L B \geq L \frac{p_{1 m}}{p_{o m}}
$$

a amostragem também é terminada com a aceitação da hipótese $H_{0}$ com probabilidade $\beta$ de incorrer em erro.

\section{2 - Escolha das Constantes $A$ e $B$}

Os valores $A$ e $B$ dependem das probabilidades de erro $\alpha$ e $\beta$, sendo $\alpha$ a probabilidade de rejeitar a hipótese $H_{0}$ quando ela for verdadeira e $\beta$ a probabilidade de aceitar $H_{0}$ quando ela for fal sa. 


$$
\begin{gathered}
\text { Uma amostra } y_{1}, y_{2}, \ldots, y_{n} \text { será do tipo } 0 \text { se } \\
\qquad B<\frac{p_{1 m}}{p_{0 m}}<A
\end{gathered}
$$

para $m=1,2, \ldots, n-1$ e

$$
B \geq \frac{p_{1 n}}{p_{o n}} .
$$

Uma amostra $y_{1}, y_{2}, \ldots, y_{n}$ serä do tipo 1 se

$$
B<\frac{P_{1 m}}{p_{o m}}<A
$$

para $m=1,2, \ldots, n-1$ e

$$
\frac{p_{I n}}{p_{0 n}} \geq A
$$

Então, uma amostra do tipo o leva a aceitar a hipótese $H_{0}$ e uma amostra do tipo 1 leva a rejeitar $H_{0}$.

A probabilidade de obter uma amostra do tipo 1 é pelo menos $A$ vezes maior sob a hipótese $H_{1}$ do que sob a hipótese $H_{0}$ 。 Então a medida da probabilidade de todas as amostras possíveis do tipo 1 é também $A$ vezes maior sob $H_{1}$ do que sob $H_{0}$. A medida da pro babilidade de todas as amostras do tipo 1 é a probabilidade que a amostragem seqüencial termine com a aceitação de $H_{1}$ (rejeição de $H_{0}$ \}。 Mas essa probabilidade é igual a $\alpha$ quando $H_{0}$ for verdadeira e (1-B) quando $H_{3}$ for verdadeira.

Obtem-se então a desigualdade $1-B \geq A \alpha$ que podeser 
escrita

$$
A \leq \frac{1-\beta}{\alpha}
$$

Logo, (1-B)/ $\alpha$ é um limite superior para $A$.

De maneira similar pode-se deduzir um limite inferior para $B$. A probabilidade de obter uma amostra do tipo 0 sob a hipóte se $H_{1}$ é no máximo $B$ vezes maior que a probabilidade de obtê-la quan do $H_{0}$ for verdadeira. Então também a probabilidade de aceitar $H_{0}$ é no máximo $B$ vezes maior quando $H_{1}$ for verdadeira que quando $H_{0}$ for verdadeira. Visto que a probabilidade de aceitar $H_{0}$ é igual a (1-a) quando $H_{0}$ for verdadeira e $\beta$ quando $H_{1}$ for verdadeira, obtem-se a de sigualdade $\beta \leq(1-\alpha) B$ que pode ser escrita

$$
B \geq \frac{B}{1-\alpha}
$$

Logo, $B /(1-\alpha)$ é um limite inferior para $B$. WALD (1947) conclui que fazendo

$$
A=\frac{1-\beta}{\alpha}
$$

e

$$
B=\frac{\beta}{1-\alpha}
$$

o erro tipo I, ou seja, a probabilidade de rejeitar $H_{0}$ quando ela for verdadeira, não excederá $\alpha$ e o erro tipo II, ou seja, a probabi lidade de aceitar $H_{0}$ quando ela for falsa, não excederá $\beta$. 
25.

A ünica desvantagem que pode ocorrer ao transformar as desigualdades $(4.2 . a)$ e (4.2.b) em igualdades é que o tamanho da amostra pode se tornar maior antes que seja tomada uma decisão.Mas, levando em consideração que nas pesquisas agrícolas a amostragem ge ralmente não é excessivamente dispendiosa, o procedimento pode ser adotado.

WALD (1947), ANDERSON (1960) e BARTENSCHLAGER (1970) discutem os valores exatos de $A$ e $B$ e as consequièncias que advem ao tomar os valores aproximados.

\section{3 - Função Operatōria Característica}

\subsection{1 - Generalidades}

Para poder desenvolver um teste seqüencial presume-se que a distribuição da variável y seja conhecida, com exceção de um nümero finito de parâmetros $\theta_{1}, \theta_{2}, \ldots, \theta_{k}$. Então a distribuição de y é dada pela função $f\left(y_{3} \Theta_{1}, \Theta_{2}, \ldots, \theta_{k}\right)$ sendo a forma da função $f$ conhecida mas os verdadeiros valores dos parâmetros $\theta_{1}, \theta_{2}$, ..., $\theta_{k}$ desconhecidos. Como a distribuição de $y$ é determinada pelos parâmetros $\theta_{1}, \theta_{2}, \ldots, \theta_{k}$ a probabilidade de que a amostragem ter mine aceitando a hipótese $H_{0}$ é determinada por esses parâmetros. Es ta funçãu é chamada "Função Dperatória Característica" e é represen tada por $P(\theta)$.

Em outras palavras, o valor da função $P(\theta)$ para cada 
grupo de parâmetros $\theta_{1}, \theta_{2}, \ldots, \theta_{k}$ é igual à probabilidade que $H_{0}$ seja aceita quando $\theta_{1}, \theta_{2}, \ldots, \theta_{k}$ são os parâmetros verdadeiros.Através da função operatória característica pode ser obtida imediata mente a probabilidade de tomar uma decisão correta para qualquer gru po de parâmetros $\theta_{1}, \theta_{2}, \ldots, \theta_{k}$ 。

A função operatória característica está estreitamente relacionada com o poder do teste na teoria comum de testes. 0 po der de um teste, frente a uma determinada hipótese alternativa, é a probabilidade de rejeitar $H_{0}$ quando esta é falsa.

Visto que se trabalhará com teste seqüencial com pro babilidade igual a 1 de que a amostragem eventualmente termine, a probabilidade de rejeitar $H_{0}$ é $[\bar{I}-P(\theta)]$.

Se houver somente um parâmetro desconhecido $\theta$, a fun ção $P(\theta)$ pode ser disposta num gráfico, sendo $\theta$ colocado no eixo ho rizontal e $P(\theta)$ no vertical.

A figura I mostra uma curva característica de operação típica para uma distribuição binomial. 
27.

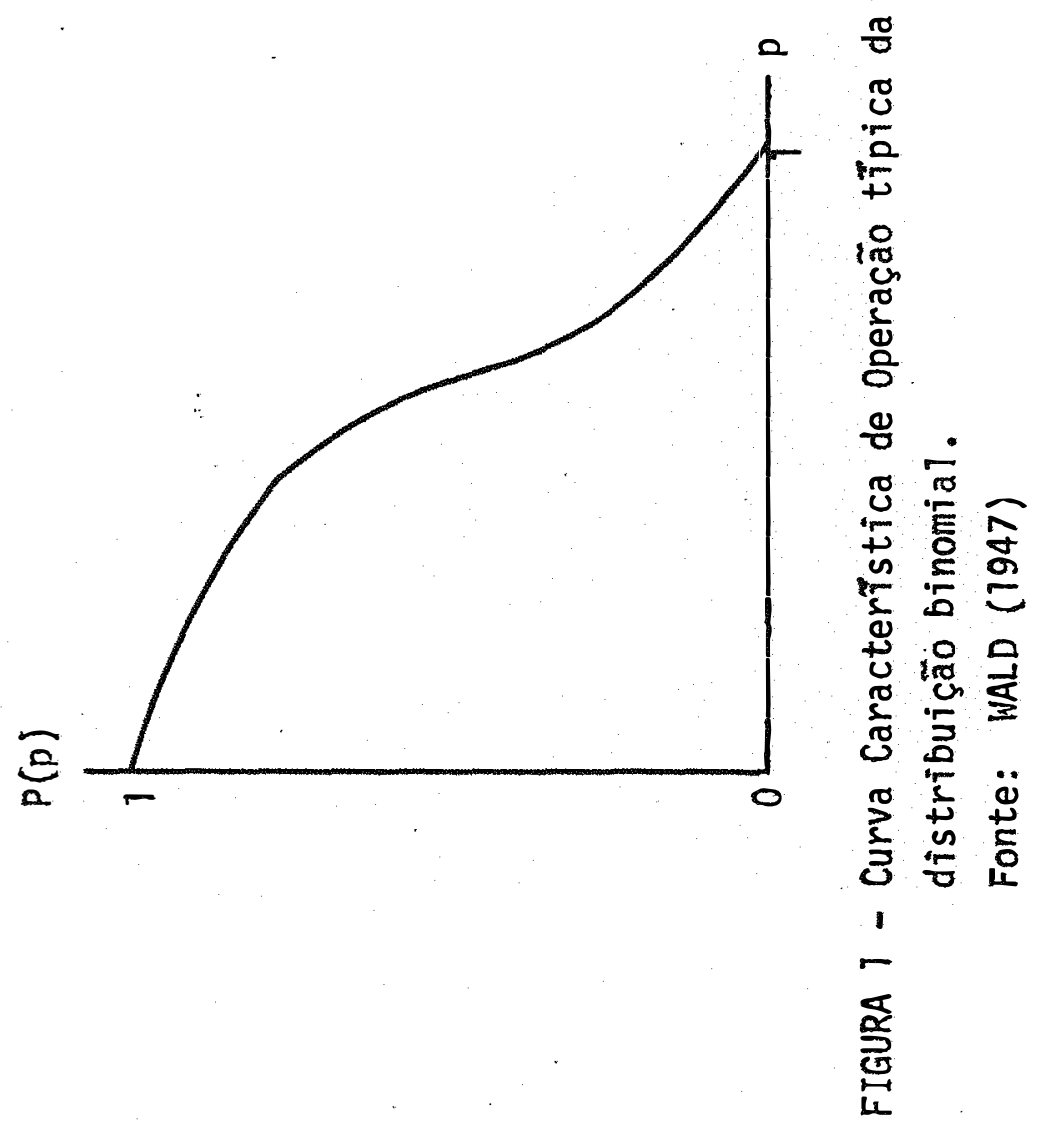


28.

\subsection{2 - Dedução da förmula geral}

Tratar-se-á aqui do caso em que há só um parâmetro desconhecido, mas os resultados podem ser estendidos sem dificuldades para qualquer nümero de parâmetros.

Considere-se a expressão

$$
\left[\frac{f\left(y_{0} \theta_{1}\right)}{f\left(y_{s} \theta_{0}\right)}\right]^{W(\theta)}
$$

Para cada valor de $\theta$, o valor $W(\theta)$ é determinado de maneira que $W(\Theta) \neq 0$ e que a esperança matemática dessa expressão seja igual a 1. Então, pela definição de esperança matemática tem- se

$$
\int_{-\infty}^{\infty}\left[\frac{f\left(y_{i} \theta_{1}\right)}{f\left(y ; \theta_{0}\right)}\right]^{W(\Theta)} f\left(y_{j} \theta\right) d y=1
$$

quando $f\left(y_{\vdots} \theta\right)$ for uma função densidade, ou

$$
\sum_{y}\left[\frac{f\left(y_{s} \theta_{1}\right)}{f\left(y_{;} \theta_{0}\right)}\right]^{W(\theta)} f(y ; \theta)=1
$$

quando $y$ for uma variável discreta.

WALD (1947) demonstrou que com algumas leves restrições a respeito da natureza da distribuição da função $f\left(y_{:} \theta\right)$, existe somente um valor $W(\theta) \neq 0$ que satisfaz plenamente $(4.3 .2 . a)$ ou $(4.3 .2 . b)$

Então para qualquer valor $\theta$, a função de $y$ dada por 


$$
f *\left(y_{j} \theta\right)=\left[\frac{f\left(y_{j} \theta_{1}\right)}{f\left(y_{j} \theta_{0}\right)}\right]^{W(\theta)} f\left(y_{;} \theta\right)
$$

é uma função de distribuição.

Como $W(\theta)$ deve ser diferente de zero, há duas possibilidades: $W(\theta)>0$ e $W(\theta)<0$. Considerar-se-á inicialmente o caso em que $W(\theta)>0$.

Seja $H$ a hipótese que $f\left(y_{j} \theta\right)$ é a verdadeira distribuição de $y$ e seja $H^{*}$ a hipótese que $f^{*}\left(y_{2} \theta\right)$ é a verdadeira distribuição de $y$. Considere-se o teste seqüencial da razão de probabilidades $S^{*}$ para testar $H$ contra $H^{*}$. Conforme foi exposto na seção 4.1 enquanto

$$
B^{W(\theta)}<\prod_{i=1}^{m} \frac{f^{*}\left(y_{i} ; \theta\right)}{f\left(y_{i} ; \theta\right)}<A^{W(\theta)}
$$

continua-se colhendo novas unidades amostrais. Quando

$$
\prod_{i=1}^{m} \frac{f^{*}\left(y_{i s} \theta\right)}{f\left(y_{i s} \theta\right)} \leq B^{W(\theta)}
$$

aceita-se a hipótese $H$, com probabilidade $B$ de cometer erro, suspen dendo-se a amostragem. Quando

$$
\prod_{i=1}^{m} \frac{f *\left(y_{i}{ }^{\circ} \theta\right)}{f\left(y_{i} ; \theta\right)} \geq A^{W(\theta)}
$$

termina-se a coleta de observações, rejeitando-se $H$ ao nível $\alpha$ de significância. Visto que

$$
\frac{f^{*}\left(y_{;} \theta\right)}{f\left(y_{2} \theta\right)}=\left[\frac{f\left(y_{;} \theta_{1}\right)}{f\left(y_{;} \theta_{0}\right)}\right]^{W(\theta)}
$$


e considerando que $W(\theta)>0$ as desigualdades $(4.3 .2 . c),(4.3 .2 . d)$ e (4.3.2.e) são equivalentes, respectivamente a

$$
\begin{gathered}
B<\prod_{i=1}^{m} \frac{f\left(y_{i} ; \theta_{1}\right)}{f\left(y_{i} ; \theta_{0}\right)}<A \\
\prod_{i=1}^{m} \frac{f\left(y_{i} ; \theta_{1}\right)}{f\left(y_{i} ; \theta_{0}\right)} \leq B \\
\prod_{i=1}^{m} \frac{f\left(y_{i} ; \theta_{1}\right)}{f\left(y_{i} ; \theta_{0}\right)} \geq A
\end{gathered}
$$

Mas essas desigualdades são idênticas àquelas defini das no teste seqüencial da razão de probabilidades $S$ para testar $H_{0}$ contra $H_{1}$ quando as constantes $A$ e $B$ são usadas. Então se o teste $S^{*}$ leva a aceitar $H$, o teste $S$ leva a aceitar $H_{0}$, e se $S^{*}$ conduz a rejeitar $H, S$ também conduz a rejeitar $H_{0}$. Deduz-se então, que a probabilidade de aceitar $H_{0}$ quando $\Theta$ é verdadeiro, isto é, o valor de $P(\Theta)$, é a mesma que o teste $S *$ conduza a aceitar $H$ quando $f\left(y_{j} \theta\right)$ é a verdadeira distribuição de $y$.

Seja $\alpha^{\prime}$ a probabilidade que $S$ conduza à rejeição de $H$ quando $H$ é verdadeira, e seja $\beta^{\prime}$ a probabilidade que $S^{*}$ conduza à aceitação de $H$ quando $H$ é verdadeira. Aplicando (4.2.c) e (4.2.d) ao teste $S^{*}$ obtem-se

$$
\begin{aligned}
& A^{W(\theta)}=\frac{1-\beta^{\prime}}{\alpha^{\prime}} \\
& B^{W(\theta)}=\frac{\beta^{\prime}}{1-\alpha^{\prime}}
\end{aligned}
$$


(4.3.2.f) obtem-se

$$
\begin{gathered}
\alpha^{\prime}=\frac{1-B^{W(\theta)}}{A^{W(\theta)}-B^{W(\theta)}} \\
\text { Mas como } \alpha^{\prime}=[1-P(\theta)] \text {, chega-se a } \\
P_{(\theta)}=\frac{A^{W(\theta)}-1}{A^{W(\theta)}-B^{W(\theta)}}
\end{gathered}
$$

De maneira análoga chega-se ao mesmo resultado para o caso $W(\Theta)$ < 0 . Esta fórmula é aproximada uma vez que não foram to mados os valores exatos de $A^{W(\theta)}$ e $B^{W(\theta)}$.

WATERS (1955) apresenta a expressão (4.3.2.h) já adap tada às distribuições binomial, normal, Poisson e binomial negativa, mas em função de outro parâmetro $x$ funcionalmente relacionado com $W$.

\section{4 - Função do Tamanho Mēdio das Amostras \\ 4.4.1 - Generalidades}

O número de observações exigido pela amostragem seqüencial não é pré-fixado, mas é uma variável aleatória, porque em cada estágio da amostragem a decisão de suspender o processo depende do resultado acumulado das observações anteriores.

0 tamanho das amostras é maior quandc $\theta^{\prime}$ está próximo do parâmetro $\theta$, e diminui à medida que $\theta^{\prime}$ se afasta de $\theta$. 
Sendo o nümero de observações necessärias para tomar uma decisão uma variável aleatória, pode-se calcular a esperança ma temática $E_{\Theta}(n) . E_{\Theta}(n)$ è o tamanho das amostras necessário, em média, para poder tomar uma decisão executando o teste diversas vezes numa mesma população quando $\Theta$ é o parâmetro verdadeiro.

Calculando a esperança matemática do tamanho das amostras $E_{\Theta}(n)$ para diversos valores de $\theta$, pode-se distribui-los num gráfico, traçando a "Curva do Tamanho Médio das Amostras".

A figura 2 mostra uma curva típica do tamanho médio das amostras para a distribuição binomial.

\section{4 .2 - Dedução da förmula geral}

Seja $n$ o nümero de observações requerido pelo teste e seja $E_{\Theta}(n)$ a esperança matemática de $n$ quando $\theta$ é o valor verdadeiro do parâmetro. o valor $E_{\Theta}(n)$ é uma função de $\theta_{\text {. }}$

Seja $N$ um inteiro suficientemente grande para permitir que a probabilidade de que $n \geq N$ seja desprezível. Então pressu põe-se que $n<N$ e pode-se escrever:

$$
z=z_{1}+z_{2}+\ldots+z_{N}=\left(z_{1}+z_{2}+\ldots+z_{n}\right)+\left(z_{n+1}+z_{n+2}+\ldots+z_{N}\right)(4.4 .2 . a)
$$

onde

$$
z_{i}=I \frac{f\left(y_{i ;} \cdot \theta_{1}\right)}{f\left(y_{i} ; \theta_{2}\right)}
$$


33.

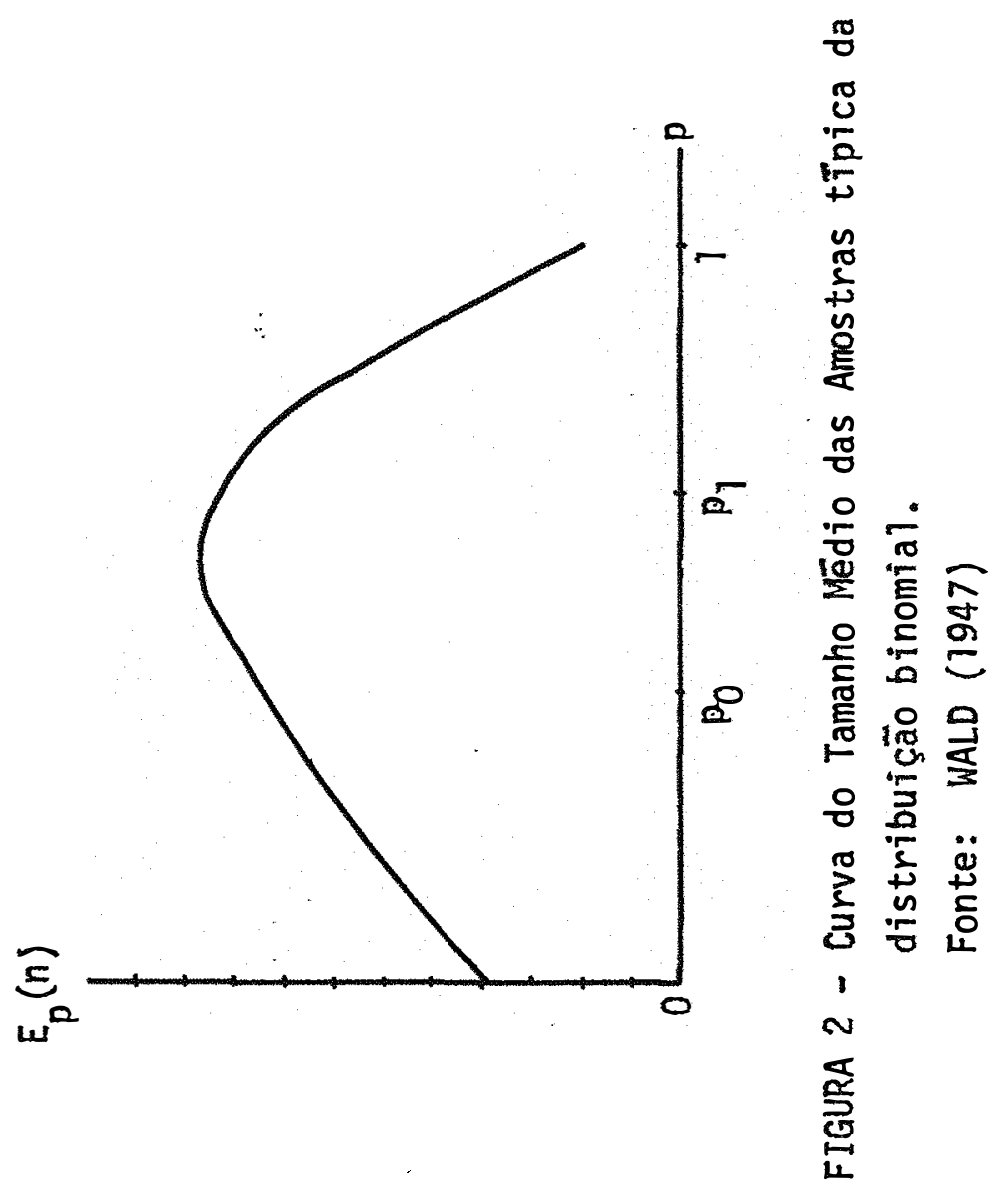



bros de $(4.4 .2 . a)$ obtem-se

$$
N E(z)=E\left(z_{1}+z_{2}+\ldots+z_{n}\right)+E\left(z_{n+1}+z_{n+2}+\ldots+z_{N}\right) \quad(4.4 .2, b)
$$

onde

$$
z=L \frac{f\left(y_{i} \theta_{1}\right)}{f\left(y_{s} \theta_{0}\right)}
$$

Visto que, para $i>n$, a variável aleatória $z_{i}$ é dis tribuida independentemente de $n$, os valores esperados de $\left(z_{n+1}{ }^{+z}{ }_{n+2}{ }^{+}\right.$ $+\ldots+z_{N}$ ) são iguais à esperança de $(N-n)$ vezes a esperança matemätica de um simples valor $z$, isto $\bar{e}$,

$$
\begin{aligned}
E\left(z_{n+1}+z_{n+2}+{ }_{0}+z_{N}\right) & =E[(N-n) E(z)]=N E(z)-E(n) E(z) \quad(4.4 .2 . c) \\
& \text { De }(4.4 .2 . b) \text { e }(4.4 .2 . c) \text { segue que } \\
& E_{\left(z_{1}+z_{2}+\ldots+z_{n}\right)-E(n) E(z)=0}
\end{aligned}
$$

donde, se $E(z) \neq 0$,

$$
E(n)=\frac{E\left(z_{1}+z_{2}+\ldots+z_{n}\right)}{E(z)}
$$

Se $\Theta$ é o valor verdadeiro do parâmetro, então $E(n)=$ $=E_{\Theta}(n)$ pela definição de $E_{\Theta}(n)$. Seja $E_{\Theta}(z)$ o valor esperado $E(z)$ de $z$ quando $\Theta$ é o verdadeiro valor do parâmetro. Então a variável alea tória $\left(z_{1}+z_{2}+z_{3}+\ldots+z_{n}\right)$ pode tomar somente os valores $L A$ e $L B$ com probabilidades $[1-P(\theta)]$ e $P(\theta)$, respectivamente. Então 
35.

$$
\begin{aligned}
& E\left(z_{1}+z_{2}+\ldots+z_{n}\right)=p(\theta) L B+[1-p(\theta)] L A \quad(4.4 .2 . e) \\
& \text { A partir de }(4.4 .2 . d) \text { e }(4.4 .2 . e) \text { chega-se à expres- }
\end{aligned}
$$

são

$$
E_{\theta}(n)=\frac{P(\theta) L B+[1-P(\theta)] L A}{E_{\theta}(z)}
$$

que permite calcular o valor da funçäo do tamanho médio das amostras para uma amostragem seqüencial.

Tomando $B=\frac{\beta}{1-\alpha}, A=\frac{1-\alpha}{\beta}$ e $P(\theta)$ calculado pela expressão $(4.3 .2 \cdot h)$ então $E_{\Theta}(n)$ será um valor aproximado.

Existem diversas sugestões para melhor aproximação das fórmulas de Wald, aqui apresentadas, para o cálculo da função operatória característica e da função do tamanho médio das amostras, entre as quais, PAGE (1954), KEMP (1958), TALLIS e VAGHOLKAR (1965) e MANLY (1969). Entretanto, as fórmulas de Wald tem precisão suficiente para fins práticos e são as mais usadas.

\section{5 - Elaboração de um Plano de Amostragem Seqüencial}

Para elaborar um plano de amostragem seqüencial é ne cessário conhecer a distribuição da variável que está sendo levantạ da pela amostragem, formular as hipóteses e estabelecer os riscos de tomar decisões erradas.

Em trabalhos de controle de insetos quatro são as dis tribuições mais comuns: binomial, normal, Poisson e binomial negati va. 
36.

Se a unidade amostral for classificada em danificada e não danificada, e considerando-se uma população de elevado número de unidades amostrais, caracteriza-se a distribuição binomial.

Se for contado o número de insetos existentes na uni dade amostral e esses insetos estiverem distribuidos ao acaso na lavoura, os dados de contagem se ajustarão à distribuição normal. Se os insetos estiverem distribuídos ao acaso mas tem baixa densidade populacional, sendo algo raros na unidade amostral, os dados de con tagem seguirão a distribuição de poisson. Entretanto, muitos insetos não estão distribufdos ao acaso na lavoura mas estão agrupados. Neste caso os dados de contagem aderirão à distribuição binomial ne gativa.

A determinação do tipo de distribuição requer um número relativamente grande de dados, embora uma coincidencia exata em geral não seja necessäria, KNIGHT (1957).

Na prática é mais difícil formular as hipóteses e es tabelecer os riscos de tomar decisões erradas. Muitas vezes são necessários dados de pesquisa de campo de vários anos antes que se possa obter um plano de razoável qualidade.

\section{6 - Riscos Tolerados de Tomar Decisões Erradas}

Qualquer plano de amostragem pode levar a uma decisão errada, uma vez que não inspeciona toda a população. Mas, como a inspeção de toda a população é muitas vezes impossível ou muito 
dispendiosa, se é levado a tolerar riscos de tomar decisões erradas. Ao decidir sobre a aplicação ou não de inseticida nu ma lavoura, em primeiro lugar deve-se determinar o nível de infesta ção $\theta^{\prime}$ tal que seja economicamente vantajoso aplicar o defensivo quando o grau de infestação da lavoura $\Theta$ for maior que $\theta^{\prime}$, e que não seja vantajoso aplicar o inseticida quando $\theta \leq \theta^{\prime}$.

0 parâmetro $\Theta$ pode representar a proporção de unidades amostrais danificadas existentes na lavoura, no caso da distribuição binomial, ou, no caso de contagem de insetos, a média populacional de insetos existentes nas unidades amostrais.

O nível de infestação $\theta^{\prime}$ depende do preço do inseti cida, do preço do produto colhido e do dano causado pela espécie de inseto em estudo.

Então o problema de aplicar ou não o inseticida na lavoura pode ser formulado como o problema de testar a hipötese que $\theta \leq \theta^{\prime}$ contra a hipótese alternativa que $\theta>\theta^{\prime}$. Se $\theta=\theta^{\prime}$ o dano causado pela praga é igual ao custo de aplicação do inseticida e é indiferente qual a decisão tomar. Se $\Theta$ é um pouco superior a $\theta$ ' o dano causado pela praga é levemente su perior ao custo de aplicação do inseticida. Então desaconselhar sua aplicação não é considerado um erro de consequiências graves. Da mes ma forma, se $\theta$ é um pouco inferior a $\theta^{\prime}$ o dano sausado pela praga é levemente inferior ao custo de aplicação do defensivo e preconizar sua utilização não constitui erro grave. 
Logo, é possível escolher dois valores, $\theta_{0}$ inferior a $\theta^{\prime}$ e $\theta_{1}$ superior a $\theta^{\prime}$, tais que preconizar a aplicação do inseticida seja considerado erro de conseqüências graves se le somente se) $\theta \leq \Theta_{0}$, e desaconselhar a aplicação seja considerado erro de con sequiências graves se (e somente se) $\theta \geq \theta_{1}$. Se $\theta_{0}<\theta<\theta_{1}$ nenhuma das decisões possíveis de serem tomadas conduz a erro de consequiências práticas.

Escolhidos os valores $\theta_{0}$ e $\Theta_{1}$ a probabilidade de acon selhar a aplicação do inseticida quando não é necessária é pré-fixa da pelo valor $\alpha$ e a probabilidade de desaconselhar a aplicação quan do necessária é dada pelo valor $\beta$ também prë-fixado.

Assim os riscos tolerados de tomar decisões erradas são fixados pelos quatro valores: $\Theta_{0}, \Theta_{1}, \alpha$ e $\beta$. A escolha dessas quatro constantes não ẽ um problema estatístico. Elas são escolhidas com base em considerações práticas para cada caso particular. Um plano de amostragem satisfazendo a essas condições é dado pelo "Teste Sequiencial da Razão de Probabilidades" para testar a hipótese $\theta=\theta_{0}$ contra a hipötese $\theta=\theta_{1}$.

Embora a terminologia usada neste trabalho esteja orientada para o problema de controle de insetos, a amostragem seqüencial é aplicada também em outras áreas de investigação. 
39.

\section{7 - Plano de Amostragem Seqüuencial para Testar a Média de Uma Distribuição Binomial}

\subsection{1 - Apresentação do problema}

Este problema surge, por exemplo, ao decidir sobre a aplicação ou não de inseticida numa lavoura, sendo as unidades amos trais classificadas em duas categorias: danificadas ou não danifica das. Seja 0 o valor atribuíto para unidades não danificadas e seja 1 o valor atribuído a cada unidade danificada. Seja $p$ a proporção (que é desconhecida) de unidades danificadas na lavoura. Entäo o re sultado y da inspeção de uma unidade amostral escolhida ao acaso pode tomar somente os valores 1 e 0 com probabilidades $p$ e $(1-p)$. respectivamente.

Isto caracteriza ume distribuição binomial cuja função de probabilidade é dada por

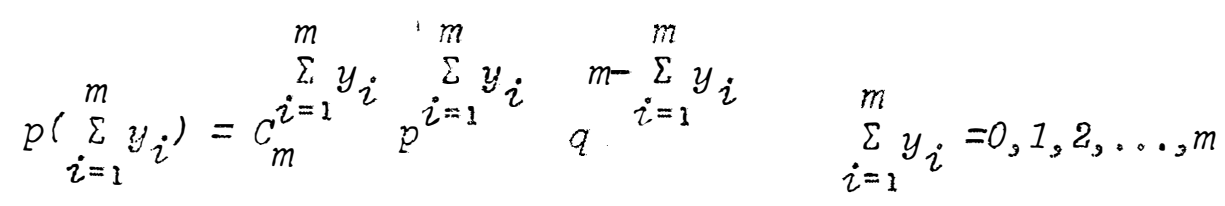

onde $q=(1-p)$, é a proporção de unidades amostrais danificadas e $m$ é o número de unidades amostrais observadas.

$$
\text { Considerando o que foi visto na seçấo } 4.6 \text { deve-se }
$$
determinar um valor $p^{\prime}$ tal que a aplicação do inseticida seja aconselhada se $P>P^{\prime}$ e não seja aconselhada se $P \leq p^{\prime}$. Deve-se também determinar dois valores $p_{0}$ e $p_{1}$ tais que não aconselhar a aplicação 
do inseticida seja um erro de conseqùências sérias se (e somente se) $p \geq p_{1}$ e preconizar o uso do inseticida seja considerado erro grave se (e somente se) $p \leq p_{0}$.

\subsection{2 - Desenvolvimento das förmulas}

o plano é delineado para testar a hipótese $p=p_{0}$ eon tra a hipötese $p=p_{1}$.

Se $p$ indicar a proporção de unidades amostrais danificadas na lavoura, obtida uma amostra de $m$ elementos, a probabilidade de obter outra amostra com o mesmo número de plantas danificatas e na mesma seqưência é dada por

$$
p_{m}=p^{\sum_{i=1}^{m} y_{i}} \quad q^{m-\sum_{i=1}^{m} y_{i}}
$$

onde $\sum_{i=1}^{m} y_{i}$ ë o nümero de unidades amostrais danificadas entre as $\mathrm{m}$. unidades da amostra.

Sob a hipótese $p=p_{1}$ esta probabilidade torna-se

$$
p_{1 m}=p_{1}^{\sum_{i=1}^{m} y_{i}} q_{1}^{m-\sum_{i=1}^{m} y_{i}}
$$

e sob a nipótese $p=p_{0}$

$$
p_{0 m}=p_{0}^{\sum_{i=1}^{m} y_{i}} q_{0}^{m-\sum_{i=1}^{m} y_{i}}
$$

Com base em (4.1.a) e (4.1.b) ao colher a emésima unidade amostral a razão de probabilidade será 


$$
\frac{p_{1 m}}{p_{0 m}}=\left(\frac{p_{1}}{p_{0}}\right)^{\sum_{i=1}^{m} y_{i}} \frac{q_{1}}{q_{0}}{ }_{i=1}^{m-\sum_{i} y_{i}}
$$

ou sob a forma logarítmica

$$
\begin{aligned}
& \quad L \frac{p_{1 m}}{p_{0 m}}=\sum_{i=1}^{m} y_{i} L \frac{p_{1}}{p_{0}}+\left(m-\sum_{i=1}^{m} y_{i}\right) L \frac{q_{1}}{q_{0}} \\
& \text { Pelas fórmulas }(4.1 . c),(4.1 . d),(4.1 . e),(4.2 . c) \text { e }
\end{aligned}
$$

(4.2.d) verifica-se que a amostragem é continuada enquanto

$$
L \frac{\beta}{1-\alpha}<\sum_{i=1}^{m} y_{i} L \frac{p_{1}}{p_{0}}+\left(m-\sum_{i=1}^{m} y_{i}\right) L \frac{q_{1}}{q_{0}} \geq L \frac{1-\beta}{\alpha}
$$

e ë terminada toda vez que isso não ocorrer. Quando

$$
\sum_{i=1}^{m} y_{i} L \frac{p_{1}}{p_{0}}+\left(m-\sum_{i=1}^{m} y_{i}\right) L \frac{q}{q_{0}} \geq L \frac{1-p}{\alpha}
$$

a amostragem é suspensa rejeitando-se a hipötese $p=p_{0}$ ao nível $\alpha$ de significância, preconizando então o uso de inseticida. Quando

$$
\sum_{i=1}^{m} y_{i} L \frac{p_{1}}{p_{0}}+\left(m-\sum_{i=1}^{m} y_{i}\right) L \frac{q_{1}}{q_{0}} \leq L \frac{\beta}{1-\alpha}
$$

a amostragem é terminada aceitando a hipótese $p=p_{0}$ com probabilidede $\beta$ de erro, não aconselhando o uso de defensivos.

$$
\text { Resalvendo }(4.7 .2 . a) \text { e }(4.7 .2 . b) \text { obtem-se respectiva }
$$

mente 


$$
\begin{aligned}
& \sum_{i=1}^{m} y_{i} \geq \frac{L \frac{1-\beta}{\alpha}}{L \frac{p_{1} q_{0}}{p_{0} q_{1}}}+m \frac{L \frac{q_{0}}{q_{1}}}{L \frac{p_{1} q_{0}}{p_{0} q_{1}}} \\
& \sum_{i=1}^{m} y_{i} \leq \frac{L \frac{\beta}{1-\alpha}}{L \frac{p_{1} q_{0}}{p_{0} q_{1}}}+m \frac{L \frac{q_{0}}{q_{1}}}{L \frac{p_{1} q_{0}}{p_{0} q_{1}}}
\end{aligned}
$$

Verifica-se da desigualdade (4.7.2.c) que o menor va lor de $\sum_{i=1}^{m} y_{i}$, e que serä chamado $r_{m}$, que permite decidir pela acei tação da hipćtese $p=p_{1}$, e conseqüentemente, seja aconselhado o tra tamento da lavoura é

$$
r_{m}=\frac{L \frac{1-\beta}{\alpha}}{L \frac{p_{1} q_{0}}{p_{0} q_{1}}}+m \frac{L \frac{q_{0}}{q_{1}}}{L \frac{p_{1} q_{0}}{p_{0} q_{1}}}
$$

Da mesma forma, verifica-se da desigualdade (4.7.2.d) Gue o maior valor de $\sum_{i=1}^{m} y_{i}$, e que será chamado de $a_{m}$, que permite decidir pela aceitação da hipótese $p=p_{0}$ e consequentemente não aconselhar o uso de defensivos é

$$
a_{m}=\frac{I \frac{\beta}{1-\alpha}}{L \frac{p_{1} q_{0}}{p_{0} q_{1}}}+m \frac{I \frac{q_{0}}{q_{1}}}{L \frac{p_{1} q_{0}}{p_{0} q_{1}}}
$$


Como $a_{m}$ \& $r_{m}$ só dependem de $p_{0}, p_{1}, \alpha$ e $\beta$ eles podem ser calculados para cada valor de $m$ antes de iniciar a amostragem e podem ser tabulados.

Ao executar a amostragem, para cada tamanho $m$ da amostra o nümero acumulado de unidades amostrais danificadas, $\sum_{i=1}^{m} y_{i}$ é comparado com os respectivos valores $a_{m}$ e $r_{m}$. Se $\sum_{i=1}^{m} y_{i} \geq r_{m}$ a amostragem $\vec{e}$ terminada rejeitando-se a hipötese $p=p_{0}$ ao nível a de significância, concluindo-se então pela aplicação do inseticida. Se $\sum_{i=1}^{m} y_{i} \leq a_{m}$ a amostragem é terminada aceitando-se $p=p_{0}$ com probabilidade $\beta$ de erro e optando, conseqüentemente, pela não utilização do inseticida. Continua-se a amostragem enquanto $a_{m}<\sum_{i=1}^{m} y_{i}<r_{m}$. A amostragem seqüiencial pode também ser delineada grạ ficamente. O número $m$ de observaçöes e colocado no eixo das abscissas e o número acumulado de unidades amostrais danificadas $\sum_{i=1}^{m} y_{i}$ no eixo das ordenadas. Os pontos $\left(m_{s} a_{m}\right)$ formam uma reta $R_{0}$ e os pontos $\left(m_{j} r_{m}\right)$ formam outra reta $R_{\mathfrak{l}}$. As duas retas são traçadas antes de $\mathrm{i}$ niciar a amostragem. Os pontos $\left(m_{;} \sum_{i=1}^{m} y_{i}\right)$ são representados no gráfico assim que inicie a inspeção da lavoura. Continua-se colhendounidades amostrais enquanto o ponto $\left(m_{i} \sum_{i=1}^{m} y_{i}\right)$ estiver situado entre $R_{0}$ e $R_{I}$. Se $\left(m_{i} \sum_{i=1} y_{i}\right)$ situar-se em $R_{0}$ ou abaixo, aceita-se a hipäte se $p=p_{0}$ com probabilidade de erro $\beta$ e conclui-se que a aplicação do inseticida não é necessária. Se $\left(m_{9} \sum_{i=1}^{m} y_{i}\right)$ se situar em $R_{1}$ ou aci mas rejeita-se $p=p_{0}$ ao nível $\alpha$ de significância e conclui-se que hä necessidade de aplicar o defensivo. 
$R_{0}$ e $R_{1}$ são chamadas linhas de decisão e são representadas pelos seguintes modelos matemáticos:

$$
\begin{aligned}
& R_{0}=h_{0}+S m \\
& R_{1}=h_{1}+S m
\end{aligned}
$$

onde $h_{0}$ e $h_{1}$ são os coeficientes I1neares, $S$ é o coeficlente angular e $m$ o número de unidades amostrais inspecionadas no ponto consi derado.

Das igualdades $(4.7 .2 . e)$ e $(4.7 .2 . f)$ verifica-se que

$$
\begin{aligned}
& h_{0}=\frac{L \frac{\beta}{1-\alpha}}{L \frac{p_{1} q_{0}}{p_{0} q_{1}}} \\
& h_{1}=\frac{L \frac{1-\beta}{\alpha}}{L \frac{p_{1} q_{0}}{p_{0} q_{1}}} \\
& S=\frac{L \frac{q_{0}}{q_{1}}}{L \frac{p_{1} q_{0}}{p_{0} q_{1}}}
\end{aligned}
$$

A figura 3 mostra o procedimento gráfico para o exæm plo anterior. 


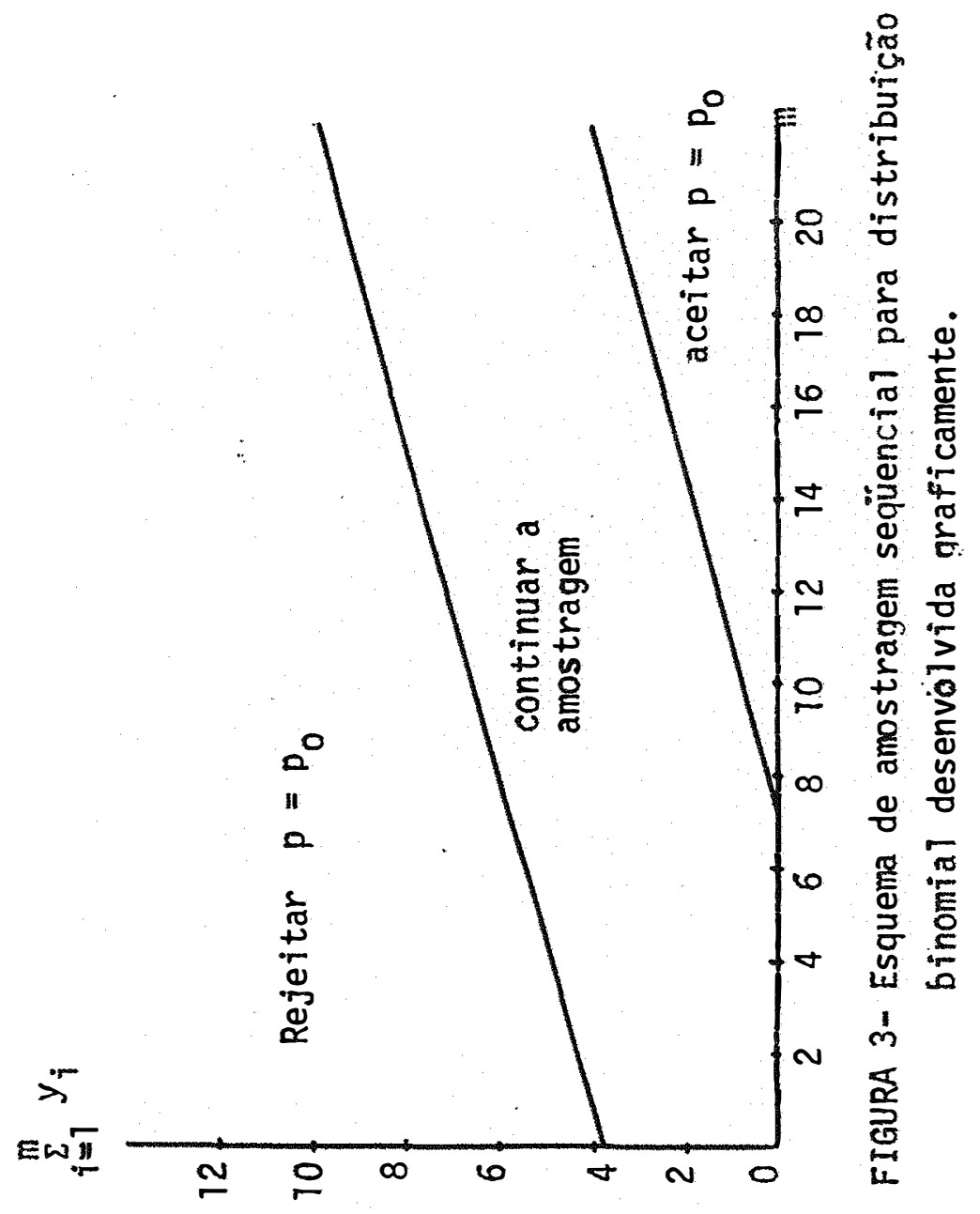


Entretanto, como as condições de trabalho na lavoura não são muito confortáveis, o processo gráfico não é muito usado. 0 processo tabular anteriormente descrito é mais adequado.

\subsection{3 - Obtenção da curva característica de operação}

Na distribuição binomial a variável y só pode tomar os valores 0 e 1 e a distribuição $f(y ; \theta)$ é dada como segue: $f(1 ; \theta)=$ $=p$ e $f(0 ; \theta)=(1-p)$ sendo $(1-p)=q \cdot$ A equação $(4 \cdot 3.2 . b)$ pode ser escrita

$$
\left(\frac{p_{1}}{p_{0}}\right)^{W(\theta)} p+\left(\frac{1-p_{1}}{1-p_{2}}\right)^{W(\theta)}(1-p)=1
$$

Para construir a curva da função característica de operação não é necessário resolver a equação (4.7.3.a). Basta consi derar $W=W(\Theta)$ um parâmetro e resolvê-la em relação a $p$. Isolando o valor de $p$ em $(4.7 .3 . a)$ obtem-se

$$
p=\frac{1-\left(\frac{q_{1}}{q_{0}}\right)^{W}}{\left(\frac{p_{1}}{p_{0}}\right)^{W}-\left(\frac{q_{1}}{q_{0}}\right)^{W}}
$$

pode ser escrita

$$
\text { Considerando } A=\frac{1-\beta}{\alpha} \text { e } B=\frac{\beta}{1-\alpha} \text { a expressão }(4 \cdot 3 \cdot 2 \cdot h)
$$




$$
P(p)=\frac{\frac{(1-\beta)^{W}}{\alpha}-1}{\left(\frac{1-\beta}{\alpha}\right)^{W}-\left(\frac{\beta}{1-\alpha}\right)^{W}}
$$

Atribuindo a $W$ valores arbitrários pertencentes ao intervalo $[-\infty,+\infty]$ obtem-se através das equações $(4.7 .3 . b)$ e $(4.7 .3 . c)$ respectivamente valores $p$ e $P(\cdot \Theta)$. A curva característica de operação pode ser traçada calculando um número suficiente de valores $p$ e $P(\Theta)$ e dispondo os pontos $\left[p_{j} P(\theta)\right]$ num gráfico.

\section{7 .4 - Obtenção da curva do tamanho mëdio das amostras}

Antes de calcular $E_{p}(n)$ é necessário calcular $E_{p}(z)$. Na distribuição binomial y só pode assumir os valores 1 e 0 , sendo $f(1 ; \theta)=p$ e $f(0 ; \theta)=(1-p)$. Então

$$
E_{p}(z)=p L \frac{f\left(1 ; \theta_{1}\right)}{f\left(1 ; \theta_{0}\right)}+(1-p) L \frac{f\left(0 ; \theta_{1}\right)}{f\left(0 ; \theta_{0}\right)}=p L \frac{p_{1}}{p_{0}}+(1-p) L \frac{q_{1}}{q_{0}}
$$

Substituindo este valor em (4.4.2.f) obtem-se

$$
E_{p}(n)=\frac{P(p) L B+[1-P(p)] L A}{p L \frac{p_{1}}{p_{0}}+(1-p) L \frac{q_{1}}{q_{0}}}
$$

OU

$$
E_{p}(n)=\frac{P(p)(L B-L A)+L}{p L \frac{p_{1} q_{0}}{p_{0} q_{1}}-L \frac{q_{0}}{q_{1}}}
$$


Dividindo o numerador e o denominador por $L \frac{p_{1} q_{0}}{p_{0} q_{1}}$ e
confrontando com $(4.7 .2 . g),(4.7 .2 . h)$ e $(4.7 .2 . i)$ obtem-se

$$
E_{\theta}(n)=\frac{P(p)\left(h_{0}-h_{3}\right)+h_{1}}{p-s}
$$

onde $P(p)$ é o valor da função operatória característica e é calcula do por (4.7.3.c), $h_{0}, h_{1}$ e $S$ são os coeficientes lineares e a incli nação das linhas de decisão, calculados por $(4.7 .2 . g),(4.7 .2 . h)$ e (4.7.2.i) e $p$ é calculado por $(4.7 .3 . b)$.

Atribuindo-se valores arbitrários a $W$ nas expressões

$(4.7 .3 . c)$ e (4.7.3.b) obtem-se, respectivamente $p$ e $P(p)$. Esses va lores são introduzidos em $(4.7 .4 . a)$ para calcular $E_{p}(n)$. Colocando num gráfico diversos pontos $\left[p_{j} E_{p}(n)\right]$, obtem-se a curva do tamanho médio das amostras.

\section{8 - Plano de Amostragem Sequencial para Testar a Mëdia de Uma Distribuição Normal}

\subsection{1 - Apresentação do problema}

Se o nümero de insetos $y$ existentes nas unidades amostrais for contado e os insetos estiverem distribuídos ao acaso na lavoura não sendo muito raros em relação à unidade amostral, e se o número de unidades amostrais for suficientemente grande para que possa ser tratado como infinito, então os dados $y$ de contagem provavelmente se ajustarão à distribuição normal. 
Pressupõe-se que a variävel y tenha distribuição nor mal com média $M$ (desconhecida) e variância $\sigma^{2}$ (conhecida).

Como foi relatado na seção 4.4 deve-se determinar o valor $M^{\prime}$ que representa o grau de infestação, ou seja, o número de insetos por unidade amostral, a partir do qual é economicamente acon selhável aplicar o inseticida. Deve-se determinar também os valores $M_{0}$ e $M_{1}$ tais que não aconselhar o uso do inseticida seja um errogra ve se (e somente se) $M \geq M_{1}$ e aconselhar sua aplicação seja conside rado erro grave se (e somente se) $M \leq M_{0}$.

\subsection{2 - Desenvolvimento das förmulas}

Conhecidos $M_{0}$ e $M_{3}$, $\alpha$ e $\beta$ pode-se elaborar um plano de amostragem seqüencial para testar a hipótese $M=M_{0}$ contra a alternativa $M=M_{1}$ 。

A distribuição normal é definida em função de dois parâmetros, a média $M$ e a variância $\sigma^{2}$, e tem a seguinte função den sidade:

$$
f(y)=\frac{1}{\sigma \sqrt{2 \pi}} e^{-\frac{(y-M)^{2}}{2 \sigma^{2}}}
$$

Obtida uma amostra de tamanhom $\left(y_{1}, y_{2}, \ldots, y_{m}\right)$ a pro babilidade de obter outra igual àquela é dada por:

$$
p_{m}=\frac{1}{\sigma \sqrt{2 \pi}} e^{-\frac{\left(y_{1}-M\right)^{2}}{2 \sigma^{2}}} \cdot \frac{1}{\sigma \sqrt{2 \pi}} e^{-\frac{\left(y_{2}-M\right)^{2}}{2}} \cdots \frac{1}{\sigma \sqrt{2 \pi}} e^{-\frac{\left(y_{m}-M\right)^{2}}{2 \sigma^{2}}}
$$


50.

ou então:

$$
p_{m}=\left(\frac{1}{\sigma \sqrt{2 \pi}}\right)^{m} e^{-\frac{1}{2 \sigma^{2}} \sum_{i=1}^{m}\left(y_{i}-M\right)^{2}}
$$

Sob a hipótese $M=M_{1}$ a probabilidade é

$$
p_{1 m}=\left(\frac{1}{\sigma \sqrt{2 \pi}}\right)^{m} e^{-\frac{1}{2 \sigma^{2}} \sum_{i=1}^{m}\left(y_{i}-M_{1}\right)^{2}}
$$

e sob a hipötese $M=M_{0}$ torna-se

$$
p_{0 m}=\left(\frac{1}{\sigma \sqrt{2 \pi}}\right)^{m} e^{-\frac{1}{2 \sigma^{2}} \sum_{i=1}^{m}\left(y_{i}-M_{0}\right)^{2}}
$$

A razão de probabilidades a ser calculada em cada es tágio da amostragem, com base nas förmulas (4.1.a) e (4.1.b) é:

$$
\frac{p_{1 m}}{p_{o m}}=\frac{e^{-\frac{1}{2 \sigma^{2}} \sum_{i=1}^{m}\left(y_{i}-M_{1}\right)^{2}}}{e^{-\frac{1}{2 \sigma^{2}} \sum_{i=1}^{m}\left(y_{i}-M_{0}\right)^{2}}}
$$

ou sob a forma logarítmica:

$$
\begin{aligned}
& L \frac{P_{i m}}{p_{o m}}=\frac{M_{1}-M_{0}}{\sigma^{2}} \sum_{i=1}^{m} y_{i}+\frac{m}{2 \sigma^{2}}\left(M_{0}^{2}-M_{1}^{2}\right) \\
& \text { A partir das förmulas }(4 . j \cdot c),(4.1 . d),(4.1 . e),
\end{aligned}
$$

$(4.2 . c)$ e (4.2.d) verifica-se que a amostragem é continuada at 


$$
L \frac{\beta}{1-\alpha}<\frac{M_{1}-M_{0}}{\sigma^{2}} \sum_{i=1}^{m} y_{i}+\frac{m}{2 \sigma^{2}}\left(M_{0}^{2}-M_{1}^{2}\right)<L \frac{1-\beta}{\alpha}
$$

E terminada, rejeitando a hipötese $M=M_{0}$ ao nível $\alpha$ de significância, e, conseqüentemente, aconselhando o uso de inseticida quando

$$
\frac{M_{1}-M_{0}}{\sigma^{2}} \sum_{i=1}^{m} y_{i}+\frac{m}{2 \sigma^{2}}\left(M_{0}^{2}-M_{1}^{2}\right) \geq L \frac{1-\beta}{\alpha}
$$

e é terminada mas aceitando a hipótese $M=M_{0}$ com probabilidade $\beta$ de erro, não aconselhando então o uso de inseticida, quando

$$
\frac{M_{1}-M_{0}}{\sigma^{2}} \sum_{i=1}^{m} y_{i}+\frac{m}{2 \sigma^{2}}\left(M_{0}^{2}-M_{1}^{2}\right) \leq L \frac{\beta}{1-\alpha}
$$

Isolando o valor $\sum_{i=1}^{m} y_{i}$ nas expressões $(4.8 .2 . a)$ e (4.8.2.b) obtem-se, respectivamente:

$$
\begin{aligned}
& \sum_{i=1}^{m} y_{i} \geq \frac{\sigma^{2}}{M_{1}-M_{0}} L \frac{1-\beta}{\alpha}+m \frac{M_{0}+M_{1}}{2} \\
& \sum_{i=1}^{m} y_{i} \leq \frac{\sigma^{2}}{M_{1}-M_{0}} L \frac{\beta}{1-\alpha}+m \frac{M_{0}+M_{1}}{2}
\end{aligned}
$$

Da desigualdade $(4.8 .2 . d)$ verifica-se que o maior va lor de $\sum_{i=1}^{m} y_{i}$, e que será chamado $a_{m}$, que permite tomar a decisão de não preconizar o uso de inseticida, isto é, aceitar a hipótese $M=$ $=M_{0} s$

$$
a_{m}=\frac{\sigma^{2}}{M_{1}-M_{0}} L \frac{\beta}{1-\alpha}+m \frac{M_{0}+M_{1}}{2}
$$


Da desigualdade (4.8.2.c) conclui-se que o menor valor de $\sum_{i=1}^{m} y_{i}$, que será chamado de $r_{m}$, que permite tomar a decisão de rejeitar a hipótese $M=M_{0}$ e então aconselhar o uso de inseticida ë

$$
\begin{aligned}
& r_{m}=\frac{\sigma^{2}}{M_{1}-M_{0}} L \frac{1-\beta}{\alpha}+m \frac{M_{0}+M_{1}}{2} \quad(4.8 .2 . f) \\
& a_{m} \text { e } r_{m} \text { são calculados antes de iniciar a amostragem }
\end{aligned}
$$
para todos os valores de $m$. Ao efetuar a coleta da amostra, em cada unidade amostral inspecionada, soma-se o número de insetos existentes à soma do número de insetos das unidades inspecionadas anterior mente, chegando-se ao valor $\sum_{i=1}^{m} y_{i}$. Este valor $\vec{e}$ comparado com os valores $a_{m}$ e $r_{m}$ réspectivos.

$$
m \text { Se } a_{m}<\sum_{i=3}^{m} y_{i}<r_{m} \text { continua-se a amostragem. Se }
$$
$a_{m} \geq \sum_{i=1} y_{i}$ a amostragem é terminada, aceitando-se a hipótese $M=U_{0}$ com probabilidade $\beta$ de erro, não aconselhando, portanto, o uso de de fensivos. Se $r_{m} \leq \sum_{i=1}^{m} y_{i}$ a amostragem é terminada, rejeitando $M=M_{0}$ ao nível $\alpha$ de significância e, então, aconselhando o uso de inseticida.

Da mesma forma que em 4.7 .2 pode-se elaborar o plano de amostragem graficamente. Coloca-se no eixo das abscissas o tamanho da amostra $m$ e no eixo das ordenadas os vaiores $\sum_{i=1}^{m} y_{i}$. As 1 inhas de decisão têrn os modelos matemáticos

$$
\begin{aligned}
& R_{0}=h_{0}+S m \\
& R_{1}=h_{1}+S m
\end{aligned}
$$


53.

onde $h_{0}$ e $h_{1}$ são os coeficientes lineares e $S$ o coeficiente angular. Das igualdades $(4.8 .2 . e)$ e $(4.8 .2 . f)$ verifica-se fa-

cilmente que

$$
\begin{aligned}
& h_{0}=\frac{\sigma^{2}}{M_{1}-M_{0}} L \frac{\beta}{1-\alpha} \\
& h_{1}=\frac{\sigma^{2}}{M_{1}-M_{0}} L \frac{1-\beta}{\alpha} \\
& S=\frac{M_{0}+M_{1}}{2}
\end{aligned}
$$

Iniciada a amostragem, para cada tamanho da amostra $m$

os pontos $\left(m_{i} \sum_{i=1} y_{i}\right)$ são representados no gráfico. Enquanto os pontos $\left(m_{\dot{3}} \sum_{i=1} y_{i}\right)$ estiverem entre $R_{0}$ e $R_{1}$ nenhuma decisão é tomada, con tinuando-se então a amostragem. Se o ponto $\left(m_{i} \sum_{i=1}^{m} y_{i}\right)$ se localizar em $R_{0}$ ou abaixo então, com probabilidade $\beta$ de erro, aceita-se a hi pötese $M=M_{0}$ e conseqüientemente não se aconselha o uso de inseticida, sendo a amostragem concluida. Se o ponto $\left(m_{\dot{g}} \sum_{i=1}^{m} y_{i}\right)$ se situar em $R_{1}$ ou acima, termina-se a amostragem, rejeitando-se a hipótese $M=M_{0}$ ao nível a de significância, fato que lova a preconizar o uso de defensivos.

\subsection{4 - Obtenção da curva característica de operação}

Quando y é normalmente distribuída com média $M$ desco nhecida e variância $\sigma^{2}$ conhecida, tem-se

$$
f(y ; M)=\frac{1}{\sigma \sqrt{2 \pi}} e^{-\frac{1}{2 \sigma^{2}}(y-M)^{2}}
$$


A equação (4.3.2.a) torna-se

$$
\left[\frac{e^{-\frac{1}{2 \sigma^{2}}\left(y-M_{1}\right)^{2}}}{-\frac{1}{2 \sigma^{2}}\left(y-M_{0}\right)^{2}}\right]^{W(M)} \frac{1}{\sqrt{2 \pi} \sigma} e^{-\frac{1}{2 \sigma^{2}}(y-M)^{2}} d y=1
$$

Resolvendo a integral acima obtem-se o valor $W(M)$ que, segundo WALD (1947) è

$$
W(M)=\frac{M_{0}+M_{1}-2 M}{M_{1}-M_{0}}
$$

Fazendo $W(M)=W$ e resolvendo em função de $M$ tem-se

$$
M=\frac{M_{0}+M_{1}-W\left(M_{1}-M_{0}\right)}{2}
$$

Na equaçäo $(4.3 .2 . h)$ fazendo $A=\frac{1-\beta}{\alpha}$ e $B=\frac{\beta}{1-\alpha}$ obtem- se

$$
P(M)=\frac{\left(\frac{1-\beta}{\alpha}\right)^{W}-1}{\left(\frac{1-\beta}{\alpha}\right)^{W}-\left(\frac{\beta}{1-\alpha}\right)^{W}}
$$

Atribuindo valores arbitrários a " $W$ nas expressões (4.8.3.a) e (4.8.3.b) obtem-se os valores $M$ e $P(M)$ respectivamente. Colocando num gráfico um número suficiente de pontos $\left[M_{j} P(M)\right]$ traça-se a curva característica de operação. 


\subsection{4 - Obtenção da curva do tamanho das amostras}

Para a distribuição normal com média $M$ desconhecida

e variância $\sigma^{2}$ conhecida a função densidade é

$$
f(y, M)=\frac{1}{\sqrt{2 \pi} \sigma} e^{-\frac{1}{2 \sigma^{2}}(y-M)^{2}} \quad-\infty<y<\infty
$$

Então

$$
z=L \frac{f\left(y_{0} \theta_{1}\right)}{f\left(y_{0} \theta_{0}\right)}=L \frac{e^{-\frac{1}{2 \sigma^{2}}\left(y-M_{1}\right)^{2}}}{-\frac{1}{2 \sigma^{2}}\left(y-M_{0}\right)}=\frac{1}{2 \sigma^{2}}\left[2\left(M_{1}-M_{0}\right) y+M_{0}^{2}-M_{1}^{2}\right]
$$

o valor $E_{M}(z)$ que indica a esperança de $z$ quando $M$ é a verdadeira média de y é

$$
E_{M}(z)=\frac{1}{2 \sigma^{2}}\left[2\left(M_{1}-M_{0}\right) M+M_{0}^{2}-M_{1}^{2}\right]
$$

Substituindo o valor $E_{M}(z)$ na equação $(4.4 .2 . f)$ obt.em-se

$$
E_{M}(n)=2 \sigma^{2} \frac{P(M) L B+[1-P(M)] L A}{2\left(M_{1}-M_{0}\right) M+M_{0}^{2}-M_{1}^{2}}
$$

que é igual a

$$
E_{M}(n)=\frac{P(M)\left(2 \sigma^{2} L B-2 \sigma^{2} L A\right)+2 \sigma^{2} L A}{2\left(M_{1}-M_{0}\right) M+M_{0}^{2}-M_{1}^{2}}
$$

Dividindo o numerador e o denominador por $2\left(M_{1}-M_{0}\right)$ e 
comparando com as expressões $(4.8 .2 . g),(4.8 .2 . h)$ e $(4.8 .2 . i)$ chega-se a

$$
E_{M}(n)=\frac{P(M)\left(h_{0}-h_{1}\right)+h_{1}}{M-S}
$$

onde $h_{0}, h_{1}$ e $S$ são calculados pelas expressões $(4.8 .2 . g),(4.3 .2 . h)$ e (4.8.2.i), $M$ é calculada por (4.8.3.a) e $P(M)$ por (4.8.3.b). Inicialmente são atribuídos valores arbitrários a $W$ em $(4.8 .3 . a)$ e (4.8.3.b) calculando respectivamente os valores $M$ e $P(M)$. Estes valores são introduzidos em (4.8.4.a) e obtidos valores $E_{M}(n)$. Um número suficientemente grande de pontos $\left[M_{g} E_{M}(n)\right]$ colocados num gráfico permitem traçar a curva do tamanho médio das amostras.

4.9 - Plano de Amostragem Seqüencial para Testar a Mëdia de Uma Distribuição de Poisson

\subsection{1 - Apresentação do problema}

Se a espécie estudada tem distribuição ao acaso na lavoura e se o inseto é raro em relação à unidade amostral utiiizada, a variável $y$, correspondente aos dados de contagem do número de insetos existentes nas diversas unidades amostrais, possivelmente se gue a distribuição de Poisson.

Da mesma forma que na seção 4.6 .1 , deve-se determinar o valor $M^{p}$ que corresponde à média de insetos por unidade amos- 
tral a partir da qual as medidas de controle seriam economicamente aconselháveis. Aplicações de inseticidas não seriam executadas se a média de insetos por unidade amostral existente na lavoura fosse menor ou igual a $M^{p}$.

Devem-se fixar também dois valores $M_{0}$ e $M_{1}$, sendo $M_{0}<M^{p}$ e $M_{1}>M^{8}$, tais que, rejeitar a hipötese $M=M_{0}$ e então pre conizar o uso de inseticidas, seja considerado erro grave se le somente se) $M<M_{0}$, e aceitar a hipötese $M=M_{0}$ não aconselhando o uso de inseticidas seja um erro grave se (e somente se) $M>M_{1}$.

Fixados $M_{0}, M_{1}$, $\alpha$ e $\beta$ pode-se desenvolver as förmulas para o plano de amostragem seqüencial para testar a hipótese $M=$ $=M_{0}$ contra a hipötese alternativa $M=M_{1}$ 。

\subsection{2 - Desenvolvimento das förmulas}

A đistribuição de Poisson é caracterizada por um üni co parâmetro, à média $M$, a qual é igual à variância. Sua função de probabilidade é

$$
p(y)=e^{-M} \frac{M^{2}}{y !}
$$

onde $y=0,1,2, \ldots$ corresponde ao número de insetos encontrados nas unidades amostrais.

Retirada uma amostra $y_{1}, y_{2}, \ldots, y_{m}$ a probabilida de de retirar outra igual é dada por 


$$
p_{m}=e^{-M} \frac{M^{y_{1}}}{y_{1} !} \cdot e^{-M} \frac{M^{y_{2}}}{y_{2}:} \cdots e^{-M} \frac{M^{y_{m}}}{y_{m} !}=e^{-m M} \frac{M^{i=1} y_{i}^{m}}{y_{1} \cdot y_{2} ! \cdots y_{m} !}
$$

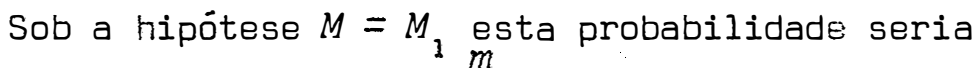

$$
p_{1 m}=e^{-m M_{1} \frac{M_{1}^{i=1} y_{i}}{y_{1} \cdot y_{2}: \ldots y_{m} !}}
$$

Sob a hipötese $M=M_{0}$ torna-se

$$
p_{0 m}=e^{-m M_{0}} \frac{\sum_{i=1}^{m} y_{i}}{y_{1} \cdot y_{2}: \cdots \cdot y_{m}^{\prime}}
$$

Partindo de (4.1.a) e (4.1.b) observa-se que a razẽo de probabilidades é

$$
\frac{p_{1 m}}{p_{0 m}}=\frac{e^{-m M_{1}} e_{M_{1}^{i=1}}^{m} y_{i}}{e^{-m M_{0}} \sum_{M_{0}^{i=1}}^{m} y_{i}}=\frac{e^{-m M_{1}}}{-m M_{0}}\left(\frac{M_{1}}{M_{0}}\right)^{\sum_{i=1}^{m} y_{i}}
$$

Ou sob a forma logarítmica

$$
L \frac{p_{1 m}}{P_{0 m}}=-m\left(M_{1}-M_{0}\right)+\sum_{i=1}^{m} y_{i}\left(I \cdot M_{1}-L M_{0}\right)
$$

Conforme foi visto em $(4.1 . c),(4.1 . d),(4.1 . e)$,

(4.2.c) e (4.2.d) continua-se a amostragem enquanto

$$
L \frac{\beta}{1-\alpha}<-m\left(M_{1}-M_{0}\right)+\sum_{i=1}^{m} y_{i}\left(L M_{1}-L M_{0}\right)<L \frac{1-\beta}{\alpha}
$$


A amostragem é terminada, rejeitando-se a hipótese $M=M_{0}$ ao nível $\alpha$ de significância, aconselhando o uso de inseticida se

$$
-m\left(M_{1}-M_{0}\right)+\sum_{i=1}^{m} y_{i}\left(L M_{1}-L M_{0}\right) \geq L \frac{I-\beta}{\alpha} \quad \text { (4.9.2.a) }
$$

e é terminada aceitando a hipótese $M=M_{0}$ com probabiıidade $\beta$ de er ro e, conseqüentemente, não preconizando o uso de defensivos, se

$$
\begin{aligned}
& -m\left(M_{1}-M_{0}\right)+\sum_{i=1}^{m} y_{i}\left(L M_{1}-L M_{0}\right) \leq \pm \frac{\beta}{1-\alpha} \quad(4.9 .2 . \mathrm{b}) \\
& \text { Isolando o valor } \sum_{i=1}^{m} y_{i} \text { nas desigualdades }(4 \cdot 9 \cdot 2 . \mathrm{a})=
\end{aligned}
$$

$(4.9 .2 . b)$ obtem-se

$$
\begin{aligned}
& \sum_{i=1}^{m} y_{i} \geq \frac{L \frac{1-\beta}{\alpha}}{L M_{1}-L M_{0}}+m \frac{M_{1}-M_{0}}{L M_{1}-L M_{0}} \\
& \sum_{i=1}^{m} y_{i} \leq \frac{L \frac{\beta}{1-\alpha}}{L M_{1}-L M_{0}}+m \frac{M_{1}-M_{0}}{L M_{1}-L M_{0}}
\end{aligned}
$$

Na expressão $(4.9 .2 . c)$ verifica-se que o menor vaIor de $\sum_{i=1}^{m} y_{i}$ que permite terminar a amostragem, rejeitando a hipótese $M=M_{0}$ e portanto aconselhar o uso de inseticidas, e que será chamado $r_{m}$, ē

$$
r_{m}=\frac{L \frac{1-\beta}{\alpha}}{L M_{1}-L M_{0}}+m \frac{M_{1}-M_{0}}{L M_{1}-L M_{0}}
$$


Da mesma forma, examinando-se $(4.9 .2 . d)$ constata-se que o maior valor de $\sum_{i=1}^{m} y_{i}$, que será chamado $a_{m}$, que possibilita terminar a amostragem com a aceitação da hipótese $M=M_{0}$ e em conseqüència não aconselhar o uso de inseticidas é

$$
a_{m}=\frac{L \frac{\beta}{1-\alpha}}{L M_{1}-L M_{0}}+m \frac{M_{3}-M_{0}}{L M_{1}-L M_{0}}
$$

Como foi visto em 4.7 .2 e 4.8 .2 os valores $a_{m}$ e $r_{m}$ são calculados antes de iniciar a coleta de amostras. Para cada uni dade amostral examinada calcula-se $\sum_{i=1}^{m} y_{i}$ que é o nümero acumulado de insetos encontrados até a unidade amostral em exame. Compara-se o valor $\sum_{i=1}^{m} y_{i}$ com os valores $a_{m}$ e $r_{m}$ correspondentes ao tamanho da amostra no momento.

$$
\text { Se } \sum_{i=1}^{m} y_{i} \leq a_{m} \text { a amostragem é suspensa aceitando-se }
$$
com probabilidade $\beta$ de erro a hipótese $M=M_{0}$, e então não preconizando o uso de inseticida. Se $\sum_{i=1}^{m} y_{i} \geq r_{m}$ também a amostragem é ter minada mas rejeitando-se ao nível a de significância a hipótese $M=M_{0}$, o que leva a aconselhar o uso de inseticida. Enquanto $a_{m}<$ $<\sum_{i=1} y_{i}<r_{m}$ novas unidades amostrais são inspecionadas.

A amostragem pode também ser desenvolvida de forma gräfica, como foi descrita nas seçōes 4.7.2 e 4.8.2. No eixo das abs cissas coloca-se a escala do tamanho da amostra $m$ e no eixo das ordenadas a escala dos valores $\sum_{i=1}^{m} y_{i}$. Os pontos $\left(a_{m}, \sum_{i=1}^{m} y_{i}\right)$ formam a linha de aceitação $R_{0}$ e os pontos $\left(r_{m}, \sum_{i=1} y_{i}\right)$ formam a linha de rejeição $R_{1}$. 
Os modelos matemáticos das linhas de decisão são

$$
\begin{aligned}
& R_{0}=h_{0}+S m \\
& R_{1}=h_{1}+S m
\end{aligned}
$$

Das expressões $(4.9 .2 . e)$ e (4.9.2.f) verifica-se que

$$
\begin{aligned}
& h_{0}=\frac{L \frac{\beta}{1-\alpha}}{L M_{1}-L M_{0}} \\
& h_{1}=\frac{L \frac{1-\beta}{\alpha}}{I M_{1}-I M_{0}} \\
& S=\frac{M_{1}-M_{0}}{L M_{1}-L M_{0}}
\end{aligned}
$$

A cada unidade amostral examinada os pontos $\left(m ; \sum_{i=1}^{m} y_{i}\right)$ são representados no gráfico. Enquanto esses pontos estiverem entre as duas linhas de decisão, novas unidades amostrais são examinadas. Se $\left(m_{i} \sum_{i=1}^{m} y_{i}\right)$ se situar em $R_{0}$ ou abaixo, a amostragem é terminada aceitando a hipötese $M=M_{0}$ com probabilidade de erro igual a $\beta$, e então não aconselhando o uso de inseticida. Se $\left(m_{j} \sum_{i=1}^{m} y_{i}\right)$ se situar em $R_{1}$ ou acima a amostragem é terminada mas rejeitando, ao nível $\alpha$ de probabilidade de erro a hipótese $M=V_{0}$, isto $\dot{e}$, preconizando o uso de inseticida. 


\subsection{3 - Obtenção da curva característica de operação}

A função de probabilidade da distribuição de Poisson

$\bar{e}$

$$
f(y, M)=e^{-M} \frac{M^{y}}{y^{\prime}} \quad y=0,1,2, \ldots, \infty
$$

A equação $(4.3 .2 . b)$ torna-se

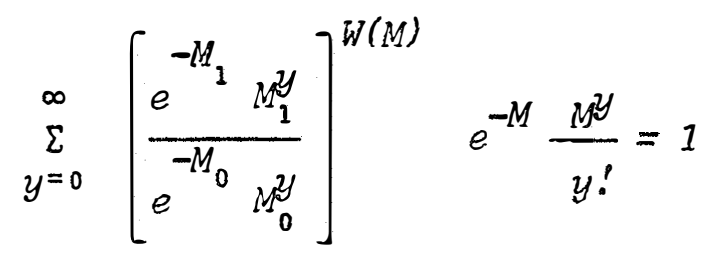

ou

$$
e^{M_{0} W(M)-M_{1} W(M)-M} \sum_{y=0}^{\infty} \frac{\left(M_{1}^{W(M)} M_{0}^{-W(M)} M\right)^{y}}{y !}=1
$$

Desenvolvendo o somatório pela série de Maclaurin e compar ndo com a expressão $e^{z}$ também desenvolvida, verifica-se que

$$
\sum_{y=0}^{\infty} \frac{\left(M_{1}^{W(M)} M_{0}^{-W(M)} M\right)^{y}}{y_{0}^{\prime}}=e^{M_{1}^{W(M)} M_{0}^{-W(M)} M}
$$

Substituindo

$$
e^{M_{0} W(M)-M_{1} W(M)-M} e^{H_{1}^{W(M)} M_{0}^{-W(M)} M}=1
$$

Aplicando logaritmos obtem-se

$$
M_{0} W(N)-M_{1} W(M)-M+M_{1}^{W(M)} M_{0}^{-W(M)} M=0
$$


63.

Fazendo $W(M)=W$ e resolvendo em relação a $M$ chega-

-se a

$$
M=\frac{W\left(M_{1}-M_{0}\right)}{M_{1}^{W} M_{0}^{-W}-1}
$$

$$
\text { Tomando-se } A=\frac{\beta-1}{\alpha} \text { e } B=\frac{\beta}{1-\alpha} \text { a expressão }(4.3 .2 . \mathrm{h})
$$

torna-se

$$
P(M)=\frac{\frac{(1-\beta, W}{\alpha}-1}{\frac{1-\beta, W}{\alpha}-\left(\frac{\beta}{1-\alpha}\right)^{W}}
$$

Atribuindo valores arbiträrios a $W$ em $(4.9 .3 . a)$ e (4.9.3.b) obtem-se respectivamente $M$ e $P(M)$. Os pontos $\left[M_{9} P(M)\right]$ colocados num gráfico permitem traçar a curva da função característica de operação.

\subsection{4 - Obtenção da curva do tamanho mëdio das amostras}

Como foi visto anteriormente, a função de probabilidade para a distribuição de Poisson ë

$$
f(y ; M)=e^{-M} \frac{M^{2} y}{y_{0}^{\prime}} \quad y=0,1,2, \ldots, \infty
$$

Então, de acordo com a seção 4.4.2

$$
z=L \frac{f\left(y_{0} M_{1}\right)}{f\left(y_{9} M_{0}\right)}=L \frac{e^{-M_{1}} M_{1}^{y}}{e^{-M_{0} M_{0}^{y}}}=L\left(e^{M_{0}-M_{1}} M_{1}^{y} M_{0}^{-y}\right)
$$




$$
z=M_{0}-M_{1}+y\left(L M_{1}-L M_{0}\right)
$$

$E_{M}(z)$, que indica o valor esperado de $Z$ quando $M$ é a verdadeira média de $y$ é

$$
E_{M}(z)=M_{0}-M_{1}+M\left(L M_{1}-L M_{0}\right)
$$

Substituindo o valor $E_{M}(z)$ na expressão $(4.4 .2 . f)$ ob tem-se

$$
E_{M}(n)=\frac{P(M) L B+[1-P(M)] L A}{M_{0}-M_{1}+M\left(L M_{1}-L M_{0}\right)}
$$

ou

$$
E_{M}(n)=\frac{P(M)(L B-L A)+L A}{M_{0}-M_{1}+M\left(L M_{1}-L M_{0}\right)}
$$

Dividindo o numerador e o denominador por ( $L M_{1}$ - $\left.L M_{0}\right)$ e comparando com $(4.9 .2 . g),(4.9 .2 . h)$ e $(4.9 .2 . i)$ chega-se a

$$
E_{M}(n)=\frac{P(M)\left(h_{0}-h_{1}\right)+h_{1}}{M-S}
$$

Para traçar a curva do tamanho médio das amostras de ve-se inicialmente calcular os valores $M$ e $P(M)$ com auxílio das expressões $(4.9 .3 . a)$ e $(4.9 .3 .6)$, o que é feito atribuindo valores ar bitrários a w.

Os valores $M$ e $P(M)$ introduzidos em (4.9.4.a) permitem calcular $E_{M}(n)$. A curva é traçada com os pontos $\left[M ; E_{M}(n)\right]$. 
65.

\subsection{0 - Plano de Amostragem Seqüencial para Testar a Média de Uma Distribuição Binomial Negativa}

\subsection{1 - Apresentação do problema}

Muitos insetos têm a tendência a formar conglomerados, não estando distribuidos ao acaso na lavoura. A causa da existência desses agrupamentos pode ser a forma da desova e o consequen te nascimento de insetos em grupos, ou o agrupamento posterior em pontos onde o ambiente é mais favorável ou o alimento mais abundante.

Dados de contagem de insetos com esta característica tendem a seguir a distribuição binomial negativa, também chamada dis tribuição de Greenwood e Yule.

A distribuição binomial negativa é descrita por dois parâmetros, a média $M$ e o expoente $k$. Sua forma geral é

$$
(q-p)^{-k}
$$

onde $p=M / k$ e $q=1+p$. A variância da distribuição é

$$
V=M+\frac{M^{2}}{k}
$$

e se caracteriza por ser superior à média.

ANSCOMBE (1949) relata que existem evidências teóricas de que o parâmetro $k$ depende de fatores intrínsecos da espécie. enquanto que a média $M$ depende de fatores ambientais. Assim, dados de contagem de insetos provenientes de diversos locais teriam apro- 
66.

ximadamente o mesmo $k$, embora com médias diferentes. Entretanto SIL VESTER e COX (1961) encontraram grande variação da estatística $k$ ao estudar Afídios em beterraba.

Da mesma forma que foi visto para outras distribuições deve-se inicialmente estabelecer o valor $M^{\prime}$ que é a média de insetos por unidade amostral a partir da qual a adoção de medidas de controle é economicamente viável. Então seriam usados defensivos so mente se a média $M$ do nümero de insetos por unidade amostral for su perior a $M^{\prime}$.

E necessārio também estabelecer dois outros valores $M_{0}$ e $M_{1}$, o primeiro menor e o segundo maior que $M^{\prime}$. A escolha deve ser feita de tal modo que não indicar a aplicação de inseticida seja considerado erro grave se (e somente se) $M \geq M_{1}$, e aconselhar o uso de controle químico seja considerado erro grave se (e somente se) $M \leq M_{0}$

\subsection{2 - Desenvolvimento das förmulas}

O teste seqüencial da razão de probabilidades permite estabelecer um plano de amostragem tal que a probabilidade de aconselhar a aplicação de controle químico não exceda o valor a quan do $M \leq M_{0}$ e a possibilidade de não preconizar o uso de defensivos não seja maior que $\beta$ quando $M \geq M_{1}$. 0 teste é delineado para testar a hipötese $M=M_{0}$ contra a hipótese $M=M_{1}$.

Inicialmente devem ser calculados os valores $p_{0}, p_{1}$, $q_{0}$ e $q_{1}$ a partir de $M_{0}$ e $M_{1}$, sabendo-se que $p=M / k$ e $q=1+p$. 
67.

A probabilidade de obter um nümero $y$ de insetos na contagem de uma unidade amostral é dada pela função de probabilidade da distribuição (BLISS e FISCHER, 1953):

$$
f(y: p)=\frac{(k+y-1) !}{y !(k-1) !} \cdot \frac{p^{y}}{q^{k+y}} \quad y=0,1,2, \ldots, \infty(4 \cdot 10 \cdot 2 \cdot a)
$$

A probabilidade de obter uma amostra de tamanho $m$, seja $y_{1}, y_{2}, \ldots, y_{m}$ è dada por

$$
p_{m}=\frac{\left(k+y_{1}-1\right) !}{y_{1} !(k-1) !} \cdot \frac{\left(k+y_{2}-1\right) !}{y_{2} !(k-1) !} \cdots \frac{\left(k+y_{m}-1\right) !}{y_{m} !(k-1) !} \cdot \frac{p_{i=1}^{\sum_{i} y_{i}}}{m k+\sum_{i=1}^{m} y_{i}}
$$

Pressupondo ter $k$ o mesmo valor quando $M=M_{1}$ e quan do $M=M_{0}$, as probabilidades, sob essas hipóteses, são, respectivamente

$$
\begin{aligned}
& p_{1 m}=\frac{\left(k+y_{1}-1\right) !}{y_{1} !(k-1) !} \cdot \frac{\left(k+y_{2}-1\right) !}{y_{2} !(k-1) !} \cdots \frac{\left(k+y_{m}-1\right) !}{y_{m} !(k-1) !} \cdot \frac{p_{1}^{i=1}}{\sum_{i} y_{i}} \\
& p_{0 m}=\frac{\left(k+y_{1}-1\right) !}{y_{1} !(k-1) !} \cdot \frac{q_{1}^{m} y_{i=1}}{y_{2} !(k-1) !} \cdots \frac{\sum_{i=1}^{m} y_{i}}{y_{m} !(k-1) !} \cdot \frac{p_{0}^{i=1}}{m k+\sum_{i=1}^{m} y_{i}}
\end{aligned}
$$

A razão de probabilidades de acordo com $(4.1 . a)$ e (4. 1.b) é 
68.

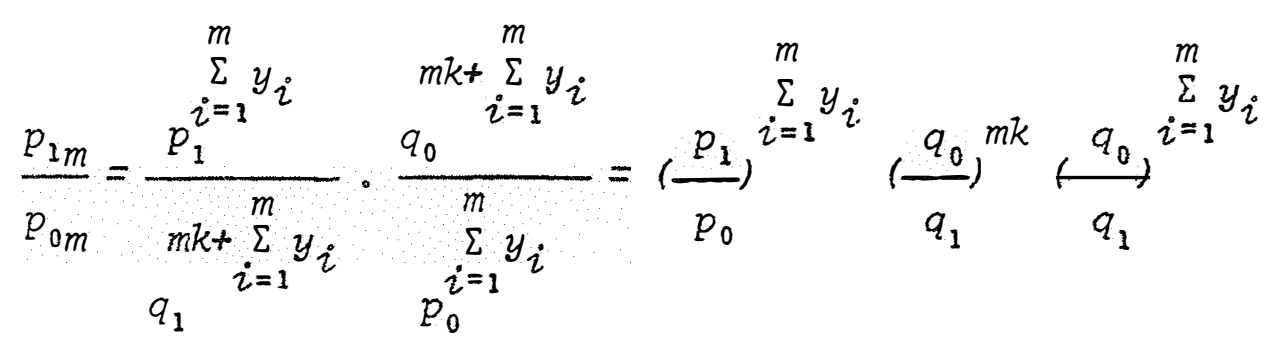

ou sob a forma logarítmica

$$
\begin{aligned}
& L \frac{p_{1 m}}{p_{0 m}}=\sum_{i=1}^{m} y_{i} L \frac{p_{1}}{p_{0}}+m k L \frac{q_{0}}{q_{1}}+\sum_{i=1}^{m} y_{i} L \frac{q_{0}}{q_{1}} \\
& \quad \text { Com base em }(4.1 . c),(4.1 . \mathrm{d}),(4.1 . \mathrm{e}),(4.2 . \mathrm{c}) \mathrm{e}
\end{aligned}
$$

(4.2.d) verifica-se que a amostragem é continuada enquanto

$$
L \frac{\beta}{1-\alpha}<\sum_{i=1}^{m} y_{i} L \frac{p_{1}}{p_{0}}+m k L \frac{q_{0}}{q_{1}}+\sum_{i=1}^{m} y_{i} L \frac{q_{0}}{q_{1}}<L \frac{1-\beta}{\alpha}
$$

e é terminada quando isso não acontece. Se

$$
\sum_{i=1}^{m} y_{i} L \frac{p_{1}}{p_{0}}+m k L \frac{q_{0}}{q_{1}}+\sum_{i=1}^{m} y_{i} L \frac{q_{0}}{q_{1}} \geq L \frac{1-\beta}{\alpha}
$$

ao nível a de significância, rejeita-se a hipótese $M=M_{0}$ e aconse1ha-se o uso de inseticida. Se

$$
\sum_{i=1}^{m} y_{i} L \frac{p_{1}}{p_{0}}+m k L \frac{q_{0}}{q_{1}}+\sum_{i=1}^{m} y_{i} L \frac{q_{0}}{q_{1}} \leq L \frac{\beta}{1-\alpha} \quad \text { (4.10.2.c) }
$$

aceita-se a hipótese $M=M_{0}$ com a probabilidade $\beta$ de incorrer em erro, não aconselhando-se então o uso de controle químico.

$(4.10 .2 . c)$, oivem-se, respectivamente

$$
\text { Isoiando o valor } \sum_{i=1}^{m} y_{i} \text { nas expressões }(4.10 .2 . b) \text { e }
$$


69.

$$
\begin{aligned}
& \sum_{i=1}^{m} y_{i} \geq \frac{L \frac{1-\beta}{\alpha}}{L \frac{p_{1} q_{0}}{p_{0} q_{1}}}+m k \frac{L \frac{q_{1}}{q_{0}}}{L \frac{p_{1} q_{0}}{p_{0} q_{1}}} \\
& \sum_{i=1}^{m} y_{i} \leq \frac{L \frac{\beta}{1-\alpha}}{L \frac{p_{1} q_{0}}{p_{0} q_{1}}}+m k \frac{L \frac{q_{1}}{q_{0}}}{L \frac{p_{1} q_{0}}{p_{0} q_{1}}}
\end{aligned}
$$

Examinando a desigualdade $(4 \cdot 10.2 . d)$ verifica-se que o menor valor de $\sum_{i=1}^{m} y_{i}$, que será chamado $r_{m}$, que permite rejeitar a hipótese $M=M_{0}$ e então preconizar o uso de inseticida é

$$
r_{m}=\frac{L \frac{1-\beta}{\alpha}}{L \frac{p_{1} q_{0}}{p_{0} q_{1}}}+m k \frac{L \frac{q_{1}}{q_{0}}}{L \frac{p_{1} q_{0}}{p_{0} q_{1}}}
$$

Da mesma forma, examinando $(4.10 .2 . e)$ verifica-se que o maior valor de $\sum_{i=1}^{m} y_{i}$, que será chamado $a_{m}$, que permite aceitar a hipótese $M=M_{0}$ e por conseguinte não aconselhar a adoção de contro le químico é

$$
a_{m}=\frac{L \frac{\beta}{1-a}}{L \frac{p_{1} q_{0}}{p_{0} q_{1}}}+m<\frac{L \frac{q_{1}}{q_{0}}}{L \frac{p_{1} q_{0}}{p_{0} q_{1}}}
$$


Da mesma forma que para as distribuições estudadas anteriormente, antes de iniciar a amostragem são calculados os valo res $a_{m}$ e $r_{m}$ para cada valor de $m_{\text {. }}$

Para cada amostra colhida é calculado o número acumu lado de insetos $\sum_{i=1}^{m} y_{i}$, correspondente a todas as unidades amostrais examinadas, o qual ë comparado com o respectivo valor $a_{m}$ e $r_{m}$. Se $\sum_{i=1}^{m} y_{i} \leq a_{m}$ aceita-se a hipótese $M=M_{0}$ com probabilidade $\beta$ de erro, não aconselhando, então, o uso de inseticida. Se $\sum_{i=1}^{m} y_{i} \geq r_{m}$ rejeita-se $M=M_{0}$ ao nível $\alpha$ de significância e, conseqüentemente, preco niza-se o uso de produto químico. Se $a_{m}<\sum_{i=1}^{m} y_{i}<r_{m}$ continua-se a amostragem.

A amostragem pode também ser desenvolvida graficamen te. As linhas de decisão seguem os modelos matemäticos

$$
\begin{aligned}
& R_{0}=h_{0}+S m \\
& R_{1}=h_{1}+S m
\end{aligned}
$$

sendo $h_{0}$ e $h_{1}$ os coeficientes lineares e $S$ a inclinação das retas.

Das igualdades $(4.10 .2 . f)$ e $(4.10 .2 . g)$ constata-se que

$$
\begin{aligned}
h_{0} & =\frac{L \frac{\beta}{1-\alpha}}{L \frac{p_{1} q_{0}}{p_{0} q_{1}}} \\
h_{1} & =\frac{L \frac{1-\beta}{\alpha}}{L \frac{p_{1} q_{0}}{p_{0} q_{1}}}
\end{aligned}
$$




$$
S=k \frac{L \frac{q_{3}}{L \frac{p_{1} q_{0}}{p_{0} q_{1}}}}{L}
$$

Ao executar a amostragem os pontos $\left(m_{m} \sum_{i=1}^{m} y_{i}\right)$ são representados no gráfico. Se o ponto $\left(m_{0} \sum_{i=1} y_{i}\right)$ estiver em $R_{0}$ ou abaixo, aceita-se $M=M_{0}$ com probabilidade $\beta$ de erro, não aconselhando o uso de inseticidas. Se o ponto $\left(m_{0} \sum_{i=1}^{m} y_{i}\right)$ estiver em $R_{1}$ ou acima, rejeita-se a hipötese $M=M_{0}$ ao nível $\alpha$ de significância, preconizando então o uso do defensivo. Enquanto $\left(m_{j} \sum_{i=1}^{m} y_{i}\right)$ estiver entre as duas retas, novas unidades amostrais são examinadas.

\subsection{0 .3 - Obtenção da curva característica de operação}

A função de probabilidade da distribuição binomial negativa como foi visto em $(4.10 .2 . a) \vec{e}$

$$
f(y ; p)=\frac{(k+y-1) !}{y !(k-1) !} \frac{p^{y}}{q^{k+y}} \quad y=0,1,2, \ldots, \infty
$$

ou como apresentada por OAKLAND (1950)

$$
f(y: p)=q^{-k} \frac{(k+y-1) !}{y !(k-1) !} \cdot\left(\frac{p}{q}\right)^{y}
$$

Então a equação $(4.3 .2 . b)$ torna-se

$$
\left.\sum_{y=0}^{\infty}\left[\left(\frac{q_{1}}{q_{0}}\right)^{-k} \frac{p_{1} q_{0}}{p_{0} q_{1}}\right]^{W(p)}\right]^{-k} \frac{(k+y-1) !}{y !(k-1) !}\left(\frac{p}{q}\right)^{y}=1
$$




$$
\text { Multiplicando por } p_{0} \text { ambos os termos da razão } q_{1} / q_{0}
$$

obtem-se

$$
\begin{gathered}
{\left[\frac{1}{\left(p_{0} q_{0}{ }^{W(P)}\right.}\right]^{-k} \sum_{y=0}^{\infty}\left[q\left(p_{0} q_{1}\right)^{W(p)}\right]^{-k} \frac{(k+y-1) !}{y !(k-1) !}\left[\frac{p\left(p_{1} q_{0}\right)^{W(p)}}{q\left(p_{0} q_{1}\right)^{W(p)}}\right]^{y}=1} \\
\text { Comparando com (4.10.3.a) e (4.10.1.a) verifica-se que }
\end{gathered}
$$

- somatório corresponde a $f\left[y_{s} p\left(p_{0} q_{1}\right)^{W(p)}\right]$. Então

$$
\left[\frac{1}{\left(p_{0} q_{0}\right)^{W(p)}}\right]^{-k}\left[q\left(p_{0} q_{1}\right)^{W(p)}-p\left(p_{1} q_{0}\right)^{W(p)}\right]^{-k}=1
$$

Elevando ambos os membros à potência $-1 / k$, e transpon

do, obtem-se

$$
q\left(p_{0} q_{1}\right)^{W(p)}-p\left(p_{1} q_{0}\right)^{W(p)}=\left(p_{0} q_{0}\right)^{W(p)}
$$

Resolvendo em relação a $p$, dividindo o numerador e o denominador por $\left(p_{0} q_{1}\right)^{W(p)}$ e considerando $W(p)=W$ chega-se a

fica

$$
p=\frac{1-\left(\frac{q_{0}}{q_{1}}\right)^{W}}{\left(\frac{p_{1} q_{0}}{p_{0} q_{1}}-1\right.}
$$

$$
\text { Considerando } A=\frac{1-\beta}{\alpha} \text { e } B=\frac{\beta}{1-\alpha} \text { a expressão }(4 \cdot 3.2 . h)
$$

$$
P(p)=\frac{\left(\frac{1-\beta}{\alpha}\right)^{W}-1}{\left(\frac{1-\beta}{\alpha}\right)^{W}-\left(\frac{\beta}{1-\alpha}\right)^{W}}
$$


Atribuindo em $(4.10 .3 . b)$ e $(4.10 .3 . c)$ valores perten centes ao intervalo $[-\infty,+\infty]$ a $W$ obtem-se respectivamente valores $p$ e $P(p)$. Ao invés de traçar a curva característica de operação comos pontos $\left[p_{9} P(p)\right]$ usa-se traçá-la com $\left[M_{9} P(M)\right]$. Para isso transforma-se os valores $p$ em $M$ pela fórmula $M=p k$.

Calculando um nümero suficientemerte grande de pontos $\left[M_{s} P(M)\right]$ è traçada a curva característica de operaçãos

\subsection{4 - Obtenção da curva do tamanho médio das amostras}

Considerando que a função de probabilidade de distrị buição binomial negativa é

$$
f(y: p)=\frac{(k+y-1) !}{y:(k-1) !} \cdot \frac{p^{y}}{q^{k+y}}
$$

então

$$
z=L \frac{f\left(y: p_{1}\right)}{f\left(y_{3} p_{0}\right)}=L \frac{p_{1}^{y}}{q_{1}^{k+y}} \cdot \frac{q_{0}^{k+y}}{p_{0}^{y}}
$$

ou

$$
z=I\left[\left(\frac{p_{1}}{p_{0}}\right)^{y}\left(\frac{q_{0}}{q_{1}}\right)^{k}\left(\frac{q_{0}}{q_{1}}\right)^{y}\right]=y L \frac{p_{1} q_{0}}{p_{0} q_{1}}-k L \frac{q_{1}}{q_{0}}
$$

o valor esperado de z quando $p$ é o verdadeiro parâmetro da distribuição é

$$
E_{p}(z)=p L \frac{p_{1} q_{0}}{p_{0} q_{1}}-k L \frac{q_{1}}{q_{0}}
$$


74.

Substituindo este valor na expressão (4.4.2.f) tem-se

$$
E_{p}(n)=\frac{P(p) L B+[1-P(p)] L A}{p L \frac{p_{1} q_{0}}{p_{0} q_{1}}-k L \frac{q_{1}}{q_{0}}}
$$

ou

$$
E_{p}(n)=\frac{P(p)(L B-L A)+L A}{p L \frac{p_{1} q_{0}}{p_{0} q_{1}}-k L \frac{q_{1}}{q_{0}}} .
$$

Dividindo o numerador e o denominador por $L \stackrel{p_{1} q_{0}}{p_{0} q_{1}}$ e comparando com $(4.10 .2 . h),(4.10 .2 . i)$ e $(4.10 .2 . j)$ obtem-se $p_{0} q_{1}$

$$
E_{p}(n)=\frac{P(p)\left(h_{0}-h_{1}\right)+h_{1}}{p-S}
$$

Considerando $M=p k$

$$
E_{M}(n)=\frac{P(M)\left(h_{0}-h_{1}\right)+h_{1}}{M-S} \quad(4.10 .4 . a)
$$

Atribuindo valores arbitrários a $W$ nas expressões $(4.10 .3 . b)$ e $(4.10 .3 . c)$ obtem-se valores $p$ e $P(p)$ respectivamente. Sabendo-se que $M=p k$ calculam-se os valores de $M$ correspondentes a p. Com os valores $M$ e $P(M)$ através da fórmula (4.10.4.a) obtem-se $E_{M}(n)$. Os pontos $\left[M_{\dot{s}} E_{M}(n)\right]$ dispostos num gräfico permitem traçar a curva do tamanho médjo das amostras. 


\subsection{1 - Arredondamento de $a_{m}$ e $r_{m}$ e Truncamento do Teste}

O tamanho $m$ da amostra só pode assumir valores intei ros e positivos. Entretanto, calculando $a_{m}$ e $r_{m}$ pelas expressões vis tas anteriormente para as distribuições binomial, normal, Poisson e binomial negativa, eles podem assumir valores não inteiros e mesmo negativos.

Se assumirem valores negativos, considera-se que para aquele tamanho de amostra é impossível determinar os limites que permitam tomar uma decisão, e novas unidades amostrais são coletadas.

Se $a_{m}$ não for um valor inteiro, deve-se substitui-lo pelo maior número inteiro menor que $a_{m}$. Da mesma forma se $r_{m}$ não for inteiro deve-se substitui-lo pelo menor inteiro maior que $r_{m^{\circ}}$

Embora Wald tenha demonstrado que a amostragem sequencial tem probabilidade 1 de terminar, não existe limite superior quanto ao tamanho da amostra necessário para se tomar uma deci são. Embora seja pequena a probabilidade do teste seqüencial exigir amostras maiores que duas ou três vezes o tamanho que teria a amostra com número fixo de ítens, é vantajoso arbitrar um limite superior $m_{0}$ para o tamanho da amostra. Esse limite poderia ser três vezes o tamanho $n$ que teria a amostra de tamanho fixo.

Então, quando $m$ alcançar o valor $m_{0}=3 n$, mesmo que não tenha sido possível tomar alguma decisão, suspende-se a coleta de amostras. O seguinte procedimento parece razoável: 
1) Se $\sum_{i=1}^{m} y_{i} \geq \frac{a_{m}+r_{m}}{2}$ rejeita-se a hipótese $M=M_{0}$ ao nível $\alpha$ de significância, aconselhando-se a aplicação de inseticida. 2) Se $\sum_{i=1}^{m} y_{i}<\frac{a_{m}+r_{m}}{2}$ aceita-se a hipótese $M=M_{0}$ com probabilidade $\beta$ de erro e, conseqüentemente, não preconizando o uso de defensivos.

Ao truncar o teste num ponto arbitrário, os erros $\alpha$ e $\beta$ são ligeiramente aumentados. Os efeitos do truncamento na magni tude desses erros são discutidos por WALD (1947) que os considera desprezivveis quando se adota $m_{0}=3 n_{0}$ ANDERSON (1960) e MADSEN(1974) apresentam métodos de delinear o teste de modo a corrigir esses efei tos. 
77.

\section{MATERIAL E METODOS}

Foram coletados dados de infestação de lagartas da so ja em três locais do Estado do Rio Grande do Sul, distantes aproximadamente 50 km, e em municípios vizinhos: Santa Maria, Faxinal do Soturno e Jülio de Castilhos, conforme está especificado na Tabela 1.

Em todos os locais a soja tinha sido semeada em linhas distantes $0,50 \mathrm{~m}$ e com uma densidade aproximada de 20 plantas por metro de linha.

Foi escolhida uma ärea de aproximadamente 1 ha em ca da local, e nesta área foram examinadas 50 unidades amostrais. A unidade amostral constou de $1,50 \mathrm{~m}$ de linha, sendo contado o número de lagartas existentes em cada uma das três porções de $0,50 \mathrm{~m}$ separadamente. Com isso obteve-se unidades amostrais de $0,50 \mathrm{~m}, 1,00 \mathrm{~m}$ e $1,50 \mathrm{~ms}$ 
78.

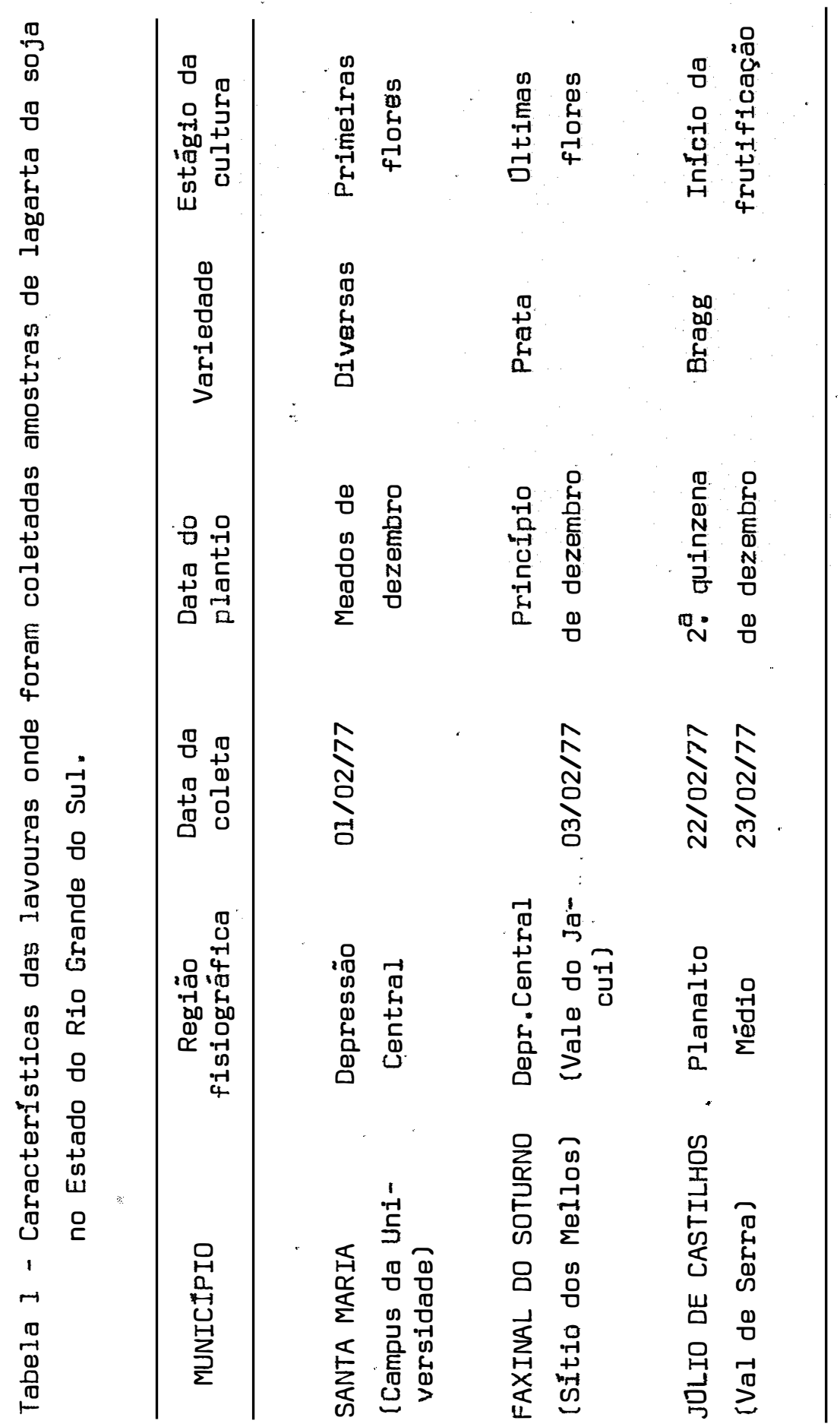


A coleta da unidade amostral foi feita ao acaso, caminhando-se em "zig-zag" pela àrea demarcada, de modo semelhante or Usado para coletar amostras de solo. 0 mesmo processo foi utilizado por ORLANDO FILHO e CAMPOS (1975) ao coletar material para a diagnose foliar em cana-de-açücar.

Para colher as lagartas, inicialmente eram afastadas as plantas da linha contígua e estendido no chão uma lona branca de dimensões $1,20 \times 0,60 \mathrm{~m}$. As plantas da primeira porção de $0,50 \mathrm{~m}$ eram curvadas em cima da lona e golpeadas violentamente para que as lagartas se desprendessem. Depois de verificar que nenhuma lagarta tinha caído fora da lona, ela era cuidadosamente dobrada. 0 processo era repetida com outras lonas de mesmas dimensões para as restan tes duas porções de $0,50 \mathrm{~m}$ da unidade amostral.

Coletadas as lagartas das três porções da unidade amostral procedia-se à contagem. Na contagem eram incluidas lagartas maiores de $1 \mathrm{~cm}$ de comprimento e das espécies Anticarsia gemmatalis (Hübner) e Plusia spp indistintamente.

A coleta era iniciada às 9:00 horas e completada aproximadamente às 19:00 horas do mesmo dia, com exceção de Júlio de Castilhos onde a chuva interrompeu o trabalno que foi completado no dia seguinte.

Pretendia-se executar amostragens em outros municipios, mas as condições meteorolōgicas foram adversas ao desenvolvimento das lagartas e à execução do trabalho. Por outro lado, ao pri 
meiro sinal da existência da praga, a maioria dos agricultores apli cava defensivos.

Inicialmente verificou-se a qual distribuição teórica os dados coletados mais se ajustavam, utilizando os modelos de Poisson e binomial negativa. Para testar a aderência foi usado o teste $x^{2}$

A estimativa $\hat{k}$ da distribuição binomial negativa foi estimada pelo método dos momentos $(3.5 . a)$, que dos métodos apresentados por ANSCOMBE (1949) é o indicado, e pelo método da máxima verossimilhança (3.5.b) apresentado por BLISS e FISHER (1953), que apesar de trabalhoso se aplica em todas as situações.

o $k$ comum aos três locais foi estimado pelo método de BLISS e OWEN (1958) (3.5.c) e pelo método da mäxima verossimilhan ça.

Para estimar $k$ e verificar o ajustamento das contagens aos modelos teóricos foi adaptada para a linguagem FORTRAN a ser usada em computador IBM-1130, programação apresentada por DAVIES (1971)。

A fim de verificar a eficiência do tamanho da amostra utilizado para estudar a distribuição espacial das lagartas da soja, foram calculadas todas as estimativas e verificado o ajustamento às distribuições teóricas, considerando somente as primeiras 40 unidades amostrais coletadas.

Embora as pesquisas desenvolvidas por BOLDT et alii 
(1975) e por THOMAS et alii (1974) tenham sido executadas nos Estados Unidos, elas serviram de base, juntamente com as recomendações de TURNIPSEED (1975), para determinar os valores $M^{p}, M_{0}$ e $M_{1}$ usados para delinear o plano de amostragem seqủencial. Quando o nümero de lagartas por metro de linha for igual ou inferior a 20 considerou- se uma infestação baixa. Quando este número for igual ou superiora 53 considerou-se infestação alta. Com um nümero de lagartas por metro de linha entre 21 e 52 caracterizou-se uma infestação moderada. $M^{\beta}$ foi então 20 e 53, respectivamente.

Para testar uma infestação baixa versus infestação mo derada considerou-se $M_{0}=15$ e $M_{1}=25$ lagartas por metro de linha. E para testar a infestação moderada versus infestação alta foram considerados $M_{0}=45$ e $M_{1}=60$.

Então. para classificar a infestação de lagartas em baixa ou moderada delineou-se o teste seqůencial para testar as hipóteses $H_{0}: M=15$ versus $H_{1}: M=25$ e para classificar a infestação em moderada ou alta o teste foi delineado para testar as hipóte ses $H_{0}: M=45$ versus $H_{1}: M=60$.

Utilizou-se $\alpha=\beta=0,05$ que ë o nível de erro mais usado em pesquisas agronômicas.

Para calcular os valores $h_{0}, h_{1}, S, a_{m}, r_{m}, P(\theta)$ e $E_{\theta}(n)$ para as distribuições binomial, normal, Poisson e binomial ne gativa desenvolveu-se programa em linguagem FORTRAN a ser utiliza do em computador IBM-1130。 
82.

\section{RESULTADOS OBTIDOS E DISCUSSÃO}

\section{1 - Distribuição Espacial das Lagartas da Soja}

A Tabela 2 mostra o nümero de lagartas obtidas nos 3 locais onde foi efetuada a coleta. 0 nümero de lagartas nas unidades amostrais de $1,00 \mathrm{~m}$ foi obtido somando o nümero de lagartas coIhidas na unidade de $0,50 \mathrm{~m}$ que aparece à esquerda ao nümero de lagartas coletadas em outra unidade amostral de $0,50 \mathrm{~m}$ contígua. Da mesma forma, o número de lagartas na unidade amostral de 1,50 m foi obtida somando ao nümero de lagartas existentes na unidade de 1,00 m o número de lagartas coletadas em outra unidade de $0,50 \mathrm{~m}$ contí gua.

As estimativas da média e da variância do número de lagartas coletadas, as estimativas $\hat{k}$ obtidas pelos métodos dos momentos e da máxima verossimilhança bem como as estimativas de suas variàncias, e ainda, os níveis mínimos de significância do teste $\chi^{2}$ 
Tabela 2 - Número de lagartas coletadas em unidades amostrais de $0,50 \mathrm{~m}, 1,00 \mathrm{~m}$ e $1,50 \mathrm{~m}$ de linha em lavouras de soja de 3 municípios do Estado do Rio Grande do Sul

\begin{tabular}{|c|c|c|c|c|c|c|c|c|c|}
\hline \multirow{2}{*}{$\begin{array}{c}\text { AMOS- } \\
\text { TRA } \\
N^{8}\end{array}$} & \multicolumn{3}{|c|}{ SANTA MARIA } & \multicolumn{3}{|c|}{$\begin{array}{l}\text { FAXINAL DO } \\
\text { SOTURNO }\end{array}$} & \multicolumn{3}{|c|}{$\begin{array}{l}\text { JULIO DE } \\
\text { CASTILHOS }\end{array}$} \\
\hline & $0,50 \mathrm{~m}$ & $1,00 \mathrm{~m}$ & $1,50 \mathrm{~m}$ & $0,50 \mathrm{~m}$ & $1,00 \mathrm{~m}$ & $1,50 \mathrm{~m}$ & $0,50 \mathrm{~m}$ & $1,00 \mathrm{~m}$ & $1,50 \mathrm{~m}$ \\
\hline 1 & 2 & 9 & 18 & 8 & 9 & 11 & 2 & 4 & 7 \\
\hline 2 & 0 & 2 & 2 & 5 & 13 & 19 & 9 & 19 & 28 \\
\hline 3 & 8 & 21 & 25 & 7 & 18 & 36 & 10 & 18 & 27 \\
\hline 4 & 6 & 13 & 17 & 3 & 11 & 23 & 5 & 10 & 14 \\
\hline 5 & 10 & 19 & 26 & 11 & 15 & 27 & 17 & 32 & 45 \\
\hline 6 & 11 & 25 & 38 & 8 & 15 & 22 & 1 & 3 & 3 \\
\hline 7 & 6 & 11 & 11 & 7 & 16 & 26 & 13 & 22 & 29 \\
\hline 8 & 2 & 6 & 7 & 7 & 15 & 19 & 5 & 11 & 14 \\
\hline 9 & 15 & 29 & 35 & 9 & 16 & 31 & 11 & 19 & 26 \\
\hline 10 & 1 & 6 & 7 & 14 & 26 & 36 & 14 & 27 & 37 \\
\hline 11 & 10 & 14 & 26 & 11 & 21 & 35 & 9 & 11 & 21 \\
\hline 12 & 10 & 14 & 25 & 7 & 18 & 33 & 4 & 7 & 17 \\
\hline 13 & 13 & 18 & 27 & 13 & 29 & 42 & 5 & 9 & 12 \\
\hline 14 & 5 & 9 & 19 & 7 & 17 & 23 & 5 & 7 & 9 \\
\hline 15 & 3 & 4 & 10 & 19 & 36 & 48 & 8 & 15 & 20 \\
\hline 16 & 6 & 15 & 23 & 11 & 20 & 30 & 12 & 19 & 25 \\
\hline 17 & 2 & 4 & 7 & 5 & 10 & 16 & 18 & 33 & 46 \\
\hline 18 & 7 & 12 & 25 & 5 & 14 & 17 & 12 & 22 & 34 \\
\hline 19 & 6 & 12 & 17 & 2 & 10 & 14 & 13 & 21 & 28 \\
\hline 20 & 9 & 16 & 25 & 8 & 13 & 29 & 1 & 1 & 1 \\
\hline 21 & 7 & 18 & 23 & 13 & 23 & 37 & 9 & 16 & 19 \\
\hline 22 & 13 & 28 & 44 & 14 & 24 & 37 & 16 & 30 & 43 \\
\hline 23 & 10 & 21 & 31 & 5 & 14 & 20 & 12 & 23 & 35 \\
\hline 24 & 6 & 10 & 15 & 5 & 8 & 11 & 8 & 14 & 22 \\
\hline 25 & 10 & 18 & 37 & 17 & 28 & 41 & 11 & 17 & 23 \\
\hline
\end{tabular}


84.

(continuação)

\begin{tabular}{|c|c|c|c|c|c|c|c|c|c|}
\hline \multirow{2}{*}{$\begin{array}{l}\text { AMOS- } \\
\text { TRA } \\
\text { N8 }\end{array}$} & \multicolumn{3}{|c|}{ SANTA MARIA } & \multicolumn{3}{|c|}{$\begin{array}{l}\text { FAXINAL DO } \\
\text { SOTURNO }\end{array}$} & \multicolumn{3}{|c|}{$\begin{array}{l}\text { JULIO DE } \\
\text { CASTILHOS }\end{array}$} \\
\hline & $0,50 \mathrm{~m}$ & $1,00 \mathrm{~m}$ & $1,50 \mathrm{~m}$ & $0,50 \mathrm{~m}$ & 1,00 & $1,50 \mathrm{~m}$ & $0,50 \mathrm{~m}$ & $1,00 \mathrm{~m}$ & $1,50 \mathrm{~m}$ \\
\hline 26 & 16 & 30 & 42 & 12 & 21 & 28 & 3 & 5 & 9 \\
\hline 27 & 2 & 5 & 8 & 1 & 4 & 11 & 8 & 13 & 20 \\
\hline 28 & 4 & 9 & 11 & 10 & 16 & 28 & 7 & 12 & 14 \\
\hline 29 & 5 & 11 & 17 & 9 & 17 & 26 & 16 & 30 & 38 \\
\hline 30 & 12 & 20 & 26 & 5 & 8 & 15 & 10 & 19 & 31 \\
\hline 31 & 9 & 18 & 26 & 6 & 15 & 20 & 9 & 17 & 23 \\
\hline 32 & 4 & 10 & 17 & 13 & 28 & 37 & 9 & 17 & 26 \\
\hline 33 & 5 & 8 & 13 & 4 & 5 & 13 & 6 & 9 & 11 \\
\hline 34 & 7 & 20 & 33 & 2 & 5 & 13 & 8 & 12 & 16 \\
\hline 35 & 9 & 15 & 20 & 2 & 5 & 10 & 7 & 12 & 17 \\
\hline 36. & 4 & 11 & 15 & 6 & 15 & 27 & 3 & 7 & 9 \\
\hline 37 & 6 & 9 & 15 & 6 & 9 & 13 & 12 & 24 & 33 \\
\hline 38 & 11 & 20 & 29 & 4 & 8 & 18 & 7 & 13 & 18 \\
\hline 39 & 3 & 9 & 11 & 5 & 9 & 21 & 9 & 17 & 25 \\
\hline 40 & 4 & 7 & 9 & 10 & 23 & 30 & 10 & 19 & 27 \\
\hline 41 & 5 & 6 & 10 & 13 & 24 & 36 & 13 & 23 & 33 \\
\hline 42 & 3 & 8 & 10 & 9 & 19 & 33 & 7 & 11 & 16 \\
\hline 43 & 1 & 4 & 6 & 8 & 17 & 28 & 1 & 5 & 7 \\
\hline 44 & 1 & 5 & 10 & 7 & 19 & 31 & 9 & 16 & 22 \\
\hline 45 & 4 & 13 & 16 & 8 & 14 & 19 & 5 & 8 & 11 \\
\hline 46 & 7 & 15 & 22 & 10 & 24 & 40 & 5 & 11 & 15 \\
\hline 47 & 2 & 4 & 12 & 4 & 9 & 13 & 15 & 24 & 36 \\
\hline 48 & 2 & 4 & 14 & 17 & 32 & 44 & 14 & 24 & 33 \\
\hline 49 & 10 & 16 & 22 & 1 & 3 & 11 & 12 & 21 & 28 \\
\hline 50 & 5 & 6 & 8 & 6 & 15 & 24 & 5 & 11 & 16 \\
\hline
\end{tabular}




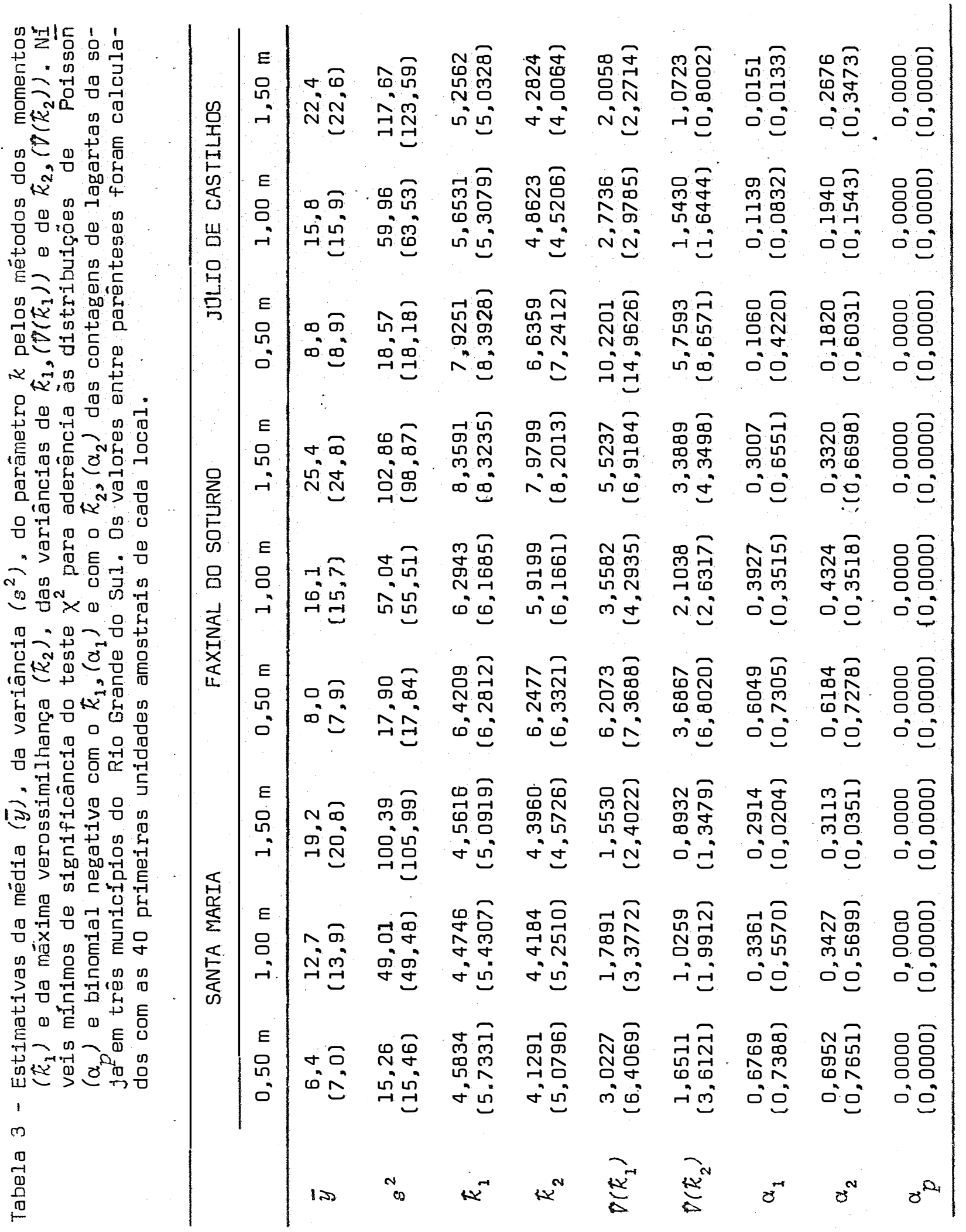


para testar a aderência dos dados à distribuição binomial negativa e Poisson, são mostradas na Tabela 3.

Examinando a Tabela 3 verifica-se que a estimativa do nŭmero de lagartas por unidade de área não sofreu alterações substanciais nem com o aumento do tamanho das unidades amostrais, nem com a diminuição do número de unidades de 50 para 40. A média do nü mero de lagartas coletadas é aproximadamente proporcional ao tamanho da unidade amostral.

A estimativa da variância do nưmero de lagartas cole tadas não sofreu grandes alterações quando o número de unidades amostrais foi reduzido de 50 para 40. Entretanto ela foi afetada pela variação do tamanho das unidades amostrais.

Se y for uma função linear do tipo

$$
y=a_{1} y_{1}+a_{2} y_{2}+\ldots+a_{n} y_{n}
$$

sua variância serä

$$
V(y)=a_{1}^{2} V\left(y_{1}\right)+a_{2}^{2} V\left(y_{2}\right)+\ldots+a_{n}^{2} V\left(y_{n}\right)
$$

Pressupondo que a maior unidade amostral $(1,50 \mathrm{~m})$ es time a variância com maior precisão, pode-se tomá-la como base e calcular as variâncias que teriam as contagens de lagartas das unidades menores $(0,50 \mathrm{~m}$ e $1,00 \mathrm{~m}\}$ se elas não fossem afetadas pela di minuição do tamanho das unidades amostrais. Considerando que a unidade de $1,00 \mathrm{~m}$ corresponde a $2 / 3$ da unidade de $1,50 \mathrm{~m}$ e que a unida de de 0,50 m corresponde a $1 / 3$ da unidade de $1,50 \mathrm{~m}$ pode-se escrever, respectivamente 


$$
\begin{aligned}
& y_{1,00}=\frac{2}{3} y_{1,50} \\
& y_{0,50}=\frac{1}{3} y_{1,50}
\end{aligned}
$$

cujas variâncias seriam, respectivamente

$$
\begin{aligned}
& V\left(y_{1000}\right)=\frac{4}{9} V\left(y_{1,50}\right) \\
& V\left(y_{0,50}\right)=\frac{1}{9} V\left(y_{1050}\right)
\end{aligned}
$$

Usando essas equaçôes calcularam-se as estimativas da variància que teriam as unidades amostrais de $0,50 \mathrm{~m}$ e $1,00 \mathrm{~m}$ se a redução do tamanho da unidade não influisse nas mesmas. A Tabela 4 apresenta essas estimativas。

Tabela 4 - Valores teóricos das estimativas da variância do nümero de lagartas da soja nas unidades amostrais de $0,50 \mathrm{~m}$ e $1,00 \mathrm{~m}$, tomando como base a unidade amostral de $1,50 \mathrm{~m}$ 。 Os valores entre parênteses correspondem às primeiras 40 unidades amostrais.

\begin{tabular}{lcc}
\hline & $\begin{array}{c}\text { Unidades amostrais } \\
0,50 \mathrm{~m}\end{array}$ & $\begin{array}{c}\text { a } \\
1,00 \mathrm{~m}\end{array}$ \\
\hline SANTA MARIA & 11,15 & 44,82 \\
& $(11,78)$ & $(47,11)$ \\
FAXINAL DO SOTURNO & 11,43 & 45,72 \\
& $(10,98)$ & $(43,94)$ \\
JULIO DE CASTILHOS & 13,07 & 52,29 \\
& $(13,73)$ & $(54,93)$ \\
\hline
\end{tabular}


Comparando as estimativas da tabela 4 com aquelas cor respondentes da Tabela 3 verifica-se que, em relação à unidade amos tral de $1,50 \mathrm{~m}$, as estimativas da variância das contagens de lagartas nas unidades amostrais de $1,00 \mathrm{~m}$ e 0,50 m foram superestimadas. Este aumento da estimativa da variância é maior na unidade de 0,50 $\mathrm{m}$, chegando a mais de $50 \%$ em Faxinal do Soturno.

Não ficou evidenciada nenhuma tendência das estimati vas $\hat{k}$ nem pelo método dos momentos nem pelo método da máxima verosimilhança com respeito à variação do tamanho da unidade amostral. Entretanto as variâncias dessas estimativas diminuiram consideravel mente com o aumento da unidade amostral.

Tanto as estimativas $k$ quanto suas variâncias aumentaram quando foi reduzido o número de unidades amostrais de 50 para 40.

Com respeito ao teste de aderência, verifica-se que em nenhum dos 3 locais, e em nenhum tamanho de unidade amostral as contagens de lagartas seguiram a distribuição de Poisson. Com exceção de Santa Maria, 40 unidades de 1,50 m, e de Júlio de Castilhos unidades de $1,50 \mathrm{~m}$ para o $\hat{k}$ estimado pelo método dos momentos, todas as contagens se ajustaram à distribuição binomial negativa. Isto discorda dos resultados a que chegaram SHEPARO e CARNER (1976) nos Estados Unidos. Esses autores concluiram que dados de contagem de lagartas da soja seguem mais a distribuição de Poisson do que a binomial negativa. 
Os nåveis mínimos de significância obtidos com o $\hat{k}$ estimado pelo método da máxima verossimilhança são um pouco superí res àqueles calculados com o $\hat{k}$ estimado pelo método dos momentos. Este fato indica uma melhor aderência dos dados à distribuição bino mial negativa quando foi usado o método da máxima verossimilhança pa ra estimar $k$.

Ao aplicar o teste $\chi^{2}$ para verificar a aderência das contagens de lagartas às distribuições teóricas não foram satisfeitas todas as exigências do teste. De fato, houve classes com freqưências esperadas menores que 1 e, em alguns casos, mais de $20 \%$ đas freqưências esperadas eram menores que 5. Classes com freqủência esperada baixa tendem a elevar o valor do teste calculado e, por con seguinte, diminuir o nível mínimo de significância. Conclui-se en-tão que o grau de aderência seria maior se o número de unidades amostrais colhidas fosse maior, e, conseqưentemente, menor o nümero de classes com frequêencia esperada baixa.

Considerando que podem ocorrer infestações mais altas do que aquelas existentes nas lavouras visitadas e com isso obter mais classes com frequêencias esperadas baixas, e considerando ainda que a egtimativa de $k$ e de sua variància foram afetadas quando o tamanho da amostra diminuiu de 50 para 40 unidades. conclui-se que 50 unidades amostrais é um nümero muito pequeno. Tal vez 100 unidades ou mais, seja um número razoável a ser adotado em próximos levantamentos. 
Ao executar as contagens em segmentos de $0,50 \mathrm{~m}$ de linha objetivou-se constatar qual o menor tamanho de unidade amostral viāvel. A unidade de $0,50 \mathrm{~m}$, além de ter a variância superesti mada, o que acarreta um maior erro padrão da média, forneceu também maior variância para $\hat{k}$, fatos que se traduzem em menor precisão para essas estimativas.

Além disso, as plantas de soja nas linhas não se encontram em distâncias iguais uma das outras, havendo inclusive espa ços de 10 a $15 \mathrm{~cm}$, e em alguns casos até $20 \mathrm{~cm}$, sem nenhuma planta. O pesquisador ao coletar as lagartas inconscientemente tenderá a iniciar a unidade amostral num local onde existam plantas, nunca no começo ou no meio de um espaço vazio. Esta tendência pode tornar a amostra viciada quando a unidade amostral for pequena. Com unidades amostrais maiores sste vício tenderā a ser compensado, uma vez que as unidades englobarão outros espaços vazios no correr da linha.

Em vista disso elegeu-se a unidade amostral de $1,00 \mathrm{~m}$ como mais vantajosa a que corresponde à recomendação de TURNIPSEED (1975). Verificou-se por outro lado que o tempo e o esforço gasto pa ra fazer o levantamento de uma unidade amostral de 1,00 m não é maior do que aquele de uma unidade de $0,50 \mathrm{~m}$. Entretanto, unidades maiores que $1,00 \mathrm{~m}$, apesar de fornecerem estimativas mais precisas, exigem mais trabalho para serem coletadas. Considerou-se também, como demonstraram PIMENTEL GOMES et alii (1963) ao estudarem o problema da amostragem se cana-de-açúcar com o fim de fazer determinações tecno- 
lógicas, que é mais vantajoso coletar maior nümero de unidades amos trais menores do que coletar um nümero mais reduzido de unidades ma iores.

Com os dados de contagem de lagartas obtidos nas uni dades amostrais de $1,00 \mathrm{~m}$ foi estimado o $k$ comum. Pelo método da má xima verossimilhança $(3.5 . b)$ encontrou-se $k_{c}=5,019863$ e pelo méto do de Bliss e Owen $(3.5 . c)$ encontrou-se $k_{c}=5,381976$. Com as primeiras 40 unidades amostrais encontrou-se respectivamente $\hat{k}_{c}=5,248466$ e $k_{c}=5,580233$, repetindo a tendência de aumentar o valor da estima tiva com a diminuição do tamanho da amostra já verificada ao estimar o $\hat{k}$ para cada local individualmente.

\section{2 - Plano de Amostragem Sequencial para Classificar a Infesta." ção de Lagartas de Lavouras de Soja em Baixa, Moderada ou Alta}

0 número de unidades amostrais para uma amostra de tamanho fixo, considerando uma população infinita, é calculado pela fórmula

$$
n=\frac{t^{2} s^{2}}{d^{2}}
$$

0 valor $t$ seria aquele da tabela com o nível a de sig nificância, no caso 0,05 , mas costuma-se usar o valor 2,00 sem que seja cometido erro apreciável. $s^{2}$ é a estimativa da variância da po. pulação. Neste caso foi calculada utilizando-se as contagens de lagartas nas unidades de $1,00 \mathrm{~m}$ dos 3 municipios onde foi feita a co- 
leta, e encontrando $s^{2}=56,88$. Considerou-se

$$
d=\frac{M_{1}-M_{0}}{2}
$$

Para testar a infestação baixa versus moderada obteve-se $d=5$ e $n=$ $=9$ e para testar a infestação moderada versus infestação alta $d=$ $=7,5$ e $n=4$.

Conforme foi discutido em 4.11 arbitrou-se o valor $m_{0}=15$ como limite superior do tamanho da amostra sequencial. Usando o $\hat{k}$ comum obtido com 50 unidades amostrais em cada local de coleta e pelo mëtodo da máxima verossimilhança e as expressões $(4.10 .2 . h),(4.10 .2 . i)$ e $(4.10 .2 . j)$ obtiveram-se as esti mativas dos porämetros das linhas de decisão para classificar a infestação de lavouras pelas lagartas:

Infestação baixa versus moderada Infestação moderada versus alta

$$
\begin{array}{ll}
h_{0}=-27,8588 & h_{0}=-115,8796 \\
h_{1}=27,8588 & h_{1}=115,8796 \\
S=19_{1} 242066 & S=51,814284
\end{array}
$$

A Tabela 5 apresenta os valores $a_{m}$ e $r_{m}$ calculados a partir desses parãmetros.

Examinando a Tabela 5 verifica-se que se existirem ne primeira unidade amostral examinada 168 lagartas ou mais, a amostra gem será suspensa rejeitando a hipótese $M=45$ om probabilidade de erro $\alpha=0,05$. Por conseguinte aceita-se a hipótese $M=60$, isto $\vec{e}_{\text {: }}$ considera-se a infestação como sendo alta. 
Tabela 5 - Valores $a_{m}$ e $r_{m}$ para o plano de amostragem seqüencial pa. ra classificar a infestação de lagartas das lavouras de soja em baixa, moderada ou alta.

\begin{tabular}{|c|c|c|c|c|c|c|c|}
\hline \multirow{3}{*}{$\begin{array}{l}\text { Número } m \text { de } \\
\text { unidades } \\
\text { amostrais } \\
\text { examinadas }\end{array}$} & \multicolumn{7}{|c|}{ In $\mathrm{f}$ e s t a çã o } \\
\hline & \multicolumn{4}{|c|}{$\begin{array}{c}\text { Baixa } \\
\text { versus } \\
\text { moderada }\end{array}$} & \multicolumn{2}{|c|}{$\begin{array}{c}\text { Moderada } \\
\text { versus } \\
\text { alta }\end{array}$} & \\
\hline & & $a_{m}$ & $r_{m}$ & & $a_{m}$ & $r_{m}$ & \\
\hline 1 & \multirow{15}{*}{ 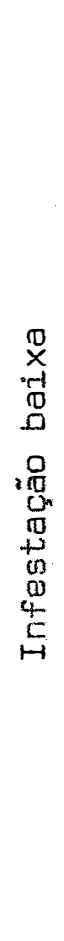 } & - & - & \multirow{15}{*}{ 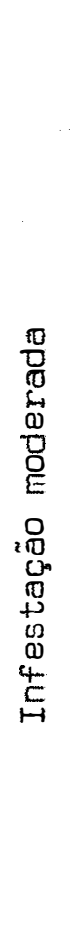 } & - & 168 & \multirow{15}{*}{ 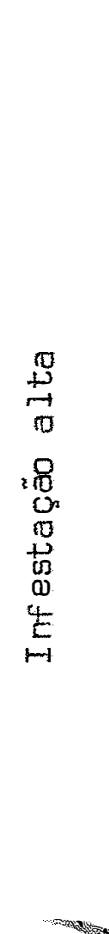 } \\
\hline 2 & & 10 & - & & - & 220 & \\
\hline 3 & & 29 & - & & - & 272 & \\
\hline 4 & & 49 & - & & - & 324 & \\
\hline 5 & & 68 & 125 & & 143 & 375 & \\
\hline 6 & & 87 & 144 & & 195 & 427 & \\
\hline 7 & & 106 & 163 & & 246 & 479 & \\
\hline 8 & & 126 & 182 & & 298 & 531 & \\
\hline 9 & & 145 & 202 & & 350 & 583 & \\
\hline 10 & & 164 & 221 & & 402 & 635 & \\
\hline 11 & & 183 & 240 & & 454 & 686 & \\
\hline 12 & & 203 & 259 & & 505 & 738 & \\
\hline 13 & & 222 & 279 & & 557 & 790 & \\
\hline 14 & & 241 & 298 & & 609 & 842 & \\
\hline 15 & & 260 & 317 & & 661 & 894 & \\
\hline
\end{tabular}

A $2 \%, 3:$ e a $4 \%$ unidades amostrais permitirão classi ficar a infestação em baixa ou em alta se o número acumulado de lagartas for, respectivamente, igual ou inferior a 10, 29 ou 49 ou igual ou superior a 220, 272 ou 324. Ainda não é possível classificar 
a infestação como moderada. A partir da 5 a unidade amostral as três classes são possíveis.

Para testar a infestação baixa versus moderada é cal culado o número acumulado de lagartas coletadas $\sum_{i=1}^{m} y_{i}$ para cada uni dade amostral coletada. Se $\sum_{i=1} y_{i}$ for igual ou menor que $a_{m}$ conclui- se que a infestação é baixa com probabilidade $\beta=0,05$ de estar in correndo em erro. Se $\sum_{i=1}^{m} y_{i}$ for igual ou maior que $r_{m}$ conclui-se que a infestação é moderada, com probabilidade de erro $\alpha=0,05$. Para classificar a infestação em moderada versus alta o mesmo procedimen to é adotado, porém com os valores $a_{m}$ e $r_{m}$ correspondentes a essa classificação.

Para ilustrar, será classificada a infestaçäo da lavoura de Faxinal do Soturno, cujos dados serviram para determinar a distribuição espacial da praga e constam da Tabela 2. Comparando o nümero acumulado de lagartas com os valores $a_{m}$ e $r_{m}$ da Tabela 5 observa-se:

\begin{tabular}{cccccc}
\hline & \multicolumn{5}{c}{ Infestação } \\
$m$ & $a_{m}$ & $\sum_{i=1}^{m} y_{i}$ & $r_{m}$ & $a_{m}$ & $r_{m}$ \\
\hline 1 & -9 & - & - & 168 \\
2 & 10 & $+13=22$ & - & - & 220 \\
3 & 29 & $+18=40$ & - & - & 272 \\
4 & 49 & $+11=51$ & - & - & 324 \\
5 & 68 & $+15=66$ & 125 & 143 & 375 \\
\hline
\end{tabular}


0 nümero acumulado de lagartas coletadas, $\sum_{i=1}^{m} y_{i}$, após examinar a 5 a unidade amostral foi 66 , inferior ao valor $a_{m}$ cor respondente que é 68 . Neste ponto o exame de novas unidades amostrais ë suspenso. Aceita-se a hipötese $M=15$, ou seja, conclui-se que a infestação da lavoura é baixa, com probabilidade $\beta=0,05$ de estar tomando uma decisão errada. Se o número acumulado de lagartas estivesse contido no intervalo $[125 ; 143]$ a lavoura seria classifica da como tendo infestação moderada. Finalmente, se o número acumulado de lagartas nas 5 unidades amostrais fosse igual ou superior a 375 a lavoura seria classificada como tendo infestação alta.

Repetindo o mesmo procedimento com as contagens de lagartas executadas em Santa Maria e em Jülio de Castilhos a mesma decisão seria tomada após examinar, respectivamente, 4 e 6 unidades amostrais.

A figura 4 apresenta a representação gräfica das linhas de decisão. A amostragem seqüencial pode ser desenvolvida atra vés desse gráfico que, embora não seja ideal para trabaihos de campo, evidencia a tendência da variável $\sum_{i=1} y_{i}$

0 mesmo exemplo anterior, ou seja, a classificação da infestação da lavoura de Faxinal é apresentada. 0 ponto $(5 ; 66)$ se Io caliza abaixo da linha de decisão $R_{0}$ para classificar a infestação em baixa versus moderada, indicando que neste estägio suspende-se a coleta de novas unidades amostrais tomando-se a decisão anteriormen te descrita para o processo tabular. 
Nümero acumulado

96.

$$
\begin{gathered}
\text { de lagartas } \\
\left(\sum_{i=1} y_{i}\right)
\end{gathered}
$$$$
900
$$
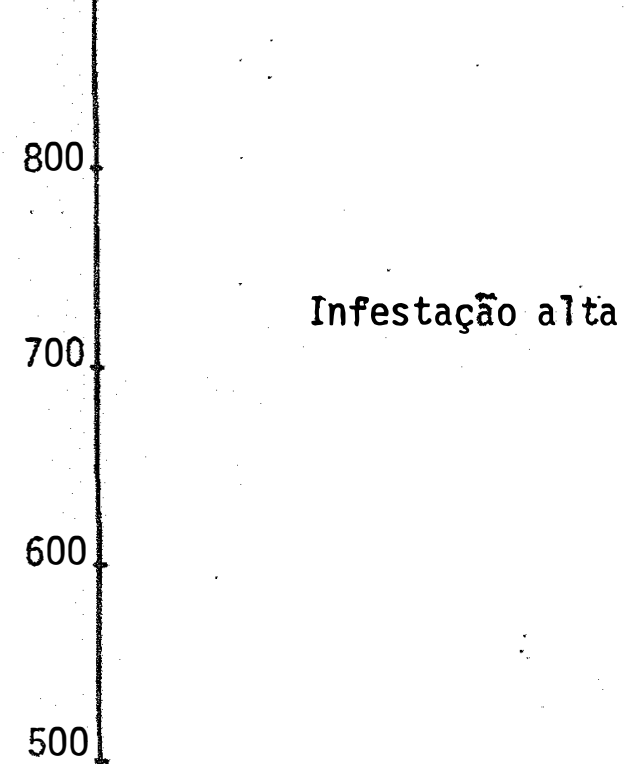

500

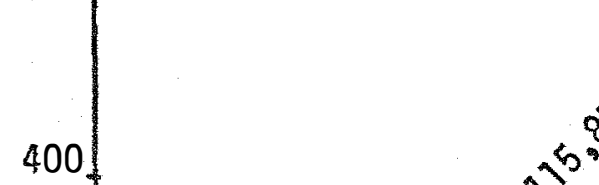

400
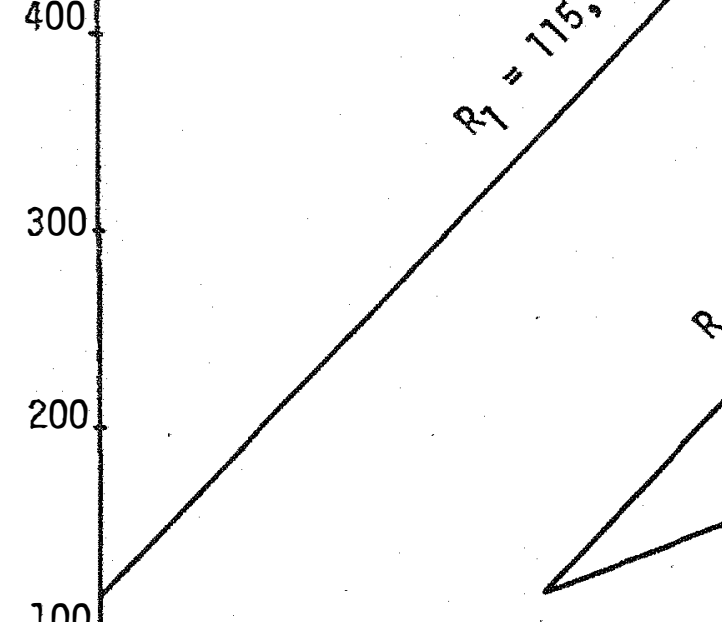

100

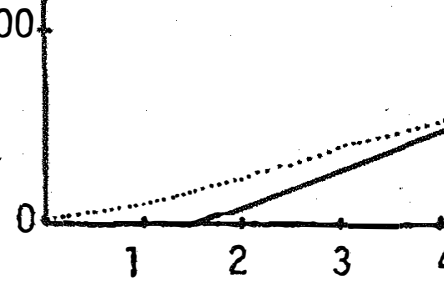

Nümero $m$ de unidades amostrais examinadas

FIGURA 4 - Representação gräfica das linhas de decisão do plano de amostragem segulencial para classificar a infestação de lagartas de lavouras de soja em baixa, moderada ou alta. A linha pontilhada foi traçada com os dados colhidos em Faxinal, do Soturno (Tabëla 2). 
Se depois de examinadas 15 unidades amostrais ainda não tiver sido tomada nenhuma decisão deve-se suspender a amostra-

gem. Com base em 4.11, se o número acumulado de lagartas, $\sum_{i=1}^{m} y_{i}$, for igual ou menor que 288 considera-se a infestação como sendo baixa. Se esse número for igual ou maior que 778 classifica-se a infestação da lavoura como alta. Um número de lagartas entre 289 e 777 caracterizará uma infestação moderada.

\section{3 - Curva Característica de Operação e Curva do Tamanho Mëdio das Amostras}

Essas curvas não são essenciais ao plano de amostragem seqüencial que pode ser desenvolvido sem elas, mas seu estudo permite avaliar o desempenho do plano.

Atribuindo valores arbitrários a $W$ nas expressões

$(4.10 .3 . b)$ e $(4.10 .3 . c)$, considerando que $M=p k$ e utilizando (4.10.4.a) calcularam-se respectivamente os valores do parâmetro $p$ da distribuição binomial negativa, os valores da função operatória característica $P(M)$, as médias $M$ e as esperanças do tamanho médio das amostras $E_{M}(n)$. Os valores atribuídos a $W$ e os outros calculados correspondentes encontram-se na Tabela 6. Com os pontos $\left[M_{9} P(M)\right]$ foi traçada a curva característica de operação, figura 5, que evidencia a variação de $P(M)$ em função de $M$, e que permite obter com aproximação o valor de $P(M)$ pa ra pontos que não constam da Tabela 6 . 
98.

Tabela 6 - Valores de $p, M, P(M)$ e $E_{M}(n)$ correspondentes aos valores atribuídos à variável auxiliar $W$.

\begin{tabular}{|c|c|c|c|c|c|c|c|c|}
\hline & \multicolumn{4}{|c|}{ Infestação baixa vs moderada } & \multicolumn{4}{|c|}{ Infestação moderada vs alta } \\
\hline & $P$ & $M$ & $P(M)$ & $E_{M}(n)$ & $P$ & $M$ & $P(M)$ & $E_{M}(n)$ \\
\hline 10,0 & 0,52 & 2,63 & 1,0000 & 1,68 & 3,20 & 16,09 & 1,0000 & 3,24 \\
\hline 8,0 & 0,72 & 3,63 & 1,0000 & 1,78 & 3,89 & 19,54 & 1,0000 & 3,59 \\
\hline 6.0 & 1,03 & 5,17 & 0,9999 & 1,98 & 4.81 & 24,16 & 0,9999 & 4,19 \\
\hline 4,0 & 1,52 & 7,65 & 0,9999 & 2,40 & 6,07 & 30,49 & 0,9999 & 5,43 \\
\hline 3,0 & 1,88 & 9,46 & 0,9998 & 2,85 & 6.88 & 34,52 & 0,9998 & 6,70 \\
\hline 2,0 & 2,36 & 11,84 & 0,9972 & 3,74 & 7,83 & 39,30 & 0,9972 & 9,21 \\
\hline 1,8 & 2,47 & 12,40 & 0,9950 & 4,03 & 8,04 & 40,36 & 0,9950 & 10,02 \\
\hline 1,6 & 2,59 & 13,00 & 0,9910 & 4,38 & 8,26 & 41,46 & 0,9910 & 10,99 \\
\hline 1,4 & 2,71 & 13,63 & 0,9840 & 4,80 & 8,49 & 42,60 & 0,9840 & 12,17 \\
\hline 1,2 & 2,85 & 14,29 & 0,9716 & 5,31 & 8,72 & 43,78 & 0,9716 & 13,60 \\
\hline 1,0 & 2,99 & 15,00 & 0,9500 & 5,91 & 8,96 & 45,00 & 0,9500 & 15,30 \\
\hline 0,9 & 3,06 & 15,37 & 0,9340 & 6,24 & 9,09 & 45,63 & 0,9340 & 16,26 \\
\hline 0,8 & 3,14 & 15,75 & 0,9133 & 6.60 & 9,22 & 46,27 & 0,9133 & 17,27 \\
\hline 0,7 & 3,22 & 16,14 & 0,8870 & 6 , & 9, & 46,92 & 0,8870 & 18,32 \\
\hline 0,6 & 3,30 & 16,55 & 0,8540 & 7. & 9,48 & 47,58 & 0,8540 & 19,37 \\
\hline 0,5 & 3,38 & 16,96 & 0,8133 & 7. & 9,6 & 48,25 & 0,8 & 20,39 \\
\hline 0,4 & 3,46 & 17.39 & 0,7645 & 7. & 9.75 & 48,94 & 0,76 & 21,33 \\
\hline 0,3 & 3,55 & 17,83 & 0,7075 & 8 , & 9,89 & 49,64 & 0,7075 & 22,10 \\
\hline 0,2 & 3,64 & 18,29 & 0,6431 & 8,36 & 10,03 & 50,35 & 0,6431 & 22,66 \\
\hline 0,1 & 3,74 & 18,76 & 0,5730 & 8,41 & 10 & 51,08 & & 22,93 \\
\hline$-0,1$ & 3,93 & 19,74 & 0,4269 & 8, & 10, & 52,57 & 0, & 22,52 \\
\hline$-0,2$ & 4,04 & 20,26 & 0,3568 & 7, & 10,6 & 53,33 & 3568 & 21,84 \\
\hline$-0,3$ & 4,14 & 20,79 & 0,2 & 7. & 0,78 & 54,11 & 2924 & 20,92 \\
\hline$-0,4$ & 4,25 & 21,33 & 0,2354 & & 0,94 & 54.91 & 0,2 & 19,82 \\
\hline$-0,5$ & 4,36 & 21,90 & 0,1866 & & 11 , & 55,72 & 0 & 18,61 \\
\hline$-0,6$ & 4,48 & 22,48 & 0,1 & & 11,26 & 56,54 & 0,1459 & 17,35 \\
\hline$-0,7$ & 4,60 & 23,08 & 0,1 & 5, & 11,43 & 57,38 & 0,1129 & 16,11 \\
\hline$-0,8$ & 4,72 & 23,70 & 0,1 & & 11,60 & 58,24 & 0 , & $14,9.1$ \\
\hline$-0,9$ & 4,85 & 24, & & & 8 & 11 & & 13,78 \\
\hline$-1,0$ & 4,98 & 25 , & & & 95 & 60,00 & 00 & 12,74 \\
\hline$-1,2$ & 5,26 & 26,38 & & & 12,32 & 61,83 & 283 & 10,92 \\
\hline$-1,4$ & 5,55 & 27,86 & & & 2,69 & 63,73 & 0159 & 9,42 \\
\hline$-1,6$ & 5,86 & 29,43 & 0,0 & 2 & 3.09 & 65.70 & 0,1 & 8,20 \\
\hline$-1,8$ & 6.20 & 31,10 & 0,0 & 2,32 & 13,50 & 67,74 & 0,00 & 7,20 \\
\hline$-2,0$ & 6,55 & 32,89 & 0,0027 & 2,03 & 13,92 & 69,87 & 0,0027 & 6,38 \\
\hline$-3,0$ & 8,73 & 43,81 & 0,0001 & 1,13 & 16,30 & 81,83 & 0,0001 & 3,86 \\
\hline$-4,0$ & 11,76 & 59,05 & 0,0000 & 0,70 & 19,19 & 96,36 & 0,0000 & 2,60 \\
\hline$-6,0$ & 22,08 & 110,83 & 0,0000 & 0,30 & 27,04 & 135,76 & 0,0000 & 1,38 \\
\hline$-8,0$ & 43,04 & 216,05 & 0,0000 & 0,14 & 38,88 & 195,16 & 0,0000 & 0,81 \\
\hline$-10,0$ & 86,55 & 434,49 & 0,0000 & 0,07 & 56.93 & 285,76 & 0,0000 & 0,49 \\
\hline
\end{tabular}


99.

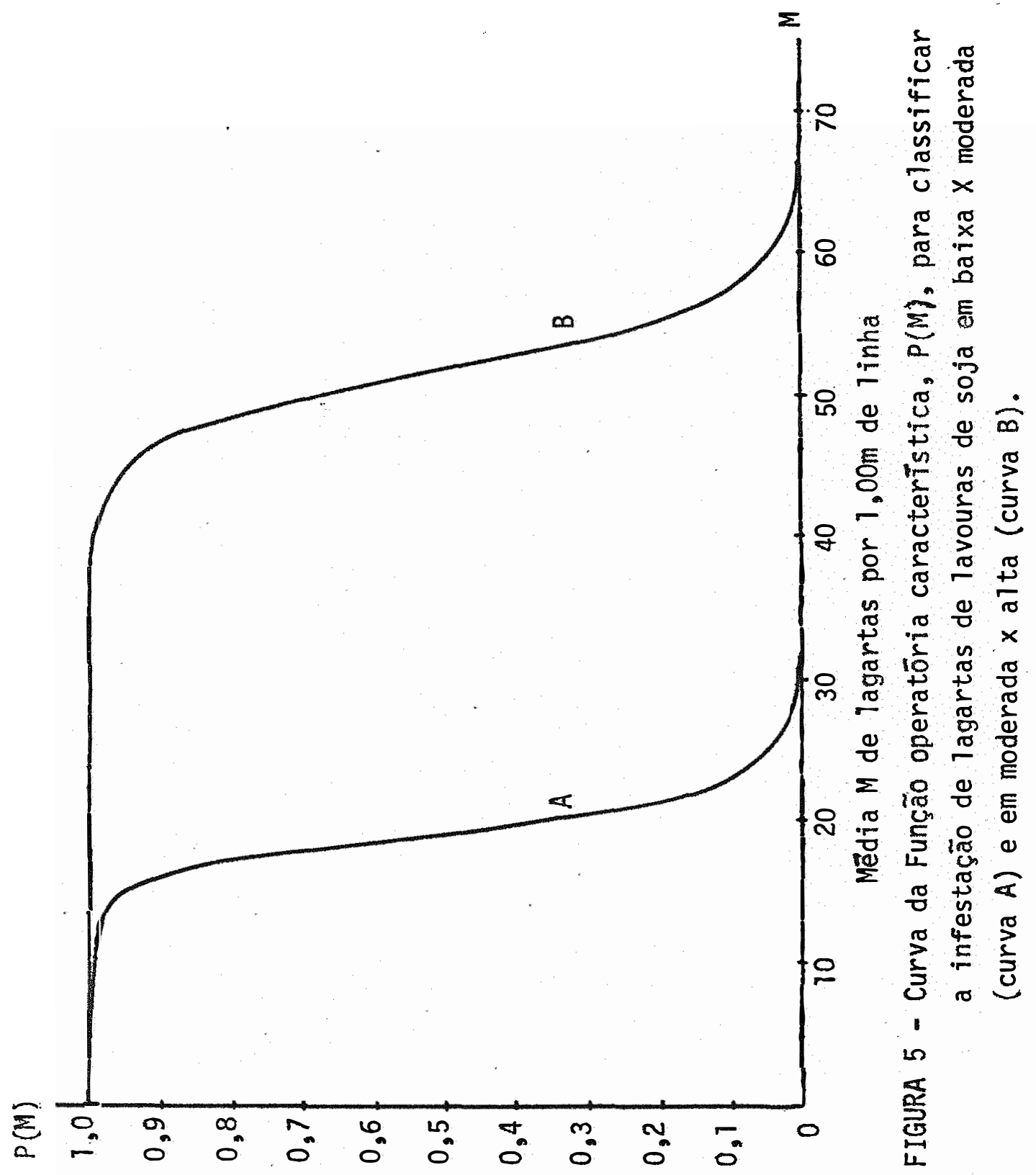


Verifica-se através da Tabela 6 e também da figura 5 que quando $M=15$ e quando $M=45$ para testar a infestação baixa ver sus moderada e moderada versus alta, respectivamente, o valor da fun ção operatória característica é 0,95. Isto indica que quando a média da lavoura atinge esses valores o teste tem probabilidade 0,95 de aceitar as hipóteses $M=15$ e $M=45$, respectivamente, Existe então a probabilidade de 0,05 de rejeitar essas hipóteses mesmo sen do verdadeiras. E a probabilidade $\alpha$ de erro. Então, quando $M=M_{0}$, tem-se $P(M)=1-\alpha$.

Quando $M=25$ e $M=60$ para testar a infestação baixa versus moderada e moderada versus alta, respectivamente, observa- se que $P(M)=0,05$. Embora as hipóteses $M=25$ e $M=60$ sejam verdadeiras existe a probabilidade de 0,05 de aceitar as hipóteses $M=$ $=15$ e $M=45$, respectivamente. $E$ a probabilidade $\beta$ de erro. Obser va-se que se $M=M_{1}$ então $P(M)=\beta$ 。

Pelo mesmo processo são obtidas as probabilidades de aceitar $H_{0}$, ou seja, de tomar decisões certas ou erradas dependendo do caso, para qualquer valor de $M$, isto $\vec{e}$, para qualquer nível de infestação da lavoura.

Com os pontos $\left[M_{\dot{g}} E_{M}(n)\right]$ foi traçada a curva do tamanho médio das amostras. Esta curva, figura 6 , além de evidenciar a variação de $E_{M}(n)$ permite obter valores dessa variável para pontos que não constam da tabela 6 . 
101.

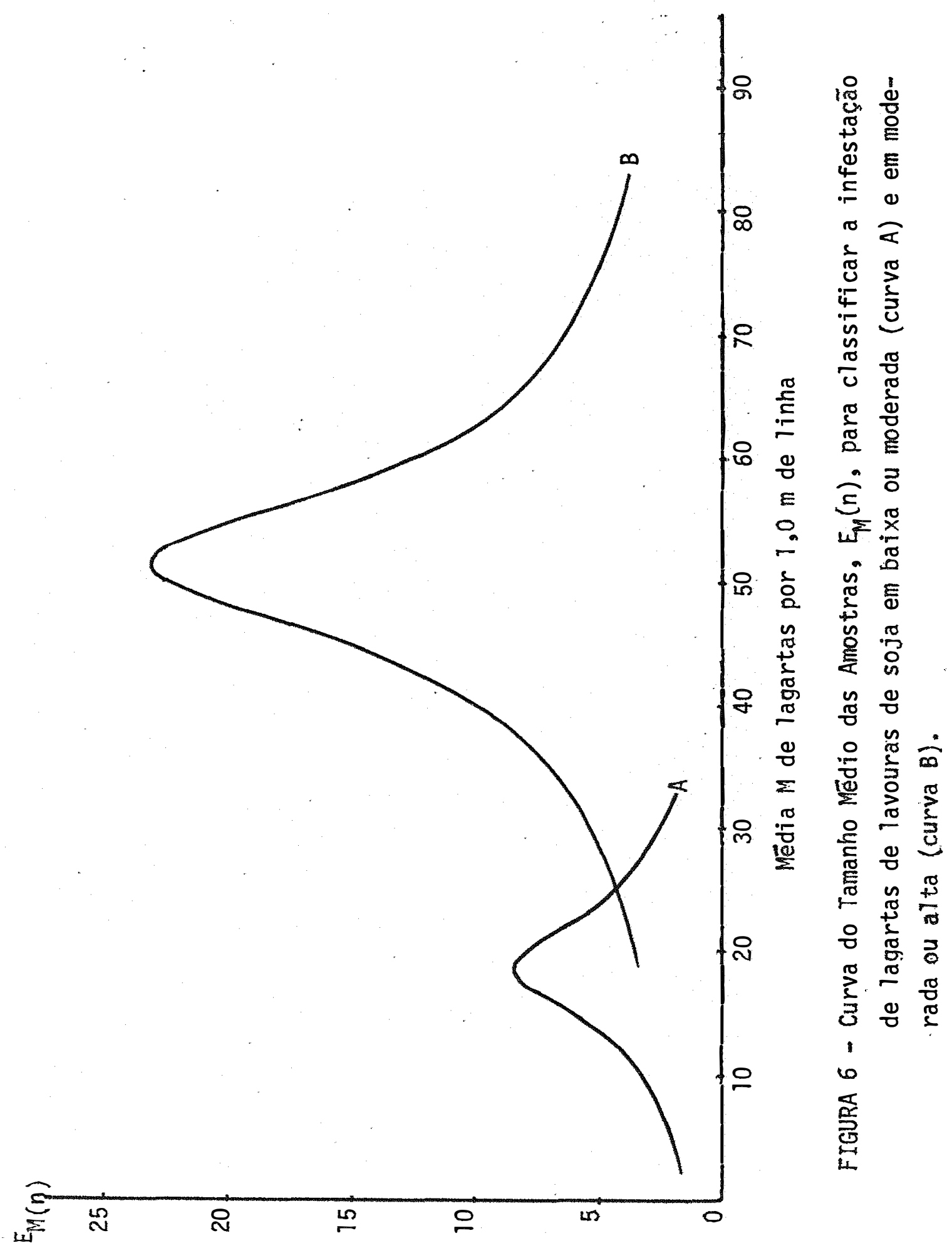


Da Tabela e figura 6 verifica-se que se $M=10$, isto é, se a infestação da lavoura corresponder a 10 lagartas por 1,00 m de linha, então $E_{M}(n) \simeq 3$. Isto indica que em lavouras com esta in festação são necessárias, em média, 3 unidades amostrais antes de tomar uma decisão. Se $M \simeq 80$ uma decisão seria tomada após examinadas, em média, 4 unidades amostrais. Para $M=50$ seriam necessárias 22 unidades amostrais, embora, como foi visto, o teste seja truncado depois de examinar 15 unidades.

Através da figura 6 fica evidenciado que o teste seqüencial exige um nümero maior de unidades amostrais para tomar uma decisão quando o grau de infestação $M$ da lavoura estä próximo do va lor $M^{\prime}$, no caso 20 e 52 para classificar a infestação em baixa ou moderada e moderada ou alta, respectivamente. Este fato pode ser con sidierado como uma vantagem do procedimento sequiencial, uma vez que ela exige maior amostragem quando é mais difícil tomar uma decisão, enquanto na amostragem convencional o tamanho da amostra seria omes mo para qualquer grau de infestação, sendo desnecessariamente grande em certos casos e pequeno demais em outros.

É óbvio que ao iniciar a amostragem numa lavoura,não se conhece a média $M$ de infestação e, por conseguinte, não se pode obter nem $P(M)$ nem $E_{M}(n)$ para essa lavoura. Mesmo assim a curva característica de operação e a curva do tamanho médio das amostras fornecem uma vísão geral do funcionamento do plano de amostragem sE qüiencial. 
103.

\section{3 - Complementações}

Este trabalho não tem pretensões de apresentar umplạ no de amostragem seqüencial perfeito nem definitivo. Pelo contrário, deve ser considerado como um primeiro passo nesse sentido, devendo ser aperfeiçoado paulatinamente, mas cuja metodologia pode ser apli cada para outras pragas e outras culturas.

Os parâmetros da distribuição espacial da praga de-

vem ser determinados com maior precisão fazendo levantamentos em outras regiões e em outros anos. Ao executar esses levantamentos de ver-se-á examinar no mínimo 100 unidades amostrais e abranger também graus mais elevados de infestação.

Houve uma diminuição do valor de $k$ quando o nümero de unidades amostrais passou de 40 para 50 . Se persistir essa tendência, com o uso de um número maior de unidades amostrais, é provável que o $\hat{k}$, então mais próximo do parâmetro populacional, seja menor do que aquele usado neste trabalho. A conseqüência da diminuição do va lor de $\hat{k}$ seria aumentar a diferença entre valores $a_{m}$ e $r_{m}$ relacionados.

Por outro lado, embora teoricamente o parâmetro não deveria variar com o aumento da infestação, diversos autores, entre eles SILVESTER e COX (1971)encontraram uma relação linear positiva entre as duas variáveis. Se existir essa relação para as lagartas da soja então lavouras com infestação elevada tenderiam a apresentar um parâmetro $k$ mais elevado do que aquele estimado neste trabalho, ha- 
vendo talvez uma compensação para a diminuição prevista a to tomar maior número de unidades amostrais.

o $\hat{k}$ estimado pelo método da máxima verossimilhança apresentou menor variância e propiciou maior aderência ao modelo teórico do que aquele estimado pelo métado dos momentos. Consideran do também que esse método se aplica em todas as situações, ele pare ce ser mais vantajoso. Entretanto exige maior número de cálculos e se torna trabalhoso para quem não dispõe de computador.

Os valores $M^{9}, M_{0}$ e $M_{1}$, bem como o grau de desfolhamento de $30 \%$ aqui usados, têm certo grau de arbitrariedade. E possível que a prática venha aconselhar alguma mudança nesses valores. Além disso eles dependem do preço da soja e do preço da aplicação do inseticida que variam de ano para ano.

Para classificar a infestação de uma lavoura deve-se com auxílio de uma lona, como foi explicado no capítulo 4, coletar amostras aleatórias do número de lagartas Anticarsia Gematalis e Plusia spp com mais de $1 \mathrm{~cm}$ de comprimento em $1,00 \mathrm{~m}$ de linha. Os números acumulados de lagartas são comparados com os valores $a_{m}$ e $r_{m}$ existentes na Tabela 5, conforme foi explicado na seção 5.2. 0 procedimento é repetido em diversos locais conforme o tamanho da lavou ra.

Quanto ao uso de inseticidas podem ser recomendadas as seguintes regras: 
a) Se a lavoura for classificada como tendo infestação baixa, não será necessário aplicar inseticidas, qualquer que seja o estágio da cultura.

b) Se a lavoura for classificada como tendo infestação alta pre conizar-se-á a aplicação imediata de inseticida.

c) Se a infestação for moderada aplicar-se-á inseticida qualquer que seja o estágio da cultura desde que haja um desfo lhamento de $30 \%$ ou mais e não existirem lagartas mortas por doenças ou parasitas. Independente do grau de desfolhamento o inseticida deverá ser aplicado se a cultura estiver na fa se de fim de floração ou formação de vagens.

d) Em qualquer caso a aplicação deverá ser retardada se houver prenüncio de chuva forte eminente. A chuva, além de lixiviar o inseticida, tornando inócua sua aplicação, reduz a popula ção da praga.

e) Entretanto, se a infestação tiver sido moderada e não for aplicado o inseticida, ou se a infestação tiver sido baixa mas a soja está em estágio de floração ou de formação de vạ gens, então a lavoura deverá ser reexaminada a cada 3 ou 4 dias.

Com base na experiência adquirida nos levantamentos exøcutados em Santa Maria, Faxinal do Soturno e Jülio de Castilhos, fixou-se o tempo de 3 minutos para uma infestação baixa e 4 minu- 
tos para uma infestação alta como sendo suficiente para examinar uma unidade amostral. Considerando o caso de uma infestação alta com - máximo de 15 unidades amostrais conclui-se que o tempo máximo necessário para inspecionar uma lavoura é de 1 hora. Entretanto, raras vezes esse tempo será necessário. O mais provável é que a inspeção termine antes de examinar as 15 unidades amostrais, muitas ve zes com 4 ou 5 unidades o que corresponde ao tempo de 15 a 20 minutos。

Para os padrões de comportamento atual dos agricultores esse procedimento pode ser considerado ärduo e moroso. Atualmente a simples presença da praga determina o uso imediado de medidas quimicas de controle, e existem aqueles que aplicam o inseticida periodicamente como tratamento preventivo, sem que haja infestação.

Mas se considerados o custo da aplicação do produto e os malefícios ao equilíbrio biológico provenientes da aplicação desnecessária do inseticida, chega-se à conclusão que há grande van tagem em adotar a amostragem, embora a tomada de decisão exija mais trabalho.

Este plano de amostragem foi delineado com base em lavouras de soja semeadas em linhas distanciadas de $0,60 \mathrm{~m}$, que é o espaçamento mais usado no Rio Grande do Sul. Para outros espaçamentos deveriam ser feitos novos estudos para verificar o comportamento das estimativas dos parâmetros da distribuição espacial da praga. 
Talvez seja suficiente corrigir o tamanho da unidade amostral ou en tão os valores $a_{m}$ e $r_{m}$. Assim, por exemplo, para o espaçamento de $0,40 \mathrm{~m}$ que corresponde a $2 / 3$ do de $0,60 \mathrm{~m}$ bastaria utilizar unidades amostrais de $1,50 \mathrm{~m}$ ou tomar como $a_{m}$ e $r_{m} 2 / 3$ dos valores apresentados na Tabela 5. Somente levantamentos de campo poderão confir mar se alguma dessas alternativas é válida. 
108.

\section{CONCLUSÕES}

Com base nos dados estudados conclui-se que:

1 - A unidade amostral constituída de $1,00 \mathrm{~m}$ de linha mostrou ser a mais viävel dentre aquelas estudadas para executar levantamen tos de infestação de lagartas da cultura da soja.

2 - Para estudar a distribuição espacial das lagartas da soja Anticarsia genmatalis e Plusia spp 50 unidades amostrais em cada lo cal são insuficientes. Devem ser examinadas no mínimo 100 unidades amostrais.

3 - As contagens do nümero de lagartas por $1,00 \mathrm{~m}$ de linha se ajustam à distribuição binomial negativa e não ao modelo de Poisson. : 4 - A estimativa do parâmetro $k$ pelo método da máxima ve rossimilhança apresenta algumas vantagens em relação ao método dos momentos. 
5 - Com o exame de, no máximo, 15 unidades amostrais, operação que exige 1 hora no máximo, é possível classificar a infestação de lagartas de uma lavoura de soja em baixa, moderada ou alta, e então decidir sobre a conveniência ou não de aplicar inseticida. 
110.

\section{SUMMARY}

A bibliographic review about the use of sequential sampling in agricultural pests control is carried out and the methodology for execution of sequential sampling plans is described. The formulae, based on aproximate Wald Sequential Ratio Test (SPRT), for calculating the slope and the intersect of the decision straight lines and the points to draw the Operating Characteristic (OC) curve and the Average Sample Number (ASN) curve for the binomial, normal, Poisson and negative binomial models are presented. A method of truncating the SPRT in practice is discussed.

A sequential sampling plan to classify in light, moderate or severe the infestation of Anticarsia gemmatalis and Plusia spp caterpillars on soybean fields was carried out.

To know the spacial distribution of the pests, samples were drawn in three municipality of the State of Rio Grande do Sul. In each site 50 sample units were chosen casually by grouflcloth-shake 
method, in an about one hectare field. Each random sample unit was represented by a portion of $1.50 \mathrm{~m}$ of a row splited in three part of $0.50 \mathrm{~m}$ each one. Thus plots of $0.50 \mathrm{~m}, 1.00 \mathrm{~m}$ and $1.50 \mathrm{~m}$ were obtained. Rows were spaced $0.60 \mathrm{~m}$ apart.

It was verified that caterpillar sounts fit the negative binomial distribution and that the maximum likelihood method of estimating $k$ had some advantages against the moment method. Also it was concluded that more than 50 sample units are necessary in each field. Maybe 100 units or more are required.

It was verified that the best sample unit size was I.00 $\mathrm{m}$ and this size was used to develop the sequential sampling plan.

To classify the infestation of a soybean field in light or moderate the sequential plan was carried out to test the hypothesis $M=15$ against $M=25$ caterpillars in 1.00 m units. To classify the infestation in moderate or severe the plan was used to test the hyphotesis $M=45$ against $M=60$ caterpillars in 1.00 m units.

A table that allows us to classify the infestation in one of the three classes above based on the cumulative number of caterpillars sampled is presented. The Operating Characteristic curve and the Average Sample Number curve are drawn.

If the infestation of the field is considered light, no chemical control measures are necessary. If the infestation is 
112.

severe the use of inseticides is recommended. If the infestation is moderate the use of chemical control depends upon the stafe of plant grown and defoliation percentage. 
113.

\section{LITERATURA CITADA}

ANDERSON, T.W:, 1960. A Modification of the Sequential Probability Ratio Test to Reduce the Sample Size. The Annals of Mathematical. Statistics, Baltimore, 31: 165-197.

ANSCOMBE, F.J.: 1949. The Statistical Analysis of Insect Counts Based on the Negative Binomial Distribution. Biometrics, Raleigh, 5: $165-173$.

BARTENSCHLAGER, $H_{0}$, 1970. Determination of the Boundaries of the Se quential Probability Ratio Test Given the Errors of the First and Second Kinds. Operations Research Verfahren, s.1. 7: 54-70.

BLISS, C.I. e .R.A.FISHER, 1953. Fitting the Negative Binomial Distribution to Biological Data. Biometrics, Raleigh 9: 176-200.

BOLDT, P.E。 K.L. BIEVER e C.M. IGNOFFO, 1975. Lepidopteran Pests of Soybeans: Consumption of Soybean Foliage and Pods and Development Time. Journal of Eoonomic Entomology, Menasha, 68: 480-482. 
CALZADA BENZA, J., 1954. Experimentación Agrícola con Aplicación a la Ganaderia. Ediciones Agro-Ganaderas, Lima, 360 pp.

DAVIES, R.G., 1971. Computer Programing in Quantitative Biology: Academic Press, Londres, 492 pp.

DODGE, H.F. e H.G. ROMIG, 1929. A Method of Sampling Inspection. The Bell System Technical Journal, Nova York, 8: 613-631.

EVANS, D.A., 1953. Experimental Evidence Concerning Contagious Distributions in Ecology. Biometrika, Londres, 40: 186-211.

HARTENSTEIN, R., 1961. On the Distribution of Forest Soil Microarthropods and their Fit to "Contagious" Distribution Functions. Ecology, San Diego, 42: 190-194.

HILLHOUSE, T。L。e H.N. PITRE, 1974. Comparison of Sampling Techniques to Obtain Measurements of Insect Populations on Soybeans. Journal of Economic Entomology. Menasha, 67: 411-414.

IVES, W.G.H. e R.M. PRENTICE, 1968. A Sequential Sampling Technique for Surveys of the Larch Sawfly. The Canadian Entomologist, ottawa, 90: 331-338.

KEMP, K.W., 1958. Formulae for Calculating the Operating Characteristic and the Average Sample Number of some Sequential Tests. Journal of Royal Statistic Society, B, Londres, 20: 379-386.

KNIGHT, F。B., 1967. Evaluation of Forest Insect Infestations. Annual Review of Entomology, Palo Alto, 12: 207-228. 
MADSEN, R., 1974. A Procedure for Truncating SPRT's. Journal of the American Statistical Association, Washington D.C., 69: 403-410。

MANLY, B.F.J., 1969. Aproximations of the Characteristics of some Sequential Tests. Biometrika, Londres, 56: 203-206.

MORRIS, R.F., 1954. A Sequential Sampling Technique for Spruce Budworm Egg Surveys. The Canadian Journal of Zoology, ot tawa, 32: $302-313$.

MORRIS, R.F., 1960. Sampling Insect Populations. Annual Review of Entomology, Palo Alto, 5: 243-264.

OAKLAND, G.B., 1950. An Application of Sequential Analysis to Whitefish Sampling. Biometrics, Raleigh, 6: 59-67.

PAGE, E.S., 1954. An Improvement to Wald's Approximation to some Properties of Sequential Tests. Journal of Royal Statistic Society, B, Londres, 16: 136-139.

PIEDRABUENA, A。E。, 1975. Algumas Considerações sobre Estruturas Binomiais no Ensino da Bio-Estatística. In: Anais da Reunião Internacional da Região Brasileira da Sociedade Internacional de Biometria, Piracicaba, Escola Superior de Agricultura "Luiz de Queiroz", em publicação.

PIMENTEL GOMES, F.; O. VALSECHI; C.P. de ABREU e E.R. de OLIVEIRA, 1963. A Amostragem da Cana-de-Açücar para Determinações Tecnológicas. Anais E.S.A. "Luiz de Queiroz", Piracicaba, 20: 89114. 
ROSAS, G.S., 1967. Influencia de la Defoliation Parcial em Plantas de Soja (Glycine max). Turrialba, Turrialba, 17: 93-97.

SHEPARD, M.; G.R. CARNER e S.G. TURNIPSEED, 1974. A Comparison of Three Sampling Methods for Arthropods in Soybeans. Environmental. Entomology, College Park, 3: 227-232。

SHEPARD, M。 e G.R. CARNER, 1976. Distribution of Insects in Soybean Field. The Canadian Entomologist, Ot'awa, 108: 767-771.

STARK, R.W., 1952. Sequential Sampling of the Lodgepole Needle Miner. Forestry Chronicle, Toronto, 28: 57-60.

SILVESTER, E.S。 e E.L. COX, 1961. Sequential Plans for Sampling Aphids on Sugar Beets in Kern County, California. Journal of Economic Entomology, Menasha, 54: 1080-1084.

TALLIS, G.M. e M.K. VAGHOLKAR, 1965. Formulae to Improve Wald's Aproximations for Some Properties of Sequential Tests. Journal. of Royal Statistics Society, B, Londres, 27: 74-81.

THOMAS, G.D.; C.M. IGNOFFO; K.D. BIEVER e D.B. SMITH, 1974. Influence of Defoliation and Depodding on Yield of Soybeans. Journal. of Economic Entomology, Menasha, 67: 683-685.

TODO, J.W. e L.W. MORGAN, 1972. Effects of Hand Defolation on Yield and Seed Weight of Soybeans. Journal of Economic Entomology, Menasha, 65: 567-570。

TURNIPSEEO, S.G., 1972. Response of Soybeans to Foliage Losses in South Carolina. Journal of Economic Entomology. Menasha, 65: 221-229. 
TURNIPSEED, S.G., 1974. Sampling Soybean Insects by Various D-Vac, Sweep, and Ground Cloth Methods. The Florida Entomologist, Gainesville, 57: 217-223.

TURNIPSEED, S.G., 1975. Manejo das Pragas da Soja no Sul do Brasil. Trigo Soja, Porto Alegre, $\underline{1}(1): 4-7$.

WADDILL, V.G.; B.M. SHEPARD; S.C. TURNIPSEED e G.R。CARNER, 1974. Sequential Sampling Plans for Nabis spp and Geocoris spp on Soybeans, Environmental Entomology, College Park, 3: 415-419.

WALD, A., 1945. Sequential Tests of Statistical Hypothesis. Annals. of Mathematical Statistics, Baltimore, 16: 117-186.

WALD, A., 1947. Sequential Analysis. John Wiley, Nova York, 212 pp. WATERS, W.E。, 1955. Sequential Sampling in Forest Insect Surveys. Forest Science, Washington D.C., 1: 68-79. 